\title{
Russland, der Ferne Osten und die "Deutschen"
}

Herausgegeben von

Heinz Duchhardt

\section{Vandenhoeck \& Ruprecht}
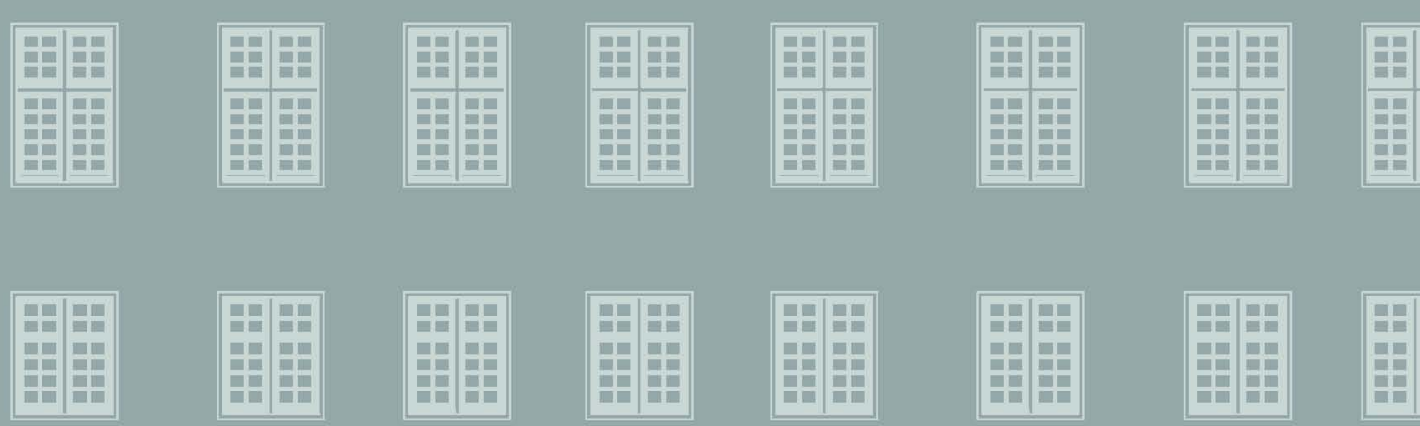

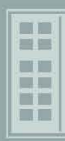

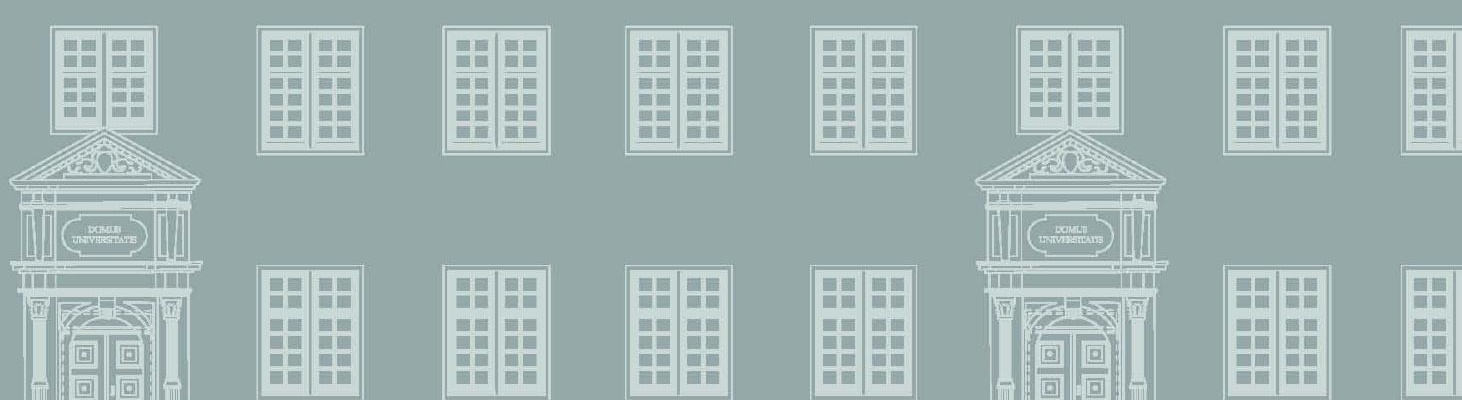




\section{VGR}




\title{
Veröffentlichungen des \\ Instituts für Europäische Geschichte Mainz
}

\author{
Abteilung für Universalgeschichte \\ Herausgegeben von Heinz Duchhardt
}

Beiheft 80

\section{Vandenhoeck \& Ruprecht}




\section{Russland, der Ferne Osten und die $»$ Deutschen $«$}

Herausgegeben von

Heinz Duchhardt

Vandenhoeck \& Ruprecht 
Bibliografische Information der Deutschen Nationalbibliothek:

Die Deutsche Nationalbibliothek verzeichnet diese Publikation in der Deutschen Nationalbibliografie; detaillierte bibliografische Daten sind im Internet über https://dnb.de abrufbar.

(C) 2009, Vandenhoeck \& Ruprecht GmbH \& Co. KG, Theaterstraße 13, D-37073 Göttingen

Das Werk und seine Teile sind urheberrechtlich geschützt.

Die Beiträge sind als Open-Access-Publikation im Sinne der Creative-Commons-Linzenz

BY-NC-ND International 4.0 (»Namensnennung - Nicht kommerziell - Keine

Bearbeitung «) unter dem DOI 10.13109/9783666100925 abzurufen. Um eine Kopie dieser

Lizenz zu sehen, besuchen Sie https://creativecommons.org/licenses/by-nc-nd/4.0/.

Jede Verwendung in anderen als den durch diese Lizenz erlaubten

Fällen bedarf der vorherigen schriftlichen Zustimmung des Verlages.

Satz und Redaktion: Vanessa Brabsche und Barbara Kunkel

Vandenhoeck \& Ruprecht Verlage | www.vandenhoeck-ruprecht-verlage.com

ISSN 2197-1056

ISBN 978-3-666-10092-5 


\section{Inhalt}

Vorwort

Christine Roll

Russland, Sibirien und der »Ferne Osten « in der russischen Kartographie der Frühen Neuzeit und der Beitrag deutscher

Wissenschaftler

\section{Dittmar Dahlmann}

Das Moskauer Reich und China.

Die russischen Beziehungen zum $»$ Reich unter dem Himmel « vom 16. Jahrhundert bis zum Ende des 18. Jahrhunderts

Eugenia Massold

»Völker in der Großen Finsterniß ihres Verstandes...»

Ethnologische Forschungen im Altaj im 18. und in der ersten Hälfte des 19. Jahrhunderts

\section{Diana Ordubadi}

»Brennendes Eis, jeden Traum verscheuchende Stürme und merkwürdige Fremde... « Carl Heinrich Merck und sein

Beitrag zur Erforschung des russischen Nordens im Rahmen der Billings-Saryčev-Expedition 1785-1795

\section{Heinz Duchhardt}

Ein deutscher Mediziner im Fernen Osten.

Joseph Rehmann und die Golovkin-Gesandtschaft 1806

\section{Jan Kusber}

Imperiale Wissenschaften und Expansion:

Das Beispiel Fedor Petrovič Litke (1797-1882)

Personenregister

Autorenverzeichnis 


\section{Vorwort}

Im Rahmen eines von der Deutschen Forschungsgemeinschaft und dem Russischen Fonds für die Geistes- und Sozialwissenschaften (RGNF) gemeinsam geförderten Forschungsvorhabens zum Anteil von »Deutschen« im russischen Dienst an der Erschließung des Fernen Ostens fanden im Dezember 2007 und im September 2008 zwei »kleine Konferenzen« in Mainz bzw. Moskau statt. Die von den deutschen Teilnehmern dabei gehaltenen Vorträge, die in Russland leider nicht publiziert werden konnten, werden in dem vorliegenden Sammelband zusammengeführt. Das genannte Forschungsprojekt war auf die Person der Bearbeiterin, Frau Prof. Dr. Tatjana Ilarionova (Russische Akademie für öffentliche Verwaltung), zugeschnitten, die die Ergebnisse ihrer Forschungen in russischen Periodika veröffentlicht hat. Um die von den deutschen Wissenschaftlerinnen und Wissenschaftlern hier und dort gehaltenen Referate, die durchweg in Neuland vorstießen und das Forschungspanorama mit vielen neuen Einblicken bereichern, der weiteren Forschung zugänglich zu machen, wurde dieser Weg einer separaten Publikation der deutschsprachigen Beiträge gewählt.

Der Reiz des Themas erschloss sich den beteiligten deutschen Wissenschaftlern sehr schnell. Es gibt zwar bereits etliche Literatur deutscher und russischer Provenienz zu dem genannten Themenfeld - zu Diplomaten, zu einzelnen Wissenschaftlern, zu Verwaltungsbeamten -, aber sie erschöpft die Thematik noch längst nicht. Gerade im Hinblick auf kulturalistische Fragestellungen - Kulturkontakte, die Entwicklung des Bildes vom jeweils Anderen, kulturelle Missverständnisse - liegen die Themen gewissermaßen auf der Straße.

Auf der anderen Seite standen die Autoren aber auch vor methodischen Problemen. Das begann schon damit, dass eine präzise Definition des »Deutschen« nicht vorgegeben wurde. Der baltische Adlige wird sich subjektiv als »Deutscher « gefühlt haben, bei im Prinzip rückkehrwilligen deutschen Wissenschaftlern wird es ähnlich ausgesehen haben, aber wie es bei einem schon Jahrzehnte im Russischen Reich lebenden, also bis zum Namen russifizierten und in die russische Gesellschaft eingeheirateten »Deutschen « aussah, erschließt sich nur schwer. Identitäten sind immer etwas Subjektives und richten sich nicht zwingend nach dem »Arbeitgeber« oder dem »Pass«. In den folgenden Beiträgen ist jeder Autor je individuell mit dem Begriff des »Deutschen« umgegangen. 
Den Band eröffnet der Beitrag von Christine Roll, die nach der kartographischen Aufarbeitung des geographischen Raums fragt, um den es geht, also nach der Erschließung Sibiriens und des fernen Ostens durch Kartenwerke - denen im Kontext der petrinischen und nachpetrinischen Zeit durchaus eine imperiale, herrschaftsdemonstrierende Funktion zukam. Der Anteil der »Deutschen« an dieser geographischen Erschließung eines bisher nahezu unbekannten Raums darf zwar nicht überschätzt werden, aber es ist dann doch bezeichnend, dass die letzten Zweifel an der topographischen Struktur Sibiriens und der Kurilen währen der Expedition Adam Johann Krusensterns im Anfang des 19. Jahrhunderts beseitigt wurden, bei der sich u. a. der Kartenzeichner Fabian Gottlieb Bellinghausen entsprechende Verdienste erwarb.

Einen Überblick über die ganz frühen, regelmäßig von erheblichen Zeremonialproblemen überschatteten China-Reisen russischer »Diplomaten«, die vor allem der Förderung des bilateralen Handels dienen sollten, gibt Dittmar Dahlmann. Erst mit dem Vertrag von Nesčinsk kam man 1689 auf eine einigermaßen feste völkerrechtliche Grundlage; zu eben dieser Zeit reisten dann auch mit Ides und Brand erstmals »Ausländer « mit einem wenigstens offiziösen Auftrag nach China, die anschauliche Berichte nicht nur über China, sondern auch über ihre gesamte Reise hinterließen.

Seit dem Ausgang des 17. Jahrhunderts begannen die Sondergesandtschaften nach China und die wissenschaftlichen Expeditionen in den $» F e r-$ nen Ostens «, meist von der Petersburger Akademie angestoßen, das Feld zu beherrschen.

Einen allgemeinen Überblick über die Erforschung der Altaj-Region im 18. und frühen 19. Jahrhundert steuert Eugenia Massold bei. Ihr Beitrag der auch die historiographiegeschichtlichen Hintergründe der bis zum heutigen Tag unbefriedigenden Forschungslage ausleuchtet, ist umfassend angelegt und berücksichtigt auch die von Russen geleiteten Expeditionen und deren Dokumentationen (u.a. Spasskij, Speranskij) Zu den »Deutschen« die diese Bergregion bereisten, und - meist aus einem deutlichen kulturellen Überlegenheitsgefühl heraus - darüber berichteten, zählten u.a. Gerhard Friedrich Müller, Johann Georg Gmelin, Peter Simon Pallas, Carl Friedrich Ledebour, Alexander von Benge, Johann Gottlieb Georg und Gregor von Helmersen, von denen etliche von der Dorpater Universität kamen und meist Mitglieder der Petersburger Akademie waren oder werden sollten.

Dem hessischen Arzt Carl Heinrich Merck, der, mehr aus Zufall, an der sowohl wissenschaftlich als auch politisch motivierten sog. BillingsExpedition in den 1780er Jahren teilnahm, widmet sich Diana Ordubadi. Merck hatte zu Beginn der Expedition, die der näheren Erforschung Ostsibiriens und Alaskas dienen sollte, bereits eine Stelle als Hospitalarzt in Irkutsk inne und wurde auf der Forschungsreise einer der Hauptverantwort- 
lichen für die Erkundung der Flora und Fauna. Sein unveröffentliches bzw. nur in einer englischen Übersetzung greifbares Tagebuch ist aber auch eine erstrangige Quelle zur Ethnographie und zur materiellen Kultur der bereisten Ethnien. Sein plötzlicher Tod 1799 beendete eine hoffnungsvolle wissenschaftliche Karriere.

Einen ähnlichen Fall, den eines Mediziners aus dem deutschen Südwesten, der wenige Jahre nach Merck an einer (erfolglosen) russischen Gesandtschaft nach China beteiligt war, wendet Heinz Duchhardt seine Aufmerksamkeit zu. Joseph Rehmann, der bis zum Chef des russischen Zivilmedizinalwesens aufsteigen sollte, hat sich seit der Rückkehr aus der Mongolei - weiter kam die Gesandtschaft nicht - um die Vermittlung des Wissens um chinesische Medizin in die russische und auch in die deutsche Gesellschaft hinein bemüht und auf seine Art zu einem begrenzten Kulturtransfer beigetragen.

Jan Kusber schließlich schlägt den Bogen zum mittleren 19. Jahrhundert: zu Friedrich Benjamin Lütke, dem Weltumsegler und Erforscher u. a. der sog. Nordostpassage, dem Akademiepräsidenten und Politiker, der nicht nur eine Autobiographie, sondern auch gehaltvolle Reiseberichte hinterlassen hat. Lütke zählt zum Kreis der founding fathers der Russischen Geographischen Gesellschaft und war eine Zeitlang deren Präsident, eine Einrichtung, deren Frühgeschichte ein Spiegelbild imperialen Expansionsdrangs war. Lütke ist eine jener faszinierenden Persönlichkeiten, die sich vorbehaltlos mit dem Imperium und der Dynastie identifizierten und aus der Kombination von Wissenschaft, Entdeckung und Expansion Politik und Karriere machten.

Ich danke den Autoren, die sich mit der relativ knapp bemessenen Frist zur Abgabe ihrer Manuskripte einverstanden erklärten, ich danke Frau Kollegin Ilarionova für viele wichtige Impulse, ich danke nicht zuletzt den beiden oben genannten deutschen und russischen Förderorganisationen für die Finanzierung der Konferenzen. Die Druckvorlage erstellte meine Sekretärin Barbara Kunkel, das Personenregister meine Hilfskraft Anna Matzkowitz; auch ihnen sei an dieser Stelle herzlich gedankt.

Mainz, im Mai 2009

Heinz Duchhardt 


\section{Russland, Sibirien und der »Ferne Osten $«$ in der russischen Kartographie der Frühen Neuzeit und der Beitrag deutscher Wissenschaftler}

Im Rahmen des großen Forschungsthemas dieses Bandes, der russischen Erschließung Ostasiens, spielt die Kartographie eine herausragende Rolle. Denn zum einen machen erst Karten die geographischen und topographischen Gegebenheiten sichtbar, die die russische Expansion nach Asien geprägt haben; neben der beeindruckenden Größe des Landes sind das vor allem die Flussverläufe, die Gebirgszüge und die Grenzverhältnisse. Zum anderen aber gehören Karten selbst, gehört die Kartographie ihrerseits, zu den Bedingungen dieser Erschließung: Karten verschafften den Zeitgenossen spezifische Visualisierungen des asiatischen Raums, ein Bild also von den räumlichen Möglichkeiten und Grenzen der Erschließung des Landes. Somit erlaubt eine Analyse dieser Karten in historischer Perspektive wichtige Aussagen darüber, welche Vorstellungen zu bestimmten Zeiten von Sibirien und Ostasien bestanden. Im Folgenden wird es demnach weniger darum gehen, die Verbesserung der geographischen und topographischen Kenntnisse und deren auf geometrisch immer exakteren Vermessungstechniken beruhende, maßstabgetreue Kartierung nachzuvollziehen, obwohl natürlich auch das eine Rolle spielt; das Ziel dieser kleinen Studie besteht vielmehr darin, sowohl genauere Einsichten in zeitgenössische Raumvorstellungen zu gewinnen als auch - und darüber hinaus - Raumprojektionen zu erfassen, wie sie in frühneuzeitlichen Karten Sibiriens und Ostasiens ihren Niederschlag gefunden haben.

Solche Einsichten erlauben Karten aufgrund der ihnen eigenen spezifischen Dialektik von Empirie und Imagination. Denn Karten bilden geographische Realitäten nicht einfach ab, kartographische »Information pur « gibt es nicht: Der Kartenausschnitt, der Maßstab der Darstellung, die Projektion und die Rahmung der Karte, ferner Einfärbungen und Benennungen, formen die kartographische Information mit und prägen auf diese Weise auch die Sehgewohnheiten der Betrachter: Karten bestimmen Weltbilder entscheidend mit ${ }^{1}$. Frühneuzeitlichen Herrschern dienten Karten insofern zwar

Dieses Verständnis von Karten ist in Deutschland erst seit etwa fünfzehn Jahren verbreitet. Nicht bloß in Deutschland, aber gerade hier, hat sich die Kartographiegeschichte nach 1945 unter 
durchaus als Quelle von Informationen über Land und Leute; Karten boten sich jedoch zugleich auch dazu an, den entstehenden Staat »abzubilden«: Die Karte wurde geradezu zu einem Symbol des Staats - und in der Hand des Herrschers zu einem Instrument politischer Herrschaft, zu einem »tool of government $\ll^{2}$. Darüber hinaus interessiert hier jene Suggestionskraft der Karten, die sogar die Visualisierung von bloß imaginisierten Räumen erlaubt. Die Analyse kartographischer Abbildungen von räumlichen Ordnungsvorstellungen und politischen - imperialen - Raumstrategien wird

dem Eindruck nationalsozialistischer Raumprojektionen in Wissenschaft und Öffentlichkeit lange überwiegend als Fortschrittsgeschichte verstanden und vor allem - Fragen der Reduktion, der Abstraktion, der Projektion oder auch der Ästhetik diskutierend - die Etappen der wissenschaftlich möglichst adäquaten, »objektiven « kartographischen Repräsentation aufzufinden gesucht. Doch in den 1980er Jahren fand ein grundlegender Wandel statt: Einerseits lehnte sich die naturwissenschaftlich und empirisch arbeitende Richtung der Kartographie an die neuen computergestützten Methoden an, andererseits aber rief diese Entwicklung scharfe Kritik hervor, insbesondere von Geographen in den USA. Wichtig war hier John B. HARLEY, Deconstructing the Map, in: Cartographica 26 (1989), S. 1-20. Harley und seine Kollegen warfen ihrer Zunft vor, die Voraussetzungen ihrer Disziplin aus dem Blick verloren zu haben, und schlugen ihrerseits eine von sozialen und kulturellen Theorien ausgehende Epistemologie vor, die einer Geschichte der Kartographie viel angemessener sei als der naturwissenschaftliche Positivismus. Diese Positionen fanden im angelsächsischen Bereich große Resonanz. In Deutschland dagegen entwickelten sich Geographie und Kartographie immer stärker zu positivistischen Naturwissenschaften. Erst in jüngster Zeit werden die angloamerikanischen Studien auch in Deutschland rezipiert, nun aber, im Rahmen vor allem des spatial turn, insbesondere in den Geisteswissenschaften: in der Literaturwissenschaft, der Geschichtswissenschaft und der Kunstgeschichte. Seither, etwa seit der Mitte der 1990er Jahre, ist die kulturelle Kontextualisierung von Karten ein verbreiteter Gegenstand interdisziplinärer Forschung. Einschlägig sind hier vor allem folgende Arbeiten: Sigrid WeIGEL, Zum »topographical turn «. Kartographie, Topographie und Raumkonzepte in den Kulturwissenschaften, in: KulturPoetik 2 (2002), S. 151-165; Ute SCHNEIDER, Die Macht der Karten. Eine Geschichte der Kartographie vom Mittelalter bis heute, Darmstadt 2004; Andreas LANGENOHL, Mental Maps, Raum und Erinnerung. Zur kultursoziologischen Erschließung eines transdisziplinären Konzepts, in: Sabine DAMIR-GAILSDORF u.a. (Hg.), Mental Maps - Raum - Erinnerung. Kulturwissenschaftliche Zugänge zum Verhältnis von Raum und Erinnerung, Münster 2005, S. 51-69, Jürgen GLAUSER / Christian Kienig (Hg.), Text - Bild - Karte. Kartographien der Vormoderne, Freiburg i.Br. / Berlin / Wien 2007.

2 Dazu nach wie vor am besten: Peter BARBER, Maps and Monarchs in Europe 1500-1800, in: Robert ORESKo / G. C. GiBbS / H. M. SCOTT, Royal and Republican Sovereignty in Early Modern Europe. Essays in Memory of Ragnhild Hatton, Cambridge 1997, S. 75-124, und David BuISSERET (Hg.), Monarchs, Ministers and Maps. The Emergence of Cartography as a Tool of Government in Early Modern Europe, Chicago / London 1992. Beide Werke thematisieren Russland leider höchstens am Rande, wie sie ihrerseits von neueren Studien zur russischen Kartographie, aber auch von neueren kulturwissenschaftlich ausgerichteten Arbeiten zur Kartographie im Allgemeinen nicht immer zur Kenntnis genommen werden. Für das vorpetrinische Russland diese Studien weiterführend und differenzierend die Forschungen von Valerie A. KIVELSON, hier vor allem: Cartography, Autocracy and State Powerlessness: The Uses of Maps in Early Modern Russia, in: Imago Mundi 51 (1999), S. 83-105. Zur Bedeutung der geographischen Wissenschaften - und in diesem Kontext auch der Kartographie - für die Staatsreformen in der Zeit Peters des Großen am besten Denis J. B. SHAW, Geographical Practice and its Significance in Peter the Great's Russia, in: Journal of Historical Geography 22,2 (1996), S. 160-176. 
möglich, von Abbildungen eben auch solcher Verhältnisse, die so nicht mehr oder hier vor allem: noch nicht bestanden ${ }^{3}$. Vor diesem Hintergrund diskutiert der vorliegende Aufsatz die russische Aneignung Sibiriens und des »Fernen Ostens « durch Karten und nimmt dabei, gemäß der Konzeption des Bandes, auch den Beitrag deutscher Wissenschaftler in den Blick.

Im ersten Abschnitt sollen mit wenigen Strichen zunächst Grundzüge der russischen Expansion nach Sibirien und Ostasien skizziert und anschließend Darstellungen dieses Raums auf frühneuzeitlichen Weltkarten gekennzeichnet werden. Der zweite Abschnitt gilt dann den frühneuzeitlichen, vorwiegend in Russland hergestellten Karten Sibiriens und Ostasiens, aber auch dem Transfer kartographischen Wissens zwischen Ost und West. Der dritte Abschnitt schließlich ist einigen Überlegungen zur Bedeutung ausländischer, namentlich deutscher Wissenschaftler für die russische Kartographie gewidmet. Insgesamt wird sich zeigen, dass sich vom 16. bis zum 18. Jahrhundert nicht nur die Karten geändert haben; einem Wandel unterlagen ebenso die Bedingungen der Kartenproduktion und in diesem Zusammenhang der Beitrag ausländischer, eben auch deutscher Wissenschaftler. Vor allem aber änderte sich die Bedeutung der Karten selbst - von den ersten tastenden Schritten zur Klärung der geographischen Struktur des Landes jenseits des Ural hin zur imperialen Aneignung Sibiriens im Verlaufe des 18. Jahrhunderts.

\section{Der historische Kontext: Die russische Expansion nach Sibirien, Ostasien und zum Pazifik}

Die territoriale Expansion über den Ural bis an die Grenze zu China und an den Pazifik verwandelte das unbedeutende slavische, orthodoxe Fürstentum

\footnotetext{
3 Die angelsächsische Empire-Forschung untersucht diese Phänomene schon länger; vgl. bereits Morag BeLl / Robin ButLin / Michael HeFfERnAN (Hg.), Geography and Imperialism, 1820 1940, Manchester 1995, und Zoë LaIDLAW, Das Empire in Rot. Karten als Ausdruck des britischen Imperialismus, in: Christof DiPPER / Ute SCHNEIDER (Hg.), Kartenwelten. Der Raum und seine Repräsentation in der Neuzeit, Darmstadt 2006, S. 147-159. In Deutschland ist diese Forschung vor allem mit dem Namen Jürgen Osterhammel verbunden. Für Russland nach wie vor am besten Marc BASSIN, Russia between Europe and Asia: The Ideological Construction of Geographical Space, in: Slavic Review 50/1 (1991), S. 1-17. Anregend und kenntnisreich die Reflexionen über den spatial turn und die Folgen von Stephan GüNZEL, Raum - Topographie - Topologie, in: Ders. (Hg.), Topologie. Zur Raumbeschreibung in den Kultur- und Medienwissenschaften, Bielefeld 2007, S. 13-29, hier besonders zum Raumbegriff einerseits als Extensions-, andererseits als Expansionsgedanke und zum Bruch mit der Substanzvorstellung des Raums, S. 13-17. Aus geschichts- und kulturwissenschaftlicher Sicht vgl. dazu jetzt Tanja MichaLSKY / Felicitas Schmieder / Gisela Engel (Hg.), Aufsicht - Ansicht - Einsicht. Neue Perspektiven auf die Kartographie an der Schwelle zur Frühen Neuzeit, Berlin 2009, die Einleitung der Herausgeberinnen, S. 7-14.
} 
Moskau von der Mitte des 15. bis zum Ende des 18. Jahrhunderts in das größte zusammenhängende multiethnische Imperium der Geschichte. Dieser weltgeschichtliche Vorgang war die Folge des Verdrängens der Goldenen Horde, das mit der Aufkündigung des Tributs durch den Moskauer Großfürsten Ivan III. 1480 erstmals sichtbar wurde und mit der Eroberung der Khanate Kazan' 1552 und Astrachan' 1556, dem entscheidenden Schritt des Moskauer Zartums zum Imperium, besiegelt war. ${ }^{4}$. Erstmals befand sich nun der gesamte Wolga-Lauf bis zum Kaspischen Meer unter russischer Herrschaft, der Handelsweg nach Süden war damit frei geworden. Angezogen vom Reichtum an wertvollen Pelzen, drangen seit den 1580er Jahren zunächst Kosaken über den Ural vor, eroberten das letzte Khanat der Goldenen Horde, das Khanat Sibir', und gründeten dort, bald unterstützt von der Moskauer Regierung, erste befestigte Orte (russ. ostrog): 1586 Tjumen, 1587 Tobol'sk. Die großen Flusssysteme erleichterten das Vordringen, so dass 1632 die Festung Jakutsk errichtet werden konnte. 1639 war man bereits am Pazifischen Ozean; 1648, im Jahr des Westfälischen Friedens, wurde Ochotsk gegründet. Weiter im Süden wurde um die Jahrhundertmitte der Baikalsee erreicht und dort mit Irkutsk 1652 eine Festung erbaut.

Seither allerdings gingen die Eroberungen langsamer vonstatten. Überhaupt erfolgte die Expansion nicht gleichmäßig, sondern in Schüben, zumal sie immer wieder durch militärische Konflikte mit den westlichen und südlichen Nachbarn des Zarenreichs, mit Polen-Litauen, Schweden und dem Osmanischen Reich, aufgehalten wurde. Seit den Vorstößen an den Baikal allerdings und vollends seit den ersten Zusammenstößen mit dem Chinesischen Reich in den 1680er Jahren kam das russische Vordringen nach Ostasien um $1700 \mathrm{zu}$ einem ersten Abschluss. Zum einen bestand ja eine große Herausforderung darin, die territoriale Expansion gegenüber den nun klarer erkennbaren Nachbarmächten, namentlich China, zu sichern und die eroberten Gebiete in das Zarenreich zu integrieren. Zum anderen lagen die politischen, außenwirtschaftlichen und kulturellen Prioritäten des Moskauer Hofs

4 Einen quellen- und forschungskritischen wie zugleich sehr anregenden Überblick bietet Basil DMYTRYSHYN, Russian Expansion to the Pacific, 1580-1700: A Historiographical Review, in: Surawu-kenyu = Slavic studies: Journal of the Slavic Institute of Hokkaido 25 (1980), S. 1-25. Hingewiesen sei hier ferner auf Andreas KAPPELER, Russland als Vielvölkerreich. Entstehung, Geschichte, Zerfall, München 1993, S. 25-56; Wolfgang REINHARD, Geschichte der europäischen Expansion, Bd. 1: Die Alte Welt bis 1818, Stuttgart u.a. 1983, S. 86-89; Mark BASsIN, Imperial Visions. Nationalist Imagination and Geographical Expansion 1840-1865, Cambridge 1999, S. 19-26, und Dittmar DahlmanN, Sibirien: Der Prozess der Eroberung des Subkontinents und die russische Zivilisierungsmission im 17. und 18. Jahrhundert, in: Boris BARTH / Jürgen OSTERHAMMEL (Hg.), Zivilisierungsmissionen. Imperiale Weltverbesserung seit dem 18. Jahrhundert, Konstanz 2005, S. 55-71. Zuletzt aus kulturwissenschaftlicher Perspektive Eva-Maria STOLBERG, Sibirien - Russlands »Wilder Osten«, Habilitationsschrift Bonn 2006, elektronische Ressource: urn:nbn:de:hbz:5-07968, alle Darstellungen mit wichtiger weiterführender Literatur, die hier nicht im Einzelnen aufgezählt werden kann. 
wie der Eliten des Zarenreichs weiterhin im Altsiedelland und in den Kontakten zum Westen; Konflikte mit dem Chinesischen Reich wollte man vor allem deshalb unbedingt verhindern. So drängte die russische Regierung zum Vertrag von Nerčinsk, mit dem 1689 die russisch-chinesische Grenze festgeschrieben wurde, aber auch für über eineinhalb Jahrhunderte der untere Amur unerreichbar blieb: Die Grenze sollte dem Argun, dem oberen Amur und dem Stanovoi-Gebirge bis zum Meer folgen. Dafür durften russische Handelskarawanen regelmäßig nach Peking kommen und dort zollfrei Handel treiben, wovon sie regen Gebrauch machten. Der Kjachta-Vertrag 1727 setzte dann eine gemeinsame Kommission ein, die in der Folgezeit auch die Nordgrenze der äußeren Mongolei festlegte 5 .

Die Halbinseln Kamčatka und Čukotka an der Pazifikküste des asiatischen Kontinents sowie die Kurilen und Aleuten wurden erst im Verlauf des 18. Jahrhunderts erobert, Sachalin gar erst im 19. Jahrhundert. Insgesamt war für die koloniale Expansion Russlands nach Asien jene spezifische Mischung aus - zumeist kosakischen - Abenteurern, gewerblichen, gleichsam privaten Jägern, Händlern und Unternehmern und erstaunlich schneller staatlicher Präsenz kennzeichnend. Die Verwaltung der Kolonie Sibirien durch die Moskauer Regierung erfolgte denn auch recht rasch, und zwar durch schlichte Ausdehnung der administrativen Strukturen des Zartums ${ }^{6}: 1599$ wurde innerhalb des für Kazan' zuständigen Amtes, des Kazaner Prikaz (Kazan'skij Prikaz), ein Büro für Sibirien geschaffen (Sibirskij Stol). Dessen Zuständigkeit ging 1637 an ein eigenes Amt, den Sibirskij Prikaz über, dem nun auch der Voevode mit Sitz in Tobol'sk verantwortlich war. Angesichts der Größe des Landes und der Entfernung zu Moskau genoss der Voevode freilich zahlreiche Freiheiten; hinzu kam, dass weitere Befugnisse für Sibirien bei anderen Moskauer Prikazen lagen, vor allem dem Außen- oder Gesandtschaftsamt, dem Posol'skij Prikaz. Eine grundlegende Veränderung dieser - im europäischen Vergleich durchaus zeittypischen - Verhältnisse bedeutete erst die Gouvernementsreform Katharinas II., in deren Rahmen 1763 ein Gouvernement Sibirien geschaffen wurde, das dann bis 1847 für das gesamte Sibirien zuständig blieb.

Schaut man nun auf zeitgenössische, in Westeuropa hergestellte Weltkarten und fragt nach den geographischen Kenntnissen der Zeitgenossen von dieser gewaltigen eurasischen Landmasse sowie nach räumlichen Vorstel-

\footnotetext{
5 Vgl. dazu und zur Bedeutung dieser Verträge im Hinblick auf die spätere Geschichte der beiden Reiche REINHARD, Geschichte, S. 88f.

6 Vgl. dazu Dmytryshyn, Expansion, S. 5-7, und Marina Tolmacheva, The Early Russian Exploration and Mapping of the Chinese Frontier, in: Cahiers du Monde russe 41/1 (2000), S. 4156, hier: S. 42f., beide mit weiterführender Literatur zur Verwaltungsgeschichte Sibiriens.
} 
lungen, so lassen sich folgende Feststellungen treffen ${ }^{7}$ : Die geographische Lage und Gestalt Skandinaviens mit dem Nordkap klärte sich endgültig um 1600, beruhend auf der Umfahrung des Nordkaps durch die Merchant Adventurers 1553 und dem Expansionsbestreben der schwedischen Krone. Unklar blieben dagegen bis weit ins 18. Jahrhundert hinein Lage und Konturen der Insel Novaja Zemlja, überhaupt die Küste des Nordpolarmeeres, ferner die ostsibirische Pazifikküste mit der Halbinsel Kamčatka und dem Ochotskischen Meer. Allerdings stellt diese relative Unkenntnis von einem so großen Kontinent noch kurz vor 1700 keineswegs eine Besonderheit dar; Ähnliches gilt auch für Nordamerika und mehr noch für Australien, das bis zur Mitte des 18. Jahrhunderts eine wahrhafte terra incognita blieb. Dieser kursorische Blick auf nur wenige Karten - endgültige Befunde müssten natürlich auf einer größeren Materialbasis ermittelt werden - zeigt ferner, dass auch die geographische Beschaffenheit Ost- und Nordostasiens mit seinen Flussverläufen, Gebirgen und den Grenzen der entstehenden Staaten lange, d.h. bis ins 18. Jahrhundert hinein, recht unklar war.

Darüber hinaus fällt auf, dass es »Sibirien« in der Vorstellungswelt der westeuropäischen Kartographen bis weit ins 18. Jahrhundert hinein gar nicht gab: Der Raum von der Wolga über den Ural bis weit nach Ostasien heißt auf diesen und den meisten anderen in Westeuropa hergestellten Karten nicht »Sibirien«, wie auf russischen Karten, sondern »Tartarei«. Ob man die Jenkinson Map von 1562 betrachtet - ihre Selbstbezeichnung lautet sogar Moscoviae et Tartariae descriptio - oder Asia summa cura recens delineata von Heinrich Hondius, die Asienkarten der Familie Blaeu aus der zweiten Hälfte des 17. Jahrhunderts, L'Asie von Guillaume Delisle aus dem Jahr 1700 oder Strahlenbergs Nova Descriptio geographica Tattaria Magnae tam orientalis quam occidentalis von 1730: Immer findet sich östlich des Moskauer Zarenreichs die »Tartarey«, nicht selten unterteilt in die »kleine europäische Tartarei«, womit das Gebiet der Khanate Kazan', Astrachan' und der Krim gemeint war, und die "große asiatische Tartarei«, die Zentral- und Nordasien umfasste; auch die Tartarei der Nogai-Tataren ist hier und da zu sehen.

Diese heute fast nur noch Staunen hervorrufende Bezeichnung »Tartarei« geht auf die »Tataren« zurück, wie die Mongolen und Turkvölker verallgemeinernd genannt wurden. Verbunden war diese Bezeichnung mit den endzeitlichen Völkern Gog und Magog aus der Johannes-Offenbarung, die

\footnotetext{
7 Zugrunde liegen diesen Befunden bekannte und vielfach publizierte Weltkarten: die Ulmer Weltkarte nach Ptolemaios aus dem Jahre 1482, die Weltkarte Martin Waldseemüllers von 1507, eine Weltkarte aus dem Atlas des Abraham Ortelius aus der Mitte des 16. Jahrhunderts und schließlich eine Weltkarte der Familie Blaeu von etwa 1660.
} 
stets am Rande der bekannten Welt vermutet und auf Karten entsprechend lokalisiert wurden ${ }^{8}$. Noch der Brockhaus von 1809 zählt verschiedene, an Himmelsrichtungen, Toponymen oder Völkerbezeichnungen orientierte »Tartareien« auf. Mit der besseren Kenntnis der geographischen und topographischen Verhältnisse im 19. Jahrhundert kam die Bezeichnung »Tartarei« dann »außer Gebrauch«, wie es in Meyers Konversations-Lexikon von 1897 heißt. Auf die Bedeutung solch unterschiedlicher Bezeichnungen dieses Raums - hier »Sibirien«, da »Tartarei«, auch auf Überlegungen, ob der mythische Kontext der »Tartarei« an der Wende zum 19. Jahrhundert den westeuropäischen Geographen noch präsent war, wenn sie den Begriff in eine Karte zeichneten - kann hier nicht weiter eingegangen werden; aber die geschilderte Diskrepanz legt es nahe, den folgenden Abschnitt mit der Frage nach dem Austausch kartographischen Wissens zwischen Russland und dem Westen zu beginnen.

\section{Russische Karten Sibiriens und des »Fernen Ostens« aus dem 17. und 18. Jahrhundert und der frühneuzeitliche kartographische Wissenstransfer zwischen Ost und West}

Die Frage, woher und auf welchen Wegen die Kartographen in Italien, in den Niederlanden, in England und im Reich - hier befanden sich bis zum 18. Jahrhundert die Zentren der europäischen Kartenproduktion - die Informationen erhielten, auf denen ihre Karten Russlands und Sibiriens beruhten, lässt sich erst ab dem späteren 17. Jahrhundert mit Sicherheit beantworten. Auch über die Anfänge der russischen Kartographie und die Verbreitung der genannten Welt- und Kontinentalkarten, überhaupt: über Kenntnisse von der westeuropäischen Kartographie im Moskauer Zarenreich, gibt es für das 16. Jahrhundert nur wenige sichere Informationen; man ist auf Indizien angewiesen und findet gut wie auch weniger gut begründete Vermutungen. Leo Bagrow, Doyen der russischen Kartographie und bis heute unumstrittene Autorität, ist zur Frage des kartographischen Wissenstransfers mit zwei wichtigen grundsätzlichen Positionen aufgetreten. Zum einen betonte er ausdrücklich, dass man bereits seit dem Beginn des 16. Jahrhunderts von einem frühen Informationsaustausch auch im Hin-

8 Eine Reihe interessanter Informationen über dieses Thema, das, wie es scheint, bislang nicht in den Fokus der Forschung gelangt ist, vermittelte der Frankfurter Vortrag von Eva-Maria Stolberg »Von der >fremden Tartareiく zur russischen Kolonie Sibirien. Wandel der westeuropäischen und russischen Raumvorstellungen im Zuge der neuzeitlichen Kolonialexpansion Russlands«; vgl. den Tagungsbericht http://hsozkult.geschichte.hu-berlin.de/tagungsbericht/id=1375. 
blick auf die Kartographie zu sprechen habe: »Russia was to become known to the West in maps drawn from materials provided by Russians « ${ }^{9}$. Zum anderen vertrat er die bislang unwiderlegte Ansicht, dass im 16. Jahrhundert kein Russe in der Lage gewesen sei, eine Generalkarte des Moskauer Zarenreichs anzufertigen ${ }^{10}$.

Im Lichte neuerer Forschungen löst sich der - ohnedies nur scheinbare Widerspruch zwischen diesen beiden Feststellungen auf, wenn man eine andere Perspektive einnimmt und davon ausgeht, dass Russland seit dem späten 15. Jahrhundert zunehmend, wenn auch nicht kontinuierlich, an dem ganz Europa erfassenden Austausch von Wissen und Weltbildern teilhatte. Den maßgeblichen Wandel leiteten die Heirat Ivans III. mit Sophia Paleo$\log$, der in Rom aufgewachsenen Nichte des letzten byzantinischen Kaisers im Jahre 1472, ferner die Aufkündigung der Moskauer Tributzahlungen an die Tataren und schließlich der Beginn der diplomatischen Kontakte des Großfürsten zu Herrschern in Westeuropa, vor allem zu Kaiser Maximilian, ein: Um 1500 kamen insbesondere aus Italien zahlreiche Künstler und Fachkräfte nach Moskau, wohl auch einige Wissenschaftler, und sie brachten Bücher und Manuskripte mit. Ausgaben des Ptolemaios dürften um diese Zeit allerdings noch nicht nach Moskau gelangt $\operatorname{sein}^{11}$. Überhaupt scheint das Bedürfnis nach kosmographischen Darstellungen im Bereich der Moskauer Kirche eher gering ausgeprägt gewesen zu sein, deshalb wohl auch die entsprechende Kompeten $z^{12}$. Regionale und lokale Karten dagegen lassen sich im Moskauer Großfürstentum seit dem 15. Jahrhundert nachweisen. Zeitgenössisch als čertež, also »Skizze« oder »Zeichnung« bezeichnet, zeigen solche Karten - für die die Bezeichnung »picture map « ${ }^{13}$ überzeugt, die ins Deutsche mit »Bildkarte« zu übersetzen wäre - vor allem Wege und Flussverläufe, bald Grenzbefestigungen und lokale Landbesitzungen, später auch Aushebungs- und Steuerbezirke. Diese Karten verdanken ihre Entstehung demnach ebenso wie entsprechende Karten im Westen dem Ausbau frühneuzeitlicher Staatlichkeit, nämlich fiskalischen, militäri-

\footnotetext{
9 Leo BAGROw, History of Cartography. Von Robert A. SKelton erweiterte, korrigierte Ausgabe von 1960, London 1964, S. 171.

10 Vgl. das Zitat bei Samuel H. BARON, B. A. Rybakov on the Jenkinson Map of Russia, in: Ders., Explorations in Muscovite History, Hampshire 1991, S. 1-11, hier: S. 7.

11 Vgl. Anm. 21.

12 Das Streben nach wissenschaftlicher Welterkenntnis, das im Bereich der mittelalterlichen lateinischen Kirche in den dortigen Klöstern ja auch Karten hervorbrachte, war in der Kirche der Rus' deutlich geringer ausgeprägt. Die bislang klügsten und differenziertesten Bemerkungen zu diesem wichtigen Fragenkreis bei Denis J. B. SHAw, Mapmaking, Science and State Building in Russia before Peter the Great, in: Journal of Historical Geography 31 (2005), S. 409-429, hier: S. 411-413.

13 Die Bezeichnung stammt von P. D. A. Harvey; vgl. dazu SHAw, Mapmaking, S. 427, Anm. 43.
} 
schen und diplomatischen Interessen und der Rechtsprechung als Gewährleistung herrscherlicher Autoritä ${ }^{14}$.

Karten kannte man also im Moskauer Zarenreich des 16. Jahrhunderts und arbeitete auch mit ihnen. Aber bis zum Beginn des 17. Jahrhunderts ist, nach allem, was man weiß, in Russland keine Karte angefertigt worden, die das gesamte Reich zeigt. Gewiss wäre eine Karte des Moskauer Großfürstentums um 1500 oder des Moskauer Zartums um 1550 eine geradezu ideale Visualisierung der erfolgreichen »Sammlung der Länder der Rus' « gewesen und hätte als »tool of government" wie auch als Element der Herrschaftsrepräsentation bestens zu Ivan III. wie zu Ivan IV. gepasst; offenbar hat sich Ivan IV. sogar um ausländische Kartographen für diese Aufgabe bemüht ${ }^{15}$. Aber es ist keine solche Karte überliefert, und nicht einmal Indizien für ihre Existenz sind zu finden. Der sowjetische Kartographiehistoriker Rybakov hat es zwar 1974 unternommen, aufgrund der in Westeuropa überlieferten Karten nicht erhaltene russische Karten des späten 15. und des 16. Jahrhunderts zu rekonstruieren, auf denen die entsprechenden westeuropäischen Karten beruht haben sollen, doch sind seine Konjekturen - abgesehen von einer Karte, die er für das Jahr 1497 vermutet, die jedenfalls Baron für nicht unwahrscheinlich hält ${ }^{16}$ - eher skeptisch beurteilt worden ${ }^{17}$.

Gleichwohl bestätigt sich die Behauptung Bagrows, dass die Karten über Russland, die im 16. und 17. Jahrhundert in den großen Kosmographien und Atlanten in Westeuropa erschienen sind - z. B. jene in der Moscovia Sigmunds von Herberstein und in der Cosmographie Sebastian Münsters, die Jenkinson-Map im Atlas des Abraham Ortelius, auch die RusslandKarten des Hassel Gerritz, des Isaac Massa und späterer Kartographen -,

14 Tolmacheva, Exploration, S. 42-44; Shaw, Mapmaking, S. 413-415. Kivelson, Cartography, weist, solche allgemeinen Tendenzen differenzierend, darauf hin, dass die Vielzahl von lokalen Karten, die für die zweite Hälfte des 17. Jahrhunderts überliefert ist, als Indiz auch für die Hilflosigkeit der Moskauer Behörden zu werten ist. Der Staat habe nämlich, so Kivelson, durchaus Probleme gehabt, einer Gerichtsentscheidung Akzeptanz zu verleihen, so dass jede Prozessentscheidung einen neuen Prozess nach sich gezogen habe. In diesen Kontext ordnet Kivelson die Vielzahl lokaler Karten nach dem neuen Gesetzbuch von 1649, dem Uloženie, ein, wie sie überhaupt zahlreiche Belege für das Angewiesensein der »Zentrale« auf die Mitwirkung der »Peripherie« bei der Anfertigung von Karten beibringt.

15 BAGROW, History, S. 171.

16 Baron traut die Anfertigung einer solchen Karte aber nur einem Ausländer zu; BARON, Rybakov, S. 7.

17 B. A. RyBAKov, Russkie Karty Moskovii XV-načala XVI veka [Russische Karten Moskoviens 15.-Anfang 16. Jahrhundert], Moskau 1974. Dabei soll es sich um Karten des Moskauer Großfürstentums gehandelt haben, die Teilfürstentümer, Steuerbezirke und die Grenzgebiete zu Polen-Litauen dargestellt hätten. Zu den Reaktionen auf dieses Buch vgl. BARON, Rybakov, S. 8, Anm. 1. Schaut man sich die - wie gesagt: bloß erschlossenen - Karten in dem Buch RYBAKOvS an, namentlich die für das Jahr 1497 angenommene Karte, spürt man die enorme Plausibilität der Einsichten, die neuere Ansätze in der Kartographiegeschichte ermöglichen: Von der »Abbildung« eines Staates in der Frühen Neuzeit muss eine enorme Faszination ausgegangen sein. 
jedenfalls teilweise und hinsichtlich vieler Details auf russischen Quellen beruhen. Dabei mochte es sich um Mitteilungen Moskauer Gesandter handeln, etwa des Dolmetschers Dmitrij Gerasimov, der 1525 als Teilnehmer einer Gesandtschaft Vasilijs III. in Rom war und sich dort im Auftrag Papst Clemens' VII. mit keinem geringeren als Paolo Giovo über die geographischen und topographischen Verhältnisse Nordeuropas austauschte ${ }^{18}$. Mehr aber noch ist zu denken an Informanten und Informationen der westeuropäischen Russlandreisenden im Zarenreich selbst, von denen diese ja auch stets berichten. $\mathrm{Zu}$ diesen Informationen dürften nach alledem schon im 16. Jahrhundert auch russische Karten, eben jene regional begrenzten, mit Bild- und anderen Symbolen angereicherten »Bildkarten«, die čerteži , gehört haben ${ }^{19}$. Seit Beginn des 17. Jahrhunderts gingen westeuropäische Kaufleute und Kartographen dann allmählich dazu über, die im Zarenreich gesehenen, teilweise wohl auch erworbenen Karten im Westen, v. a. in den Niederlanden, stechen und drucken zu lassen ${ }^{20}$ - was freilich nicht ungefährlich war, denn Karten galten, im Zarenreich wie auch sonst, als vertrauliches Material.

In umgekehrter Richtung dürfte der Informationsfluss ebenfalls im frühen 16. Jahrhundert, mit den Schriften im Gefolge der Sophia Paleolog und den Informationen Herbersteins, eingesetzt haben. Bagrow berichtet von der Mitteilung des Dorpater Pfarrers Wettermann, der in dem - bis heute nicht wieder aufgefundenen - Keller Ivan Groznyjs dessen Bibliothek mit einer Kartensammlung gesehen haben will ${ }^{21}$. Spätestens seit dem Ende des 16. Jahrhunderts wurden in Russland die großen kartographischen und kosmographischen Werke Westeuropas rezipiert, zunächst die Werke Mercators und Ortelius', später auch die anderen Atlanten und Kosmographien.

18 Das Werk von Giovo enthielt auch eine auf den Informationen Gerasimovs beruhende, von Battista Agnese gezeichnete Karte Russlands; vgl. dazu BArON, Rybakov, S. 2, und BAGROw, History, S. 171. Zu Gerasimov: Norbert ANGERmanN, Deutsche Übersetzer und Dolmetscher im vorpetrinischen Rußland, in: Eckhard HÜBNER (Hg.), Zwischen Christianisierung und Europäisierung. Beiträge zur Geschichte Osteuropas in Mittelalter und früher Neuzeit. Festschrift für Peter Nitsche zum 65. Geburtstag, Wiesbaden 1998, S. 221-249, hier: S. 228f. Zu den zahlreichen Text »anleihen« der westeuropäischen Autoren bei bereits erschienenen Reiseberichten vgl. Walter LEITSCH, Herberstein's Impact on the Reports about Muscovy in the 16th and 17th Centuries: Some Observations on the Technique of Borrowing, in: Forschungen zur Osteuropäischen Geschichte 24 (1978), S. 163-177.

19 Bagrow vermutet, dass Herberstein während seines ersten Aufenthalts 1516 von dem Bojaren Ivan Ljatskoj eine Karte des Großfürstentums Moskau erbeten und bei seinem zweiten Aufenthalt 1526 »a map of some sort« zu sehen bekommen habe. Grundzüge dieser Karte gelangten dann, so Bagrow weiter, vermittelt durch den Kupferstecher und Drucker Anton Wied als des »Moscowiters lands newe beschreibung« in Münsters Cosmographie von 1544; BAGROW, History, S. 172.

20 Ebd.

21 BAGRow, History, S. 170f. Wettermann soll bemerkt haben, dass eine Ptolemaios-Ausgabe nicht dabei gewesen sei. 
Dabei ist davon auszugehen, dass es stets des Lateinischen kundige Fachleute am Zarenhof gegeben hat; zudem lagen diese Werke seit den ersten Jahrzehnten des 17. Jahrhunderts in gekürzten, handschriftlichen Umarbeitungen, aber auch in Übersetzungen $\operatorname{vor}^{22}$. Ab der Mitte des 17. Jahrhunderts wurden die Übersetzer des Posol'skij Prikaz - etwa der oftmals für kaiserliche Gesandte zuständige Ivan Dorn - auch zur Übersetzung geound kosmographischer Werke eingesetz $\mathrm{t}^{23}$. Vor diesem Hintergrund komplexer Transferprozesse erscheint die in der älteren, auch in der sowjetischen Literatur immer wieder diskutierte Frage, ob der Bol'šoj Čertežž ${ }^{4}$, die »Große Bildkarte«, als »selbständige« Leistung russischer Kartographen gewertet werden muss oder ob das Werk unter - wie hoch auch immer zu veranschlagendem - westeuropäischem «Einfluss« entstanden ist, müßig und in die Irre führend.

Um nun zu den Kenntnissen und Vorstellungen von Sibirien und Ostasien in der russischen Kartographie zu kommen, sei erneut mit der Karte Herbersteins begonnen. Wenn man davon ausgeht, dass diese Karte die Grundzüge des am Hof des Moskauer Großfürsten vorhandenen topographischen und geographischen Wissens über Sibirien und dessen Osten spiegelt, dann zeigt sich, dass die Flussverläufe weitgehend zutreffend gezeichnet sind, ihre Ausrichtung indessen nur zum Teil. Immerhin wird der Ob schon abgebildet, aber er ist im Osten bereits die Grenze der geographischen Kenntnisse. Die Quelle des Ob vermutet Herberstein im »Kythai Lacus", in dessen Nähe er wiederum auch die Hauptstadt von Kythai, Chumbalik Regia, einzeichnet. Von der Mündung des Ob, die man um 1530 demnach noch nicht kannte, hätte man, so die Vorstellung Herbersteins, nur den $\mathrm{Ob}$ hinaufgehen müssen - und wäre in China gewesen! Angesichts der Popularität des Herbersteinschen Werks kann es nicht verwundern, dass die Engländer um 1550 auch diesen Weg nach China suchten. Doch wie in seinen Schriften leistet Herberstein auch in dieser Karte einen selbständigen Beitrag zur Kenntnis Russlands und Sibiriens sowie zur Interpretation des ihm vorliegenden Materials: Zum einen notiert er im

\footnotetext{
22 Ol'ga A. AleKSANDRovSKAJA, Stanovlenie geografičeskoj nauki v Rossii v XVIII veke [Die Herausbildung der geographischen Wissenschaft in Russland im 18. Jahrhundert], Moskau 1989, S. 20, sowie TolmacheVA, Exploration, S. 50 mit weiterer Literatur; SHAw, Geographical Practice, S. 163f. betont eher die geringe Anzahl und die geringe Verbreitung dieser Werke.

23 SHAW, Mapmaking, S. 413, Anm. 23, mit Hinweis auf T. RAJNOv, Nauka v Rossii XI-XVII vekov [Wissenschaft in Russland 11.-17. Jahrhundert], Moskau / Leningrad 1940, wo S. 418f. die Namen der Übersetzer genannt sind.

24 Bei der »Großen Bildkarte«, englisch als »Great Sketch« bezeichnet, handelt es sich um ein nicht überliefertes Kartenwerk, das zu Beginn des 17. Jahrhunderts entstanden ist; erhalten sind bloß die in Buchform überlieferten, offenbar sehr präzisen Erläuterungen; zu der »Kniga bol’šomu čertežu« vgl. BAGROW, History, S. 172 und neuerdings die Analyse von SHAw, Mapmaking, bes. S. 416-424.
} 


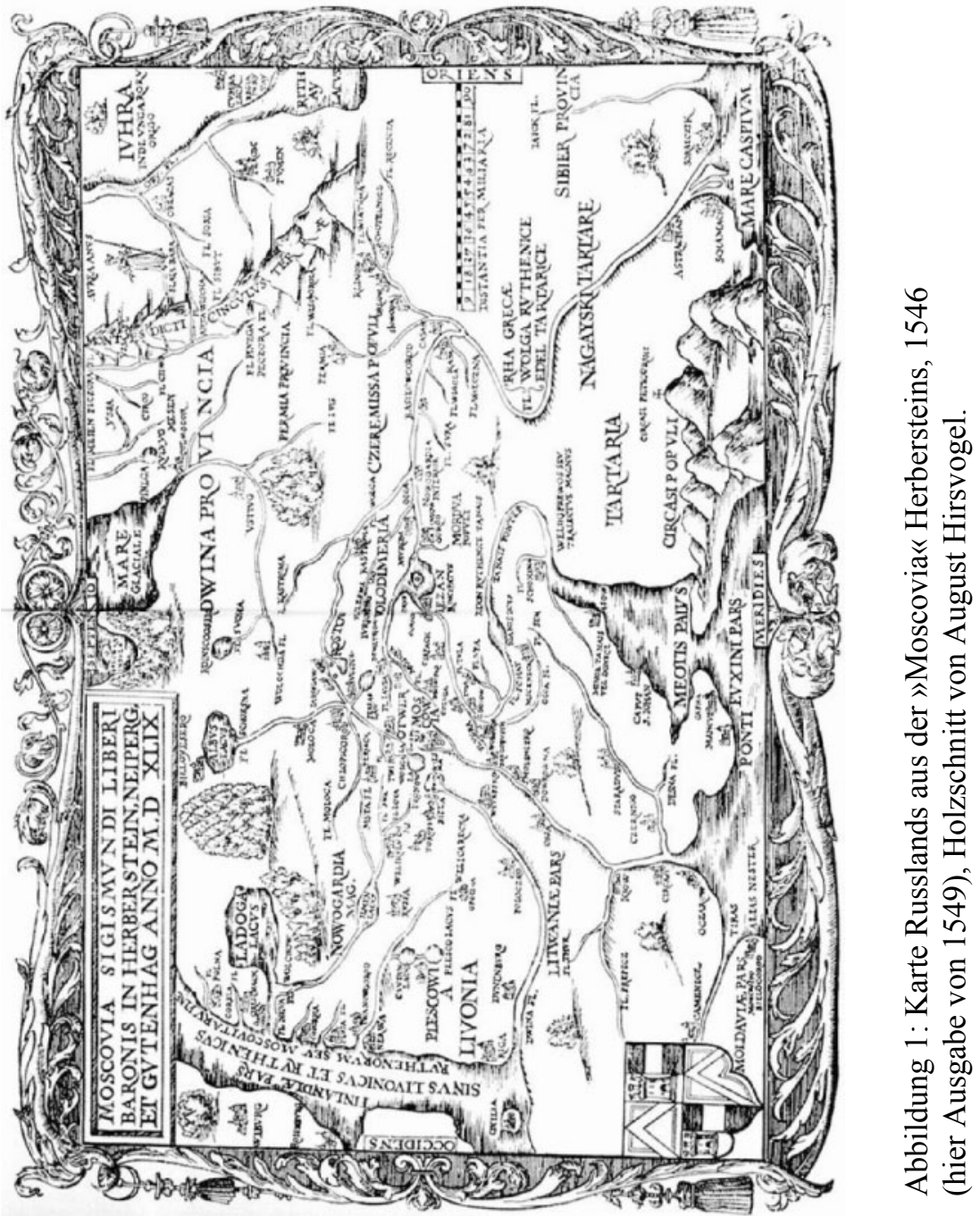


Osten der »Tartarey« die Bezeichnung Sibirien, »Sibier Provincia«, was sich, wie gesagt, in der westeuropäischen Kartographie nicht durchgesetzt hat. Zum anderen vollzieht er, der selbstverständlich eingebunden war in das Weltbild der Renaissance und die antiken geographischen Vorstellungen, einen Bruch mit der herkömmlichen Fabel von den »Hyperboräischen Bergen « und zeichnet statt dessen den Ural in Nord-SüdRichtung als »Montes dicti cingulus terrae« - wie in seinen Schriften also differenziert und, im Rahmen seines Weltbildes, um Aufarbeitung und Einordnung der neuen Informationen bemüht. Freilich zeigen diese wie auch andere nach Westeuropa gelangte Karten Russlands und Sibiriens, dass die Kenntnisse über den asiatischen Teil Russlands und das östliche Asien in Russland noch nicht sehr präzise, ja: von manchen Irrtümern geprägt waren.

Doch im Zuge der Durchdringung Sibiriens und seines allmählichen Einbaus in die Moskauer Verwaltung ab den 1580er Jahren dürfte in den Moskauer Ämtern, aber auch bei den Voevoden in Sibirien selbst, der Bedarf nach detaillierteren Karten vom asiatischen Teil des Kontinents sehr schnell gewachsen sein. Von besonderem Interesse war seit den 1640er Jahren China. Zum einen nämlich bestand der Wunsch, die Wege für Handelskarawanen dorthin genauer kennen zu lernen, denn der Zar betrieb einen umfangreichen Eigenhandel. Zum anderen interessierte, aus Sicherheitsgründen, die Grenze: Insbesondere der Posol'skij Prikaz, aber auch der Sibirskij Stol resp. Prikaz, hat, wie aus schriftlichen Quellen hervorgeht, solche »Grenzkarten«, porubeznye čerteži, in großer Zahl gesammelt, sich stets um weitere Informationen zur Verbesserung der Detailkarten bemüht ${ }^{25}$. Die frühesten bis heute erhaltenen kartographischen Abbildungen des Chinesischen Reiches in der russischen Kartographie finden sich aber erst in den Karten der sibirischen Kartographen-Familie Remezov $^{26}$.

Die Sibirien-Karten der Remezovs gehen auf einen entsprechenden Auftrag des Voevoden von Tobol'sk, Semen Godunov, aus dem Jahre 1667 zurück. Offenbar noch im gleichen Jahr fertigte wohl Uljan Remezov eine erste Karte an - sie ist nicht überliefert -, die mehrfach kopiert und von ihm selbst wie bald auch von seinem Sohn Semen, dem Bagrow ab etwa 1670

25 Die meisten Detail- und Grenzkarten Sibiriens sind allerdings im 18. Jahrhundert in sibirischen Archiven gefunden worden und sind nach wie vor unpubliziert; TOLMACHEVA, Exploration, S. 43. Die Handels- und die Sicherheitsinteressen der zentralen wie der lokalen Verwaltungen bedingten offenbar auch die China-Vorstellungen der Russen, wobei für die selektive Wahrnehmung auch der Mangel an Sprachkenntnissen eine Rolle spielte; vgl. dazu Andreas KAPPELER, Die Anfänge eines russischen China-Bildes im 17. Jahrhundert, in: Saeculum 31 (1980), S. 27-43.

26 TolmacheVA, Exploration, S. 43. 


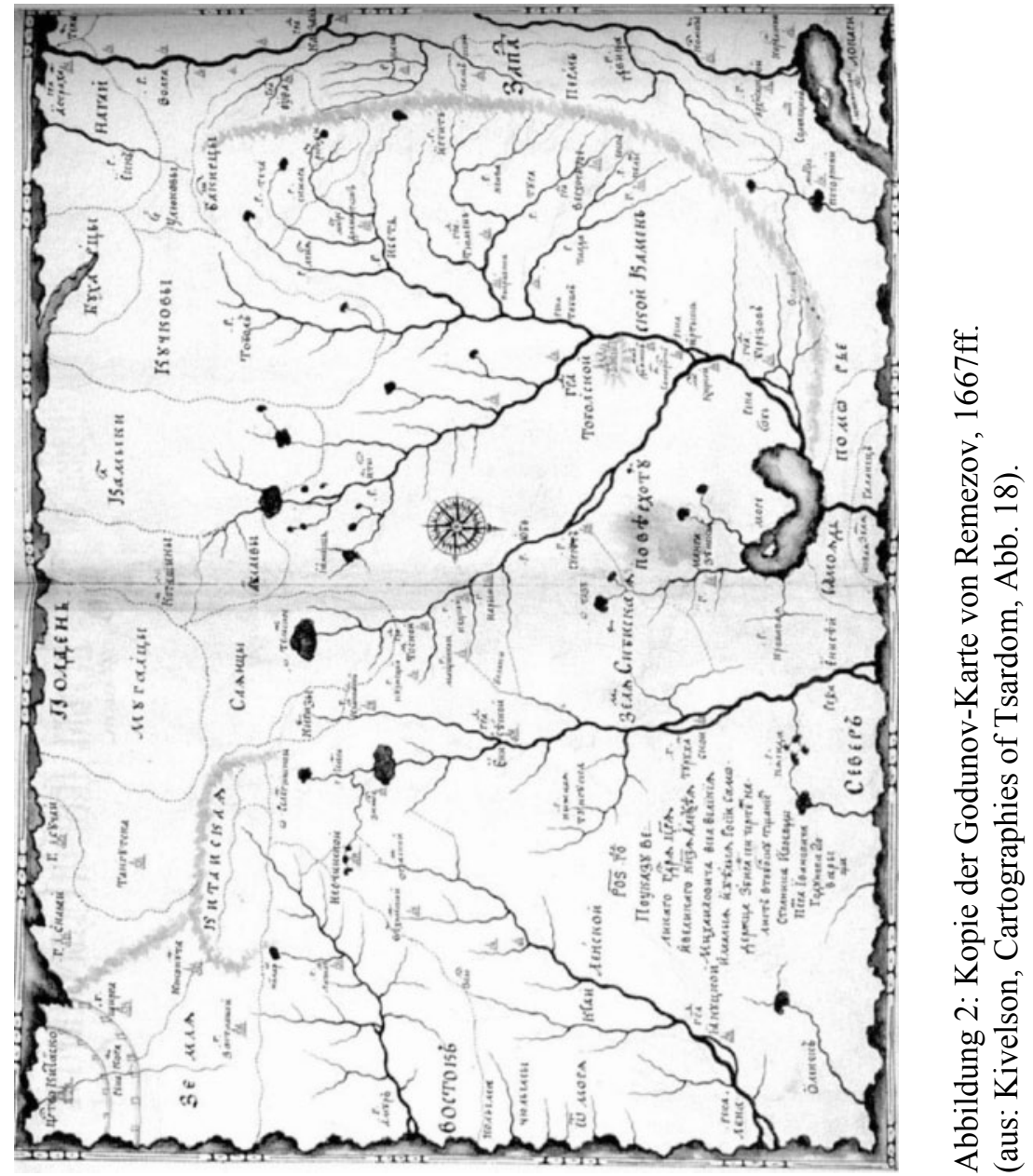




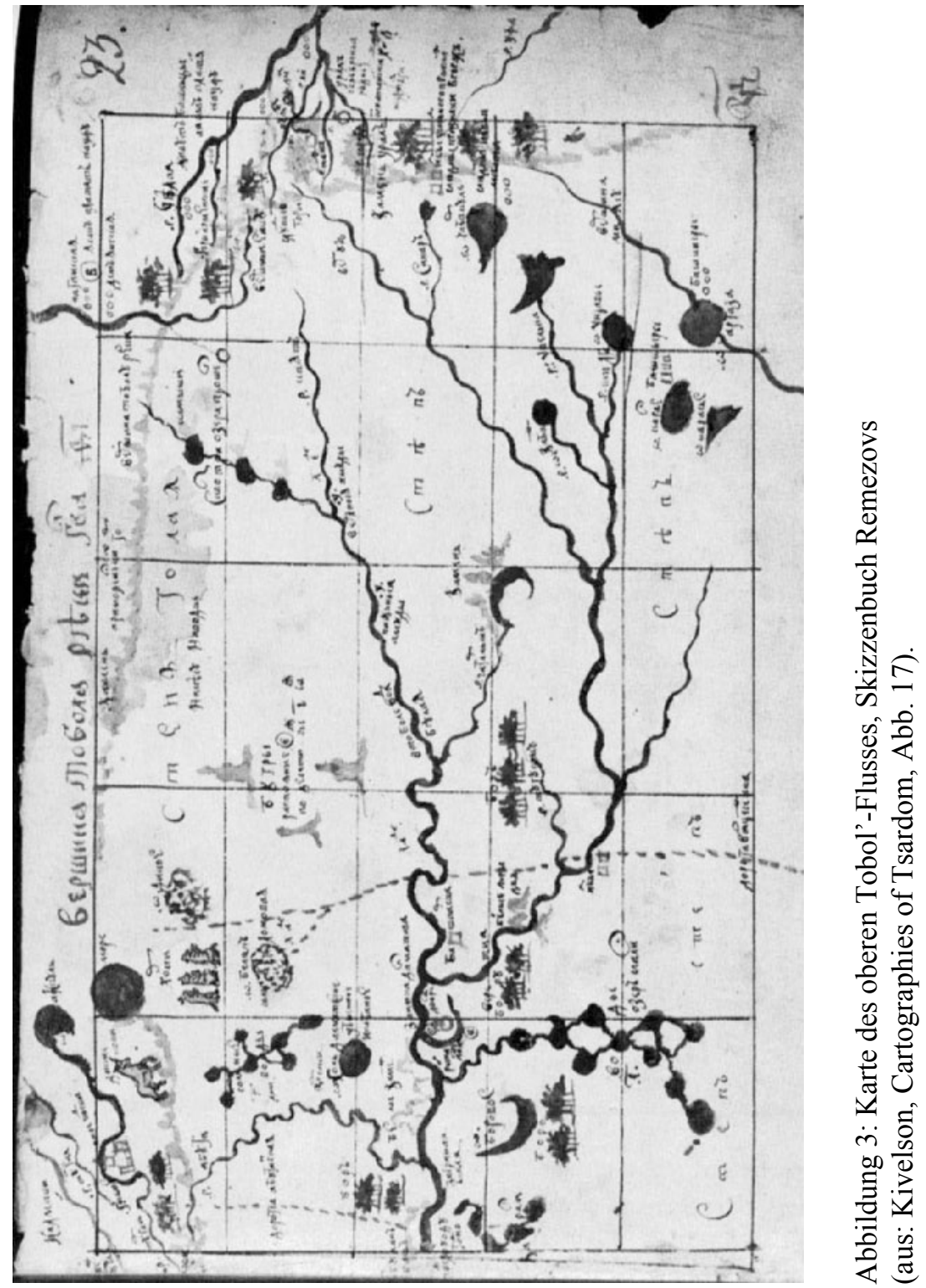


die Hauptarbeit zuschreibt ${ }^{27}$, immer wieder überarbeitet wurde. Dabei gingen weitere Informationen in die Karten ein, von denen sich Remezov einige selbst beschaffte; andere wurden gezielt durch Gesandte eingeholt. Insbesondere der Gesandte Milescu Spathary (russ. Spafarij) brachte 1675 viel Wissenswertes von seiner Gesandtschaftsreise nach China mit ${ }^{28}$, ebenso Isbrandt Ides $^{29}$. Auch besondere Wünsche des Zaren resp. der Moskauer und sibirischen Prikaze und Kanzleien hatte Remezov zu berücksichtigen ${ }^{30}$. Viele der Karten Remezovs, der durch diese Arbeit gewiss zu einem der besten Kenner des Landes avancierte, wurden in drei Atlanten gesammelt, die zwischen 1699 und 1715 erschienen $^{31}$. Auch Informationen aus chinesischen Karten dürften in den Atlas eingegangen sein. Ergänzt wurden die Karten durch teilweise ausführliche Beschreibungen ${ }^{32}$.

Nun kann die Entwicklung der Karten Remezovs hier nicht im Einzelnen nachvollzogen werden ${ }^{33}$, doch einige Grundzüge verdienen Beachtung. Remezov fertigte seine Karten im traditionellen čertež-Stil an. Das wichtigste Merkmal der čerteži ist die Verbindung der Plan- mit der Frontaldarstellung auf einem Blatt, anders formuliert: die Kombination von Aufsicht (»Vogelperspektive«) und Ansicht (»Bild«). Perspektivische Panoramakarten, wie sie seit dem 16. Jahrhundert in Westeuropa zu finden sind, scheint es unter den čerteži indessen nicht gegeben zu haben. Ferner weisen čertež $i$ kein Netz von Längen- und Breitengraden auf, auch sonst keine Skalierungen. Sie folgen nicht konsequent der Nord-Süd-Ausrichtung, und von einem

27 In der Einleitung zu Remezovs Sibirischem Atlas: The Atlas of Siberia by Semyon U. Remezov, 's-Gravenhage 1958, S. 8f. Zu Remezov, dem »energetic autodidact«, siehe die Literatur bei KiVELSON, Cartography, S. 103, Anm. 16.

28 Spathary war ein griechischer Adliger aus Moldavien mit europäischem Bildungshorizont. Er sollte, so seine Instruktion, Informationen über Wege von Sibirien nach China beschaffen, sich über Städte und Orte in China kundig machen und klären, welche Völker zwischen Sibirien und China lebten und wie das Verhältnis von deren Herrschern zum Zaren einzuschätzen sei; Tolmacheva, Exploration, S. 46, zur Person S. 50. Er brachte recht präzise Informationen mit offenbar auch Karten -, insbesondere eine ausführliche Beschreibung des Amur, des Wasserwegs nach China über den Amur, der Schwierigkeiten, China von Europa aus über die Nordostpassage $\mathrm{zu}$ erreichen, vor allem aber darüber, dass es keinen Fluss gab, der Sibirien direkt mit China verband; ebd., S. 47.

29 Vgl. dazu TolmacheVA, Exploration, S. 46.

30 So erging 1696 ein Befehl an Remezov, auf einer Karte die Jasak-Bezirke besonders deutlich einzuzeichnen, jene Gebiete also, in denen der Zar Abgaben erheben konnte; TolmaCHEVA, Exploration, S. 44.

31 Bagrow hat im Jahr 1958 eine Faksimile-Ausgabe dieses Atlas veranstaltet: The Atlas of Siberia by Semyon U. Remezov, 's-Gravenhage 1958; zu anderen Editionen auch TOLMACHEVA, Exploration, S. 44, Anm. 9.

32 Vgl. dazu A. V. PostniKov, Razvitie krupnomasštabnoj kartografii v Rossii [Die Entwicklung der russischen Kartographie mit großem Maßstab], Moskau 1989, S. 30-33.

33 Die verschiedenen Karten Remezovs unterzieht Tolmacheva, Exploration, einer differenzierten Analyse. 


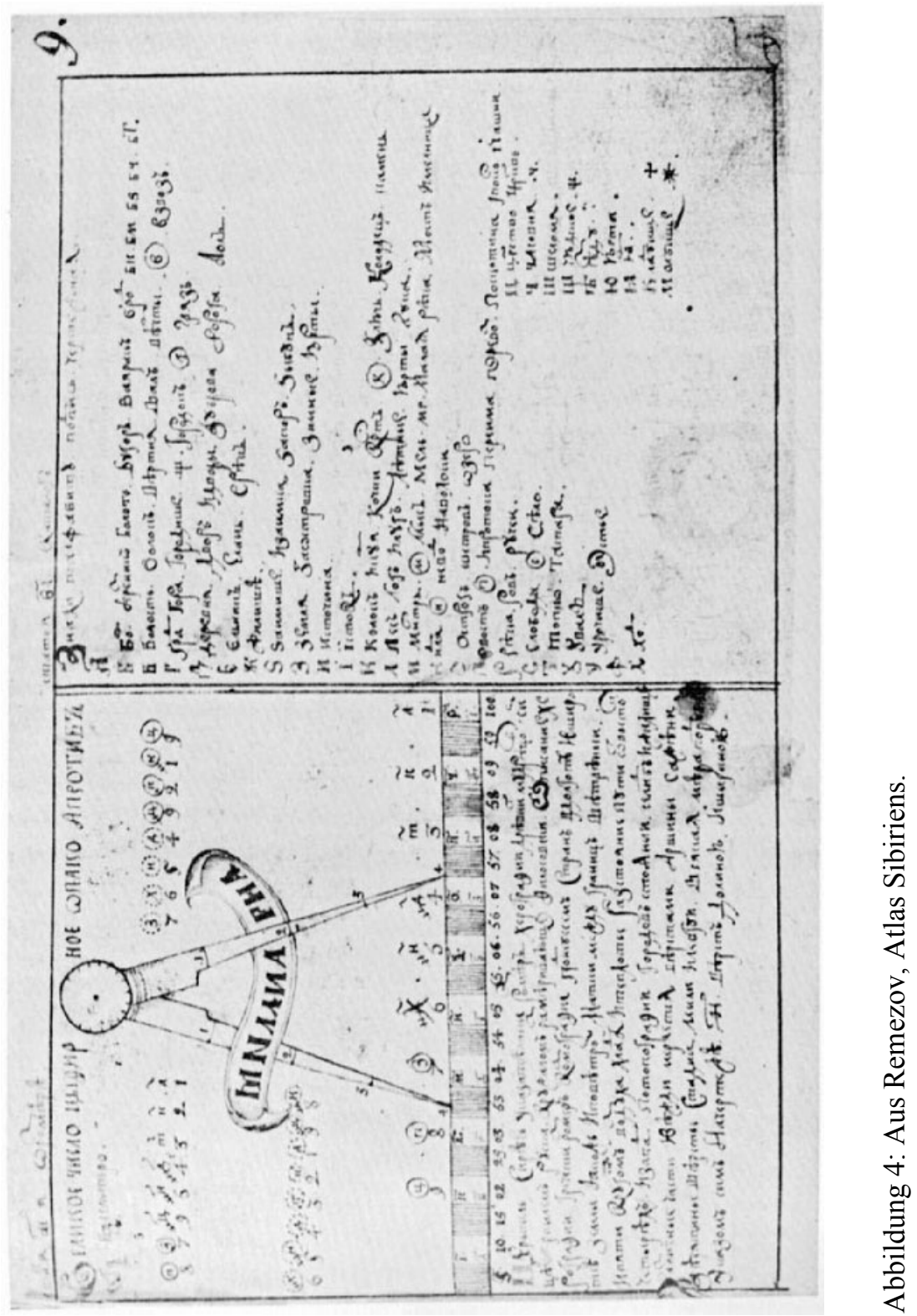


einheitlichen Maßstab der zahlreichen Karten, überhaupt von einem Maßstab, kann nicht die Rede $\operatorname{sein}^{34}$. Zeichen der Modernisierung sind indessen unübersehbar: Bald finden sich Abbildungen von Windrosen, von Zirkel und Lineal, auch von Orientierungshilfen wie Gitternetzen, die vielleicht Längen- und Breitengrade symbolisieren sollen. Auch eine Standardisierung der Bezeichnungen entsteht allmählich ${ }^{35}$. Wie schon in den früheren Sibirien- und Russland-Karten fällt auch bei Remezov die große Bedeutung der Flussverläufe auf: Sie waren als Transportwege unverzichtbar ${ }^{36}$ und dienten schon deshalb auch der Orientierung. Die zunehmende Präzision der geographischen und topographischen Kenntnisse kann an den über die Jahrzehnte entstandenen Karten also gut nachvollzogen werden. Aber nicht nur das: Vor allem werden topographische Details, die von besonderem Interesse waren, größer - eben überhaupt nicht maßstabsgerecht - und besonders sorgfältig gezeichnet: Stets sind insbesondere die russischen Festungen und Städte abgebildet. Auch die Jasak-Bezirke sowie zahlreiche Namen sibirischer Völker finden sich.

Am interessantesten freilich erscheint die kartographische Darstellung Chinas $^{37}$ : Das Chinesische Reich, das carstvo kitajskoe, liegt hinter einer Mauer! Augenfälliger als mit den Sibirien-Karten Remezovs lässt sich demnach kaum der Nachweis führen, dass die »Zeichnungen« oder Bilder-Karten, die čerteži $i$ den Bedürfnissen der zentralen wie der lokalen Behörden des Zarenreichs im 17. Jahrhundert auch hinsichtlich ihres Interesses an Informationen in kontinentalem Maßstab durchaus angemessen waren. Die Darstellung der Küsten scheint nicht interessiert zu haben, ebenso wenig die Verbindung Sibiriens mit dem europäischen Teil Russlands. Als Informationsquelle für westeuropäische Wissenschaftler, Reisende und Kartographen waren die čerteži bis in die ersten Jahre des 18. Jahrhunderts ohnedies von hohem Interesse ${ }^{38}$. Ihre Defizite, vor allem ihre - im Vergleich mit zeitgenössischen Karten Mittel- und Westeuropas - geringere Präzision und das Fehlen eines Maßstabs wurden offenbar erst seit den 1690er Jahren als

\footnotetext{
34 Einen guten Überblick über die Merkmale der čerteži gibt PostNIKov, Razvitie, S. 11-15.

35 Ebd., S. 23 mit der Diskussion möglicher Vorläufer und der Zusammenhänge des Kartenzeichnens mit der Ikonenmalerei.

36 In der chinesischen Kartographie spielen Flüsse eine ebenso wichtige Rolle. Sie dienten in China aber vor allem der Bewässerung. Zur Bedeutung des Flussnetzes für die Durchdringung Sibiriens vgl. Carsten GoEHRKE, Geographische Grundlagen der russischen Geschichte, in: Jahrbücher für Geschichte Osteuropas N.F. 18 (1970), S. 161-204, hier bes. S. 178-180, der aber sonst ganz andere Fragen als die hier verfolgten diskutiert.

37 Zur Klärung irriger Vorstellungen von China durch Spathary siehe TOLMACHEVA, Exploration, S. 45.

38 Das Interesse der westeuropäischen Kartographen gerade an den Sibirien-Karten Remezovs schildert Leo BAgRow, The First Russian Maps of Siberia and their Influence on the WestEuropean Cartography of N. E. Asia, in: Imago Mundi 9 (1952), S. 83-93.
} 
solche empfunden ${ }^{39}$. Aus heutiger Sicht sind die čerteži zudem von außerordentlichem ästhetischem Reiz, und nicht zuletzt exemplifizieren sie die Dialektik von Empirie und Imagination in der Kartographie besonders eindringlich.

Bezeichnend für die Verflechtung der Kartographie mit politischen und diplomatischen Strategien der Regierung wie zugleich für die Entwicklung der russischen Kartographie der Zeit ist darüber hinaus Folgendes: Der Erfolg der russisch-chinesischen Verhandlungen in Nerčinsk 1689 und dann in Kjachta 1727, d.h. die in diesen Verhandlungen erreichte Stabilität der Grenze, führte dazu, dass im weiteren Verlauf des 18. Jahrhunderts kein großes Interesse an genauerer geographischer Erschließung und kartographischer Erfassung der Grenze zu China, überhaupt des Amur-Gebiets bestand $^{40}$. Für die Zeit unmittelbar vor und nach Nerčinsk und für die 1720er Jahre lassen sich dagegen zahlreiche Karten des Amurgebiets nachweisen. Nach Kjachta aber erlahmte das kartographische Interesse an dieser Region: Gemeinsam mit dem Interesse der kolonialen Expansion richtete es sich nun auf die nördliche Pazifik-Küste: die Halbinsel Kamčatka, die Čukotka, die Kurilen und die Verbindung zwischen Asien und Amerika. Die Erschließung auch dieser Gebiete begann, gegen teilweise erbitterten Widerstand der dortigen Bevölkerung, gleich nach dem Vertrag von Nerčinsk und wurde in der Zeit Peters des Großen forciert. Sie fand ihren kartographischen Niederschlag unter anderem auf den beiden Generalkarten des Russischen Imperiums, die 1734 und 1745 jeweils in einem Atlas Russicus erschienen.

Insbesondere die Karte von 1745 spiegelt viele der Neuerungen, die ein halbes Jahrhundert zuvor eingeleitet worden waren. Schon die ersten fünfzehn Jahre der eigenständigen Regierung Peters, die man um 1695, nach dem Tod der Mutter des Zaren, ansetzen sollte, haben ja auch hinsichtlich der Kartographie, insbesondere hinsichtlich der Bedingungen der Kartenproduktion, in Russland vieles verändert. Denn mit noch sehr viel größerer Entschlossenheit als seine Vorgänger nahm der Herrscher nach seiner »Großen Gesandtschaft« 1697/98 alle Teilvorgänge der Kartenherstellung in die Hand und bemühte sich vor allem um ihre systematische Organisation $^{41}$. Das Personal rekrutierte Peter einerseits aus seinem Land, setzte aber entschiedener als seine Vorgänger auch in diesem Bereich auf auswärtige Fachleute. So ergingen um 1700 Einladungen an ausländische, vor allem deutsche und holländische Vermessungsfachleute, »gollandskie nemcy«,

39 Die Defizite der geographischen Wissenschaften im vorpetrinischen Russland, darunter auch der Kartographie, betont am überzeugendsten SHAW, Practice, 163f. und S. 171f.

40 Das änderte sich aber um die Mitte des 19. Jahrhunderts; vgl. dazu BASSIN, Imperial Visions.

41 Im Anspruch auf Systematisierung wird man mit SHAw, Practice, überhaupt die bedeutsamste Veränderung im petrinischen Russland zu sehen haben. Das Folgende dort S. 164-167. 
während gleichzeitig schon russische Kartenstecher nachweisbar sind; einer von ihnen, Vasilij Kiprianov, Kupferstecher, Kartograph und Verleger in einer Person - und somit von entsprechender Profession wie seine westeuropäischen Kollegen -, erhielt bald das Privileg, die erste bürgerliche Druckpresse in Russland zu eröffnen ${ }^{42}$. Ferner trieb Peter die Ausbildung russischer Landvermesser voran - 1701 etablierte er eine mathematischnavigatorische Schule für Kartographen in Moskau - und ließ sie bald über ganz Russland und seine Grenzgebiete ausschwärmen ${ }^{43}$. Die Zuständigkeiten wurden im Kartographie-Amt zentralisiert, dem ab 1719 Ivan Kirillov vorstand ${ }^{44}$. Gleichzeitig begann nun, mit der Expedition unter Leitung des Danziger Arztes Daniel Gottlieb Messerschmidt, die Zeit der wissenschaftlichen Expeditionen, deren Ziel es war, Sibirien und Ostasien gründlicher $\mathrm{zu}$ erforschen, zu vermessen und zu kartieren. Die wissenschaftliche Leitung sollte bei einer wissenschaftlichen Akademie liegen. Die Gründung einer solchen Institution war zwar schon lange, bereits im späteren 17. Jahrhundert, ins Auge gefasst worden; schließlich wurde die Kaiserliche Akademie der Wissenschaften von Peter I. 1724 per Erlass gegründet, aber erst nach seinem Tod 1725 eröffnet $^{45}$.

Wie die politischen und militärischen Ziele waren indessen auch die kartographischen Bestrebungen des Zaren Peter im Laufe der Jahre anspruchsvoller und ausgreifender geworden, zumal nach dem Sieg bei Poltava 1709. Ein Russländisches Imperium, das dem britischen Paroli bieten konnte, stand vor der Vollendung, und seine kartographische Abbildung auf einer Generalkarte und in einem Atlas sollte sie begleiten, ja: ihr vorausgehen. Allerdings erlebte Peter die Fertigstellung und Publikation der ersten, auf umfassenden Vermessungsarbeiten beruhenden Generalkarten Russlands so wenig wie die Gründung der Akademie der Wissenschaften.

Die hier abgebildete Karte geht zurück auf die bereits vorliegende Karte aus dem 1734 von Ivan Kirillov publizierten Atlas - der natürlich seinerseits auf älteren russischen und westeuropäischen Karten beruhte ${ }^{46}-$, vor

42 BAgRow, History, S. 174.

43 Martin AUST, Vermessen und Abbilden des russländischen Raumes nach der kulturellen Revolution Peters des Großen, in: Lars Behrisch (Hg.), Vermessen, Zählen, Berechnen. Die politische Ordnung des Raums im 18. Jahrhundert, Frankfurt a.M. 2006, S. 27-44, hier: S. 31.

44 Unter der Leitung Kirillovs und in Zusammenarbeit mit dem Franzosen Joseph Nicolas Delisle entstanden Teile eines ersten Atlasses Russlands; das Projekt blieb aber, 1734 bereits in Teilen publiziert, wohl nicht zuletzt durch den Tod Kirillovs 1736, für einige Jahre stecken; BAGROW, History, S. 175, mit schöner Schilderung der Debatte zwischen den beiden über die auf Russland anzuwendenden Prinzipien der Vermessung.

45 Statt der Spezialliteratur zur Akademie der Wissenschaften sei hier die knappe, auf unsere Thematik ausgerichtete Darstellung von Dittmar DAHLMANN genannt, in: Dittmar DAHLMANN (Hg.), Johann Georg Gmelin, Expedition ins unbekannte Sibirien, Sigmaringen 1999, Einleitung, S. 15-20, mit weiterer Literatur.

46 Vgl. Anm. 44. 


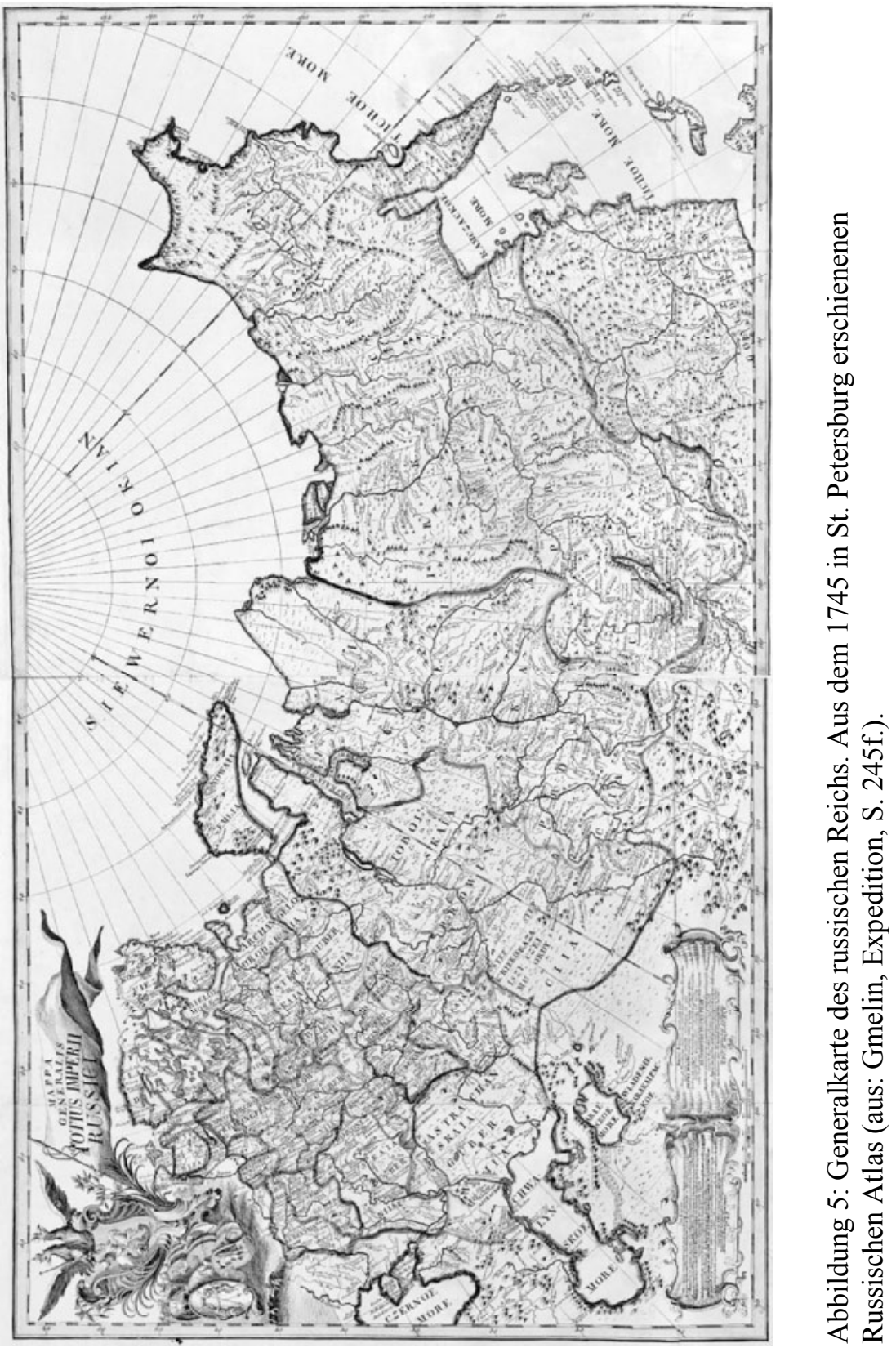


allem aber auf Ergebnissen der »Großen Nordischen Expedition«. Sie stand unter der Leitung des Dänen Vitus Bering, wurde begleitet von den beiden jungen deutschen Wissenschaftlern Gerhard Friedrich Müller und Johann Georg Gmelin und fand zwischen 1733 und 1743 statt. Diese auch »Zweite Kamčatka-Expedition« genannte Unternehmung überstieg alle bisherigen Dimensionen - sie war die größte wissenschaftliche Expedition Russlands bis ins 20. Jahrhundert. Ihre Aufgabe bestand darin, weitere und präziser gefasste Angaben über die Pazifik- und die Eismeerküste zu besorgen, Lage und Größe der Pazifikinseln zu bestimmen, nach einer Nordostpassage zu suchen und nicht zuletzt zu klären, ob und wenn ja wo eine Landbrücke nach Amerika bestand. Deutlicher noch als frühere Expeditionen diente diese nicht bloß wissenschaftlichen Zwecken, oder anders: hier waren die wissenschaftlichen Ziele noch deutlicher auf Möglichkeiten der territorialen Erweiterung wie der Ausdehnung der Handelsbeziehungen gerichtet ${ }^{47}-$ das Prestige Russlands durch Dokumentation seiner imperialen Größe war das Hauptziel. Und tatsächlich waren die wissenschaftlichen Ergebnisse beeindruckend, so beeindruckend, dass manchen Befunden, etwa den Beschreibungen und Kartierungen Japans, in St. Petersburg zunächst gar nicht geglaubt wurde ${ }^{48}$ !

Im Vergleich zur vorpetrinischen Zeit hatte die Gruppe die Expedition unter anderen Prämissen unternommen: Nun gab es ein wissenschaftliches Konzept, ausgearbeitet von Mitgliedern der Akademie der Wissenschaften in Petersburg. Neu waren damit auch die wissenschaftliche Dokumentation, die Organisation, die Zielorientiertheit und die staatliche Förderung der Expedition. Der Atlas von 1745 mit seinen 19 Regionalkarten und der Generalkarte bot ein sehr viel akkurateres Bild als alle Eurasienkarten zuvor. Die Generalkarte zeigt die uns heute vertraute Sicht auf den eurasischen Kontinent mit den Küstenlinien und einigen auch heute ganz ähnlich noch bestehenden Grenzen, mit dem Gitternetz der Längen- und Breitengrade und vielen anderen Attributen frühneuzeitlicher Kartographie. Sie wurde zur Grundlage für fast alle Russland-Karten der folgenden Jahrzehnte, im Inwie im Ausland. Beschriftet als Karte des Imperiums, versehen mit dem Wappentier des Zaren wie des neuen Imperators, dem zweiköpfigen Adler, zeigte sie den Zeitgenossen, wie Bagrow formuliert hat, »Russia's place amongst the kingdoms of Europe $\ll^{49}$.

\footnotetext{
47 Dahlmann betont, dass die weit gesteckten Aufgaben kaum zu erfüllen gewesen seien; vgl. dazu DahlmanN, Gmelin, Einleitung, S. 36-43.

48 Ebd., S. 48f.

49 BAGROW, History, S. 176.
} 
Am Ende des 18. Jahrhunderts waren Russland, Asien und der »Ferne Osten « kartographisch also weitgehend erschlossen. Dabei kam auch den geographischen Benennungen eine nicht unbedeutende Rolle zu; so stammt die Bezeichnung »Ferner Osten« aus der Sprache des britischen Empire im 19. Jahrhundert und wurde erst im weiteren Verlauf des 19. Jahrhunderts allmählich auch in den russischen Sprachgebrauch übernommen und wie der Raum dem Imperium angeeignet - in einem umfassenden Austausch von Wissen und Wissenschaft und nicht zuletzt durch den Beitrag deutscher Wissenschaftler, der nun abschließend in den Blick genommen werden soll.

\section{Der Beitrag ausländischer, besonders deutscher Wissenschaftler zur kartographischen Erschließung Sibiriens und Ostasiens}

Eine präzise Erfassung des Beitrags deutscher Wissenschaftler zur russischen Erschließung Sibiriens und Ostasiens wie zur Kartierung dieser Gebiete ist aus verschiedenen Gründen keine einfache Aufgabe. Schon eine Bestimmung derjenigen, die zu den »Deutschen« zu zählen wären, ist angesichts der Unschärfe der zeitgenössischen Verwendung des Begriffs »nemec« wie auch der im steten Wandel begriffenen Loyalitäten und Identitäten der betreffenden Personen nahezu unmöglich. Auch reichen die Vorarbeiten für ein ausgewogenes Urteil über den Beitrag von Ausländern zur russischen Kartographie im Grunde nicht aus. Angesichts dessen erscheint es sinnvoll, nach dem Wandel der Rolle, oder präziser: nach dem Wandel der Funktion der Ausländer, insbesondere deutschsprachiger Ausländer, zu fragen und dabei, wie bereits im zweiten Abschnitt, von komplexen Prozessen des Transfers von geographischen und topographischen Informationen sowie kartographischen Wissens auszugehen.

Folgt man diesen Prämissen, dann fällt auf, dass die Deutschen und ihre Nachbarn im 16. Jahrhundert und noch bis ins letzte Drittel des 17. Jahrhunderts hinein sowohl selbst Kartographen als auch Multiplikatoren russischer geographischer Kenntnisse im Westen waren. Sie verschafften sich Informationen, publizierten die Karten im Westen, hatten aber an der Beschaffung geographischer und topographischer Kenntnisse »vor Ort« keinen Anteil. Der Idealtyp einer solchen Gestalt wäre Herberstein, aber dasselbe dürfte für Jenkinson, Massa und Hessel Gerritz gelten. Den Wandel, der im späten 17. Jahrhundert, in der im eigentlichen Sinne »vorpetrinischen « Zeit, beobachtet werden kann, zeigt die Person des Jakov Brjus an: Er war Russe schottischer Herkunft (James Bruce), hatte eine mathematische Ausbildung genossen und fertigte um 1695 zusammen mit dem Vermessungsfachmann Ju. A. Mengden eine Karte Südrusslands mit dem Don-Ufer an, also jenes 
Gebiets, das im Krieg gegen Osmanen und Tataren besonders umkämpft war. Diese Karte wurde 1699 in den Niederlanden gedruckt - als die vermutlich erste russische Karte $^{50}$.

Nach der Großen Westeuropareise Zar Peters 1697/98 erfuhr die Rolle der Ausländer dann einen grundlegenden Wandel: Viele ausländische Vermessungsfachleute, Geographen und Kartenstecher, gerade auch deutsche, wurden nun offiziell angeworben. Sie standen zunächst wohl direkt im Dienst des Herrschers selbst, bald im Dienst des Kartographie-Amtes und dann im Dienst der Akademie der Wissenschaften, vielfach auch als deren Mitglieder. Seit etwa 1720, beginnend mit Messerschmidt und als Höhepunkt in der ersten Hälfte des 18. Jahrhunderts Johann Georg Gmelin, Gerhard Friedrich Müller und Vitus Bering, traten Deutsche auch als wichtige Mitglieder oder sogar als Leiter der nun für die Kartierung des Landes und seiner östlichen Grenzen immer wichtiger werdenden Forschungsexpeditionen hervor. Viele der letzten Unklarheiten über die topographische Struktur Sibiriens, Sachalins, der Kurilen und der japanischen Inseln beseitigte schließlich Adam Johann Krusenstern, der von 1803 bis 1806 diese Weltgegend im Auftrag der Regierung bereiste und mit Fabian Gottlieb Bellinghausen auch einen deutschen Kartenzeichner in seinem wissenschaftlichen Gefolge hatte. Nach seiner Reise - die den Handel Russlands mit China allerdings nicht, wie erhofft, beförderte - wurde Krusenstern Ehrenmitglied der Akademie der Wissenschaften und Mitbegründer der Russischen Geographischen Gesellschaft ${ }^{51}$. An der veränderten Rolle dieser und vieler anderer Ausländer für die Geographie und Kartographie des Russländischen Imperiums zeigt sich mithin auch die Professionalisierung und Ausdifferenzierung der geographischen Wissenschaften überhaupt sowie ebenso die entschlossene Öffnung der politischen Eliten Russlands gegenüber diesen Wissenschaften spätestens seit der Mitte des 18. Jahrhunderts.

Nimmt man abschließend die Russland-Karte Herbersteins aus der Mitte des 16. Jahrhunderts - die Asien allerdings nur bis zum Kaspischen Meer zeigt -, ferner die čertež genannte russische Karte Sibiriens und der Grenze zu China aus der Feder des Semen Remezov aus der zweiten Hälfte des 17. Jahrhunderts und die russische Generalkarte aus dem Jahre 1745 noch einmal gemeinsam in den Blick, ergibt sich zunächst der wenig erstaunliche Befund, dass sich die Art der Karten über die Jahrhunderte hinweg erheblich änderte und die Darstellung präziser wurde. Der Fortschritt in der Kartographie allein schon dadurch, dass seit der Wende zum 18. Jahrhundert das Land konsequent vermessen und eine maßstabsgetreue Darstellung an-

\footnotetext{
50 SHAW, Practice, S. 164.

51 Adam Johann von KRUSENŠTERN, Reise um die Welt in den Jahren 1803, 1804, 1805 und 1806, Köln / Wien 1986.
} 
gestrebt wurde, ist unübersehbar. Bis dahin wiesen die russischen Karten ja eine bloß geringe Standardisierung auf: topographische Phänomene von größerem Interesse wurden auch relativ größer gezeichnet. Vom 16. über das 17. bis ins 18. Jahrhundert verschoben sich aber auch die Interessen an Karten: Zunächst dienten Karten den Russen wie den westeuropäischen Kartographen vor allem der Orientierung: der Klärung der geographischen Struktur des Landes, insbesondere der Flussverläufe, ferner der Lokalisierung von Grenzen, Ansiedlungen und Völkern sowie der Markierung von besonderen Orten. $\mathrm{Zu}$ erkennen ist freilich seit dem 16. Jahrhundert auch schon das zarische Interesse an Steuereinkommen. Dieses fiskalische, im Kern staatliche Interesse an Karten und das Interesse des Staats überhaupt als exklusiven Veranstalters von Kartographie blieb auch im 18. Jahrhundert erhalten. Dieses staatliche Interesse verschob sich aber nun hin zur Visualisierung des vermessenen und abgesteckten staatlichen Raums: zur Abbildung des Russländischen Imperiums.

Voraussetzung dafür - wie überhaupt von enormer Bedeutung - war freilich der Wandel in der kontinentalen Zuordnung Russlands, auf den hier abschließend nur hingewiesen werden kann: In eben diesen Jahren, um 1730, setzte sich, ausgehend von dem russischen Historiker Vasilij Tatiščev, die Verschiebung der Grenze zwischen Europa und Asien vom Don in den Ural durch ${ }^{52}$. Das Russländische Imperium bestand nun offiziell aus einem europäischen und einem asiatischen Teil - und »die ... Atlanten visualisierten diesen Blick auf Russland, das nun erstmals in seiner Gänze auf einer einzigen Karte russländischer Provenienz zu betrachten war $\ll^{43}$. Die um die Mitte des 18. Jahrhunderts gefundene Imaginisierung des Russländischen Imperiums - vor seiner Verwirklichung in Politik und Verwaltung - wurde seither übrigens für Russland wie für Westeuropa verbindlich, es entstand eine einheitliche kartographische Ikonographie und zumindest auf der Karte ein einheitliches Bild von diesem Imperium.

52 Dazu nach wie vor am besten Mark BAssin, Russia between Europe and Asia. The Ideological Construction of Geographical Space, in: Slavic Review 50/1 (1991), S. 1-17, hier vor allem S. 5-7.

53 Aust, Vermessen, S. 31. 


\title{
Dittmar Dahlmann
}

\section{Das Moskauer Reich und China}

\author{
Die russischen Beziehungen zum »Reich unter dem Himmel« \\ vom 16. Jahrhundert bis zum Ende des 18. Jahrhunderts ${ }^{1}$
}

Jene Kontakte, die zwischen der Rus' und China in den Zeiten der Mongolenherrschaft von den 1240er Jahren bis zum Ende des 14. Jahrhunderts bestanden, endeten nach dessen Zerfall, und die Erinnerung daran ging rasch verloren ${ }^{2}$. Erst um die Mitte des 15. Jahrhunderts bereiste der aus Tver' stammende russische Kaufmann Afanasij Nikitin Indien und verfasste darüber einen ausführlichen Bericht, in dem er auch einige wenige Nachrichten über China vermittelte. Doch hatte er das Land selbst nie gesehen, konnte also nur Gehörtes mitteilen ${ }^{3}$.

Um 1520 suchte der Genueser Kaufmann Paolo Centurione China auf dem Landweg durch Russland zu erreichen, gelangte jedoch nie dorthin ${ }^{4}$. Nicht nur in Russland, sondern auch im übrigen Europa wusste auch die gebildete und gelehrte Welt wenig über das Reich der Mitte. Dort war seit Marco Polos Bericht vom Beginn des 14. Jahrhunderts der spanische Augustinermönch Juan González de Mendoza 1585 der erste, der über dieses asiatische Reich berichtete 5 . Wenige Jahre später schrieb Matteo Ricci, der die Jesuitenmission in China am Ende des 16. Jahrhunderts begründete,

\footnotetext{
1 China wurde in Russland häufiger als »podnebesnaja strana« oder »podnebesnaja imperija« , »Land unter dem Himmel« oder »Reich unter dem Himmel« bezeichnet.

2 Giovanni Stary, Chinas erste Gesandte in Russland, Wiesbaden 1976, S. 5.

3 Afanasij Nikitin, Choženie zu tri morja Afanasija Nikitina, 1466-1472gg., Moskau 1960, eine sehr schön gestaltete Fassung mit einem Teil der Handschrift als Beilage sowie einer Übersetzung ins Hindi und ins Englische; eine deutsche Fassung mit Farbtafeln: Die Fahrt des Afanassij Nikitin über die drei Meere 1466-1472, hg. von Ilse MIRUS, München 1966; eine erste englische Fassung erschien in der Reihe der Haklyut Society: Richard M. MAJOR (Hg.), The Travels of Athanasius Nikitin, in: India in the 15th Century, London 1857 (Series 1, Bd. 22). Zur Geschichte der Überlieferung und den verschiedenen Textfassungen vgl. Jean-Pierre SABSOUB, Die Reise des Kaufmanns Nikitin von der Rus' nach Indien 1466-1472: Ein Beitrag zur Begegnung mit dem Anderen, Bonn 1988, S. 25-34. Vgl. auch Gail Lenhoff / Janet MARTIN, The Commercial and Cultural Contacts of Afanasij Nikitin's Journey Beyond the Three Seas, in: Jahrbücher für Geschichte Osteuropas, N.F. 37 (1989), S. 321-344.

4 Mark Mancall, Russia and China. Their Diplomatic Relations to 1728, Cambridge, Mass. 1971, S. 37.

5 Jürgen Osterhammel, China und die Weltgesellschaft. Vom 18. Jahrhundert bis in unsere Zeit, München 1989, S. 23.
} 
eines der bedeutendsten Werke über dieses Land, in dem er über zwanzig Jahre gelebt hatte ${ }^{6}$. Über eine Rezeption dieses Werkes in Russland, das schon in den 1620er Jahren aus dem Lateinischen in zahlreiche Sprachen übersetzt worden war, ist nichts bekannt.

China war, wie es Jürgen Osterhammel formulierte, »manchmal Vorbild, manchmal Zerrbild, immer jedoch Gegenbild Europas: eine hochkomplexe Zivilisation, deren auffällige Eigenarten in vergleichender Betrachtung die Besonderheiten des Westens um so deutlicher hervortreten ließen. Europa hat China in sich aufgenommen und sich doch immer wieder von ihm abgegrenzt $\ll$ ?

Für das Moskauer oder Russische Reich bis zur Herrschaft Peters I., des Großen, am Ende des 17. Jahrhunderts, als sich dessen Kontakte und Beziehungen zum westlichen Europa intensivierten, gilt dies nicht. Russlands Blick richtete sich nach Westen. Dies war Vorbild, Zerrbild und Gegenbild. China blieb bis zum 18. Jahrhundert, als auch in Russland der Prozess der Ausbildung der Wissenschaften einsetzte, weit stärker der potentielle Handelspartner, von dessen Reichtümern man profitieren konnte. So stand denn auch stets bei den Gesandtschaften von Russland nach China die Anbahnung solcher Beziehungen im Vordergrund, dahinter traten bisweilen sogar Diplomatie und Politik ins zweite Glied. Doch galt dies, dies ist zu betonen, nicht uneingeschränkt, und hier wirkte offensichtlich die im Gedächtnis haftende Zeit der Mongolenherrschaft nach. Die von China verlangte Unterwerfung, die Einstufung als ein tributärer Staat, wurde so lange als möglich verweigert, obwohl es dabei durchaus auch Ausnahmen gab, wie noch $\mathrm{zu}$ zeigen sein wird. Dieser Artikel kann das Problemfeld der russischchinesischen Begegnungen nur anreißen, aber nicht erschöpfend behandeln ${ }^{8}$.

Als um die Mitte des 16. Jahrhunderts, in der Regierungszeit Ivans IV., das Moskauer Reich die Chanate von Kazan' und Astrachan' niederwarf und damit Gebiete gewann, die niemals zuvor russisch gewesen waren, dehnte sich auch das Imperium der Kaufmannsfamilie Stroganov im Grenzgebiet des Ural mehr und mehr aus und knüpfte über die zentralasiatischen Handelsstädte wie Buchara Verbindungen zu chinesischen Händlern. Nach allem, was bekannt ist, waren diese Geschäfte ausgesprochen lohnend, und auch die Stroganovs suchten einen Weg nach China, dessen Hauptstadt

\footnotetext{
6 Ebd., S. 23ff. Zu den frühneuzeitlichen Reiseberichten über China vgl. Walter DEMEL, Fremde in China. Das Reich der Mitte im Spiegel frühneuzeitlicher europäischer Reiseberichte, München 1992.

7 Osterhammel, China und die Weltgesellschaft, S. 3.

8 Grundlegend für das 17. Jahrhundert ist die Dokumentation von S. L. TichvinsKiJ (Hg.), Russko-kitajskie otnošenija v XVII v., 2 Bde., Moskau 1969/1972.
} 
Chanbalik am Oberlauf des Ob' vermutet wurde'. Buchara erreichte im Jahre 1562 auch der englische Kaufmann Anthony Jenkinson, der zur Muscovy Company gehörte, um mit den Chinesen zu handeln, aber die chinesischen Karawanen hatten ihre Reisen dorthin eingestellt ${ }^{10}$. In jedem Fall war China ein lohnendes Ziel, Handelsgeschäfte versprachen hohen Profit, so dass immer wieder neue Versuche unternommen wurden. So sollte am Ende der Regierungszeit Ivans IV. 1582 eine russische Gesandtschaft nach China geschickt werden, und 1587 erlaubte Zar Fedor bzw. der als Reichsverweser für den debilen Herrscher agierende Boris Godunov litauischen und polnischen Kaufleuten freien Transit nach China und dem Orient ${ }^{11}$. Doch verhinderte die »Zeit der Wirren« (smuta) an der Wende vom 16. zum 17. Jahrhundert jede weitere Verfolgung solcher Ziele.

Das endgültige Zusammentreffen von Russland und China war schließlich eines der Ergebnisse der russischen Eroberung Sibiriens seit 1581, begann also im frühen 17. Jahrhundert. In den ersten beiden Jahrzehnten des 17. Jahrhunderts versuchten die Voevoden von Tomsk und Tobol'sk sowie die Moskauer Regierung ebenfalls über Zentralasien, Verbindungen nach China anzuknüpfen. Doch verliefen diese Bemühungen ohne konkrete Ergebnisse $^{12}$. Erst die Stabilisierung der Lage im Moskauer Reich nach dem Ende der »Zeit der Wirren«, nachdem Michail Fedorovič zum ersten Zaren aus dem Hause Romanov gewählt worden war, führte zu konkreteren Unternehmungen. Die Moskauer Regierung beauftragte 1617 den Tobol'sker Voevoden, Fürst I. S. Kurakin, eine Gesandtschaft nach China zu entsenden, um handfeste Erkundigungen einzuholen und konkrete Kenntnisse über dieses unbekannte Land zu gewinnen. Eine kleine Delegation unter Führung von Ivan Petlin, einem schreibkundigen Beamten, erreichte 1619 auch die chinesische Hauptstadt Peking. Es war die erste russische Gesandtschaft, die dorthin gelangte. Doch waren die Probleme des Zeremoniells und der Etikette sowie die Frage der Gleichrangigkeit der beiden Staaten unüberwindbare Hindernisse für erfolgreiche Verhandlungen. Für die chinesische Seite gehörte das Moskauer Reich zu den tributpflichtigen Ländern $^{13}$. Da jedoch Petlins Gesandtschaft keine Geschenke in ausreichendem Wert mitführte, die erkennen ließen, dass man zu Tributzahlungen bereit war, wurde der Gesandte gar nicht erst vom chinesischen Kaiser empfan-

\footnotetext{
9 Dittmar DahlmanN, Sibirien. Vom 16. Jahrhundert bis in die Gegenwart, Paderborn u.a. 2009, S. 39ff.

10 Ebd., S. 56.

11 MANCALL, Russia and China, S. 38.

12 Ebd., S. 38f.

$13 \mathrm{Zu}$ den Außenbeziehungen Chinas in jener Zeit vgl. John K. FaIRBanKS (Hg.), The Chinese World Order. Traditional China's Foreign Relations, Cambridge, Mass. 1968; Mark MANCALL, China at the Center. 300 Years of Foreign Policy, New York / London 1984.
} 
gen $^{14}$. Petlin verfasste jedoch eine erste Beschreibung Chinas und seiner Hauptstadt, verstand allerdings wenig von den dort herrschenden politischen Gepflogenheiten. Zum Abschied erhielt er ein Schreiben, vermutlich von einem subalternen Beamten verfasst, das weder er noch irgendjemand sonst in Russland lesen konnte. Die Übersetzung erfolgte erst 1675. China erklärte sich zu Handelsgeschäften bereit, die jedoch auf der Basis eines tributären Verhältnisses zu erfolgen hatten ${ }^{15}$. So blieb das gesamte Unterfangen wirtschaftlich und politisch folgenlos. Der Bericht Petlins, der zudem eine Karte seines Weges zeichnete oder zeichnen ließ, gelangte rasch auch nach Westeuropa und erschien bereits 1625 in London im dritten Band der Neuauflage des Pilgrimage des englischen Geistlichen Samuel Purchas und bald darauf auch in deutschen, französischen, schwedischen und holländischen Übersetzungen ${ }^{16}$.

Anfang der 1640er Jahre erreichte einer der russischen Kosakentrupps, die die russische Expansion in Sibirien vorantrieben, unter Führung von Vasilij Pojarkov, über den, ebenso wie über die meisten anderen dieser Kosakenführer, wenig bekannt ist, den Amur. Pojarkov war allerdings kein gewöhnlicher Kosak, sondern ein Kanzleivorsteher (pis'mennyj golova), also des Lesens und Schreibens wohl kundig, und besaß Erfahrungen in Handelsgeschäften und im Eintreiben des jasak, des Tributs, den die Russen von der indigenen Bevölkerung verlangten ${ }^{17}$. Seinen blutigen Spuren folgte bald Erofej Chabarov, der zunächst in Diensten des Hauses Stroganov das Salzsieden betrieben hatte und während seiner Zeit in Sibirien durch Salzund Transportgeschäfte sowie mit Pelzhandel bereits zu erheblichem Wohlstand gekommen war. Als er von den Unternehmungen im Amurgebiet hörte, rüstete er eine eigene Expedition mit rund 150 Mann aus, die sich im Jahre 1650 auf den Weg machte ${ }^{18}$. Die indigene Bevölkerung flüchtete auf-

$14 \mathrm{Zu}$ den Problemen des Zeremoniells, der Etikette und der prozeduralen Form bei der Begegnung zwischen den russischen Gesandtschaften und den chinesischen Beamten bzw. der Zulassung zur Audienz beim Kaiser und den damit verbundenen Fragen des Status der aus fremden Ländern kommenden Gesandtschaften vgl. unten. Zur Wahrnehmung des Fremden von Diplomaten vgl. Michael Rohrschneider / Arno Strohmeyer (Hg.), Wahrnehmung des Fremden. Differenzerfahrungen von Diplomaten im 16. und 17. Jahrhundert, Münster 2007. Während sich immerhin zwei Beiträge mit dem Osmanischen Reich befassen, fehlt ein Beitrag über das östliche Europa.

15 MANCALL, Russia and China, S. $41 \mathrm{ff}$.

16 John F. BADDELEY, Russia, Mongolia, China. Being Some Record of the Relations Between Them From the Beginning of the XVIIth Century to the Death of the Tsar Alexei Mikhailovich A.D. 1602-1676, 2 Bde., New York o.J., hier Bd. 2, S. 65-86; Petlins Bericht auch in: Basil DMYTRYShYN u.a. (Hg.), To Siberia and Russian America. Three Centuries of Russian Eastward Expansion. Bd. 1: Russia's Conquest of Siberia 1558-1700. A Documentary Record, 2. Aufl., Portland 1990, S. 82-91.

17 Juri SEmJonow, Sibirien. Schatzkammer des Ostens, Düsseldorf 1975, S. $105 f$.

18 James Forsyth, A History of the Peoples of Siberia. Russia's North Asian Colony 15811990, Cambridge 1994, S. 104f.; W. Bruce LinColN, Die Eroberung Sibiriens, München / Zürich 
grund ihrer äußerst unliebsamen Erfahrungen mit den russischen Eroberern bei deren Herannahen in unwegsames Gelände. Kämpfend, plündernd und marodierend zogen die russischen Eroberer den Amur entlang. Trotz aller Bemühungen der Russen verweigerte die indigene Bevölkerung jede Art von Tributzahlung und verwies darauf, dass sie bereits dem Bogdo-Chan, dem chinesischen Kaiser, verpflichtet sei $^{19}$. Dennoch setzten Chabarov und seine Männer ihren Weg den Amur entlang fort und gründeten schließlich die Festung Ačansk. Bald darauf allerdings gerieten Chabarov und seine Männer in bewaffnete Auseinandersetzungen mit den Chinesen, die sich als Oberherrn des gesamten Territoriums bis hinunter an den Pazifik betrachteten. Die ersten Feindseligkeiten mit einer mandschu-chinesischen Armee konnten die Russen noch siegreich gestalten, in den folgenden Jahren wurde die Lage dann immer kritischer ${ }^{20}$.

Für die Russen versprach die Region vieles. Der Amur war fischreich, die Einheimischen bauten Getreide an und damit war eine ausreichende Lebensmittelversorgung gesichert. Darüber hinaus gab es Pelztiere und im nahegelegenen China oder sogar direkt vor Ort weitere Schätze: Seide, Silber und Gold. Dies alles veranlasste Chabarov, dem Voevoden in Jakutsk die Kolonisierung des Gebietes nahezulegen, was ordnungsgemäß nach Moskau weitergemeldet wurde. Dort wurde der Vorschlag aufgegriffen und vom Zaren wohlwollend befürwortet. Es sollte sogar eine kleinere Armee in die Gegend geschickt werden ${ }^{21}$.

Die andauernden Unruhen an ihren Grenzen veranlassten die Herrscher der Mandschu-Dynastie in China zur entschiedenen Abwehr der Eindringlinge. Die Mandschu hatten 1644 Peking erobert und große Teile des Landes unter Kontrolle gebracht. Nun konnten sie trotz der Bedrohung durch die Dsungaren den sich im Nordwesten des Amurgebietes festsetzenden Russen mehr Aufmerksamkeit schenken. Im März 1652 griff eine kleinere chinesische Armee die Festung Ačansk an und konnte nur mit äußerster Mühe zurückgeschlagen werden ${ }^{22}$. Die militärischen Auseinandersetzungen

\footnotetext{
1996, S. 90ff.; amerik. Original: The Conquest of a Continent. Siberia and the Russians, New York 1994, unveränderter Nachdruck als Paperback Ithaca / London 2007, in der deutschen Ausgabe fehlt der Bildteil; Bericht des Voevoden von Jakutsk an Zar Aleksej Michajlovič, vermutlich vom Dezember 1650, in: DMYTRYShyn u.a. (Hg.), Bd. 1: Russia's Conquest of Siberia, S. 251-255.

19 LinCOLN, Eroberung Sibiriens, S. 90f. Von russischer Seite wurde für den chinesischen Kaiser die mongolische Bezeichnung »Bogdo-Chan« (Bogdychan), was sich als »Heiliger oder Großer Herrscher« übersetzen läßt, übernommen.

20 Ebd., S. 93.

21 Bericht des Voevoden von Jakutsk an Zar Aleksej Michajlovič, vermutlich vom Dezember 1650, in: DMYTRYSHYN u.a. (Hg.), Bd. 1: Russia's Conquest of Siberia, S. 254f.; Lincoln, Eroberung Sibiriens, S. 93.

22 Bericht von Erofej Chabarov an den Voevoden von Jakutsk, August 1652, in: DMYTRYSHYN u.a. (Hg.), Bd. 1: Russia's Conquest of Siberia, S. 260-278.
} 
setzten sich in den nächsten Jahren fort. Im folgenden Jahr wurde Chabarov als Befehlshaber abgelöst, unter Anklage gestellt und nach Moskau geschickt. Dort jedoch gelang es ihm, die Zentralbehörden von seiner Unschuld, sogar von seinen Heldentaten zu überzeugen und sich als würdiger Nachfolger des sibirischen Eroberers Ermaks zu präsentieren. Er wurde in den niederen Adel erhoben und durfte sich auf Ländereien in der Nähe der sibirischen Stadt Ilimsk niederlassen ${ }^{23}$.

Schließlich drangen kosakische Einheiten um die Mitte der 1650er Jahre auf dem Sungari, einem Nebenfluss des Amur, in die Mandschurei ein. Sie gerieten mit seiner Schar an eine größere chinesische Truppe und musste, da ein Kampf aussichtslos gewesen wäre, den Rückzug antreten. Nach jahrelangen Auseinandersetzungen gelang es den Chinesen schließlich 1658, den Russen eine vernichtende Niederlage beizubringen, die sich daraufhin vorläufig aus diesen Gegenden zurückzogen ${ }^{24}$.

In jene Jahre fiel auch die erste offizielle russische Gesandtschaft nach China unter Führung von Fedor I. Bajkov, der 1653 zunächst nach Tobol'sk geschickt wurde, um die Handelsprobleme mit China zu studieren. Schließlich wurde er Anfang 1654 als Gesandter dorthin entsandt. Der russische Handel lag aufgrund innerer und äußerer Probleme in jener Zeit darnieder, so dass neue Handelsmöglichkeiten erschlossen werden sollten. Bajkov erhielt umfassende Instruktionen und ein Schreiben an den chinesischen Herrscher. Die Anweisungen seiner Regierung ließen ihm wenig Spielraum, um mit den Chinesen zu verhandeln, denn sie untersagten jede Geste der Unterwerfung. Zugleich aber sollte Bajkov so viele Informationen über China, insbesondere über dessen Wirtschaftsund Handelspotential sammeln wie nur möglich. Die diplomatische Mission endete nach langwierigen Verhandlungen als vollständiger Fehlschlag, denn die chinesische Seite betrachtete die Russen weiterhin als mögliche Tributzahler und erwartete Gesten der Unterwerfung, die Bajkov grundsätzlich verweigerte. Nach längeren und wiederholten Unterredungen über das diplomatische Procedere, bei dem der russische Gesandte nicht einlenken wollte, forderten ihn die chinesischen Beamten schlieBlich zum Verlassen der Hauptstadt auf ${ }^{25}$. Es liegt gewiss nahe, einen unmittelbaren Zusammenhang mit den militärischen Auseinandersetzungen zu vermuten. Doch lässt er sich aus den überlieferten Quellen nicht belegen.

23 Benson BobricK, Land der Schmerzen - Land der Hoffnung. Die Geschichte Sibiriens, München 1993, S. 71f.; die engl. Ausgabe erschien unter dem Titel: East of the Sun. The Conquest and Settlement of Siberia, London 1992. In der dt. Fassung fehlen aus unerklärlichen Gründen die Anmerkungen.

24 Ebd., S. 73f.

25 Mancall, Russia and China, S. 44ff.; Baddeley, Russia, Mongolia, China, Bd. 2, S. 130-166. 
Diplomatisch und wirtschaftlich erfolglos, denn Bajkov brachte Waren mit, die noch nicht einmal 2.000 Rubel wert waren, lieferte er aber doch umfassende Informationen über China. Von der Hauptstadt Peking zeigte er sich sehr beeindruckt, vor allem von den sauberen Straßen. Auch die Vielfalt der Waren, beginnend mit Obst, Gemüse und Lebensmitteln bis hin zu Seide, Samt und Gold, beschrieb er ausführlich. Allerdings sei alles sehr teuer und die Münzen durch die Beimengung von Kupfer verdorben. Für russische Waren auf dem chinesischen Markt sah er keine großen Chancen außer für Hermeline und arktische Fuchsfelle ${ }^{26}$. Zur gleichen Zeit hielt sich in Peking auch eine holländische Gesandtschaft auf. Zwar wusste man voneinander, doch verhinderten die Chinesen jegliches Zusammentreffen ${ }^{27}$.

In den folgenden Jahrzehnten dehnte sich die russische Herrschaft am Amur erneut aus, begleitet wiederum von erheblichen Plünderungen und Übergriffen auf die einheimische Bevölkerung. Seit der Mitte der 1660er Jahre wuchs der Zustrom von Kosaken und Deserteuren noch weiter an. Zugleich versuchte die russische Regierung durch Handelskarawanen und erneute diplomatische Missionen ins Reich der Mitte, ihre Position zu sichern, vor allem aber einen gewinnträchtigen Handel zu etablieren. Doch war die chinesische Seite, die den gesamten Raum als eigenen Machtbereich betrachtete, an beidem wenig interessiert. Die russischen Diplomaten, mit den Gepflogenheiten am chinesischen Hofe kaum vertraut und mit wenig Einsicht in das Wesen der chinesischen Herrschaft, kehrten weitgehend erfolglos zurück. Mit der Konsolidierung der Herrschaft des chinesischen Kaisers K'ang-hsi (1661-1722) ging Peking dann offensiver gegen einen weiteren russischen Machtzuwachs und den fortgesetzten Zustrom von Russen $\operatorname{vor}^{28}$.

Die militärischen Befestigungen in der nördlichen Mandschurei wurden ausgebaut, weiteres Militär in die Grenznähe verlegt. Die Chinesen drängten aufgrund ihrer militärischen und zahlenmäßigen Überlegenheit die Russen mehr und mehr aus der Amur-Region hinaus. Als kein Übereinkommen über den russischen Rückzug zustande kam, griff eine chinesische Armee im Sommer 1685 das befestigte Albazin an. Nach einer nur wenige Tage dauernden Belagerung kapitulierte die russische Besatzung und durfte sich nach Nerčinsk zurückziehen. Nachdem sie das Fort niedergebrannt hatten, zogen die Chinesen $\mathrm{ab}^{29}$. Nun kehrte der geschlagene russische Komman-

\footnotetext{
26 MANCALL, Russia and China, S. 52.

27 BAdDeley, Russia, Mongolia, China, Bd. 2, S. 150ff.

28 STARY, Chinas erste Gesandte in Russland, S. 6ff.

29 Mancall, Russia and China, S. 131ff.; Bericht des Voevoden von Nerčinsk, Ivan Vlasov, an Fürst Konstantin Ščerbatov, Voevode von Enisejsk, über die Belagerung von Albazin, nach dem 20. Juni 1685, und Bericht des Voevoden von Nerčinsk an den Voevoden von Enisejsk, nach dem 26. August 1685, in: DMYTRYSHYN u.a. (Hg.), Bd. 1: Russia's Conquest of Siberia, S. 469-475.
} 
dant Aleksej Tolbuzin mit einer verstärkten Mannschaft zurück und baute die zerstörte Festung wieder auf. Im nächsten Jahr griffen chinesische Einheiten erneut an, doch gelang es ihnen in zehnmonatiger Belagerung nicht, den erbitterten Widerstand der Russen zu brechen. Während dieser Kämpfe einigten sich beide Seiten darauf, über die strittigen Fragen zu verhandeln. Der chinesische Kaiser hob sogar die Belagerung des Forts Albazin auf ${ }^{30}$.

Zuvor hatte sich erneut eine russische Gesandtschaft unter Führung des aus dem Fürstentum Moldau stammenden Gesandten Nikolaj G. Spatharij (auch Spafarij) in den Jahren 1675 bis 1678 in China aufgehalten. Spatharij hatte sich auf seinem Weg durch Sibirien bis zur chinesischen Grenzen über die Lage am Amur und die Verhältnisse in China informieren lassen. Aufgrund dieser weitgehend falschen Berichte ging er davon aus, dass die Macht der Mandschus noch nicht gefestigt und eher ein schwaches Gegenüber zu erwarten war $^{31}$. Dies allerdings erwies sich als Fehlinformation, obschon die chinesische Regierung eher vorsichtig taktierte, um Russland nicht herauszufordern. Schon beim ersten Zusammentreffen mit einem kaiserlichen Unterhändler an der Grenze begann die langwierige Erörterung über das weitere Procedere, über Etikette und Zeremonien. Das Symbolische des Handelns war für beide Seiten von enormer Bedeutung. Dahinter trat die politische Frage des russischen Vordringens am Amur und das Problem der Überläufer fast zurück ${ }^{32}$.

Für die chinesische Seite gehörte das Russische Reich weiterhin zu den tributpflichtigen Ländern, denn es war durch eine Landgrenze mit China verbunden. Dafür war der Li-fan yuan zuständig, der »Hof der kolonialen Angelegenheiten«. Die Behandlung solcher Gesandtschaften folgte einem strikt festgelegten Ritual, das entsprechend zu beachten war $^{33}$. Davon wollte die chinesische Seite unter keinen Umständen abweichen, um keinen Präzedenzfall zu schaffen. So verhandelten die beiden Vertreter Russlands und Chinas wochenlang an der Grenze, bis die Anordnung aus Peking kam, den Gesandten unverzüglich dorthin zu bringen.

Auf dem Weg in die chinesische Hauptstadt und auch in Peking setzten sich die Probleme fort, die kaum zu lösen waren, wenn nicht eine der beiden Seiten ihr Gesicht verlieren wollte. So scheiterten die Verhandlungen bereits im Vorfeld, ohne dass die wichtigsten Punkte überhaupt erörtert wurden. Da sich Spatharij weigerte, ein Antwortschreiben des Kaisers an

\footnotetext{
30 Mancall, Russia and China, S. 134ff.; Bericht von Fedor Golovin an Zar Ivan V. und Peter I. aus dem Jahr 1687 über die die Belagerung im Jahre 1686, in: DMYTRYSHYN u.a. (Hg.), Bd. 1: Russia's Conquest of Siberia, S. $482 \mathrm{f}$.

31 Beate HILl-PAULUS, Nikolaj Gavrilovič Spatharij (1683-1708) und seine Gesandtschaft nach China, Hamburg 1978, S. 28 f.

32 Ebd., S. 36 .

33 Ebd., S. Xf., Anm. 35.
} 
den Zaren auf der Basis des chinesischen Zeremoniells anzunehmen, blieb er ohne Antwort, denn er habe sich »ungehörig benommen«. Der nächste Gesandte aus Russland solle, so gab man ihm mit auf den Weg, »ein sehr gescheiter Mann sein und soll alles, was wir befehlen, nach unseren Sitten tun und auf keinen Fall widersprechen ${ }^{34}$. Zudem sei es angebracht, bessere Dolmetscher mitzubringen, denn die Verständigung erwies sich als äußerst problematisch. So nutzten auch die Vermittlungsversuche des jesuitischen, aus Flandern stammenden Missionars Ferdinand Verbiest, mit dem Spatharij auf Latein konferierte, nichts. Schließlich wurden zudem die gewünschten Handelsbeziehungen abgelehnt. Die Delegation selbst machte gleichfalls schlechte Geschäfte, da die chinesischen Beamten den Handel auf die letzten Tage vor der Abreise beschränkten, als die Russen gezwungen waren, ihre Waren zu Schleuderpreisen abzusetzen, um sie nicht mit zurücknehmen zu müssen ${ }^{35}$.

Während sich Spatharij, dessen Halsstarrigkeit sogar die Mitglieder seiner Gesandtschaft gegen ihn aufbrachte, als schlechter Diplomat erwies, zeigte er sich als guter Beobachter. In seinem Bericht über die gesamte Reise (Putešestvie), die er auch in einer Karte festhielt, und in seinem Tagebuch (statejnyj spisok) beschrieb er ausführlich die Verhältnisse in China. Die Große Mauer beeindruckte ihn eben so sehr wie die zahlreichen Menschen in den Städten. Er notierte, dass die Torwachen der Städte nicht nur die ankommenden Menschen zählten, sondern auch deren Waffen, und stellte fest, wo die Herrschaftsbezirke der regionalen Machthaber endeten. Ebenso wusste er von den gespannten Beziehungen zwischen »den alten Chinesen « und den mandschurischen Eroberern zu berichten ${ }^{36}$. So kehrte der Gesandte mit grundlegenden Kenntnissen über das chinesische Kaiserreich zurück, die für die weitere Politik Russlands von nicht unerheblicher Bedeutung werden sollten. Noch während seiner Reise und kurz nach seiner Rückkehr verfasste Spatharij eine »Beschreibung Chinas« (Opisanie Kitajskago Gosudarstva), die erstmals 1910 in Kazan' im Druck erschien. Zuvor kursierten verschiedene Manuskriptfassungen, die für das Chinabild in Russland von großer Bedeutung waren. Dieser Text ist, wie John F. Baddeley schon wenige Jahre später feststellte, eine fast wortgetreue Über-

\footnotetext{
34 Ebd., S. 81.

35 Ebd., S. 67.

36 Vgl. dazu Hill-Paulus, Spatharij, S. 43ff.; DMytryshyn u.a. (Hg.), Bd. 1: Russia's Conquest of Siberia, S. LXff.; BAdDEley, Russia, Mongolia, China, Bd. 2, S. 204-422 druckt den Text der »Reisebeschreibung« und des »statejnyj spisok«. Als »statejnyj spisok« wird das Tagebuch bezeichnet, das jeder russische Gesandte an einen fremden Hof zu führen hatte. Beide Texte lieferte Spatharij nach seiner Rückkehr an das »Außenamt« (posol'skij prikaz) ab. Sie wurden erst am Ende des 19. bzw. im frühen 20. Jahrhundert veröffentlicht, waren also bis dahin nur den höheren Beamten, den Ministern oder dem Zaren zugänglich.
} 
setzung des Werkes Novus Atlas Sinensis des Jesuiten Martino Martini, der 1635 in Amsterdam im lateinischen Original erschienen war $^{37}$.

Als sich die russisch-chinesischen Grenzprobleme verschärften, reiste Anfang 1687 Fedor A. Golovin, der aus einem Bojarengeschlecht stammte und dessen Vater Voevode in Tobol'sk war, als russischer Gesandter nach Sibirien, um mit den Chinesen über die bestehenden Konflikte, sowohl über den Grenzverlauf als auch über die Handelsbeziehungen, zu verhandeln. Er war mit den dortigen Angelegenheiten entsprechend gut vertraut. Auch an der Spitze der chinesischen Mission standen hohe Beamte. Die Instruktionen für den russischen Unterhändler besagten, dass die Grenze dem Lauf des Amur bis zur Mündung der Zeja folgen solle, eine Auslieferung des Tungusenfürsten Gantimur, der sich von China ab- und Russland zugewandt hatte, dürfe es nicht geben. Falls die chinesische Seite auf einem Rückzug der Russen aus dem Amurgebiet beharre, sollte ein zweiseitiger Handelsvertrag verbindlich zugesagt werden ${ }^{38}$.

Nachdem erste geplante Gespräche in der russischen Gründung Selenginsk nicht zustandegekommen waren, fanden die endgültigen Verhandlungen im August des Jahres 1689 in der Nähe einer der neugegründeten russischen Festungen, Nerčinsk, statt. Auf chinesischer Seite fungierten dabei drei jesuitische Missionare als Dolmetscher und Berater. Beeinflusst wurden die Verhandlungen von zwei wesentlichen Faktoren; zum einen führten die Dsungaren, vereinigte westmongolische Stämme, einen recht erfolgreichen Kampf gegen China und hatten große Teile der Äußeren Mongolei unter ihre Kontrolle gebracht, zum zweiten waren die Herrschaftsverhältnisse in Russland noch ungeklärt. Just im August und September 1689 tobte in Moskau der Kampf um die Herrschaft. Peter I. gelang es, seine Halbschwester Sofija zu verdrängen. Davon konnte der russische Geschäftsträger noch nichts wissen. Doch ihm war bekannt, dass ein russischer Feldzug auf die Krim kurz zuvor ergebnislos geblieben war und erhebliche Kosten verursacht hatte, so dass die Staatsfinanzen noch stärker zerrüttet waren als zuvor. Von daher wurden russischerseits gewisse Hoffnungen auf die Einnahmen aus dem Handel mit China gesetzt ${ }^{39}$.

Die Chinesen demonstrierten trotz der mongolischen Bedrohung ihre Macht und ließen vor Nerčinsk eine Armee von weit über 10.000 Mann aufmarschieren. Dem hatte die russische Seite wenig entgegenzusetzen, denn die eigene Besatzung der Festung zählte gerade einmal 2.000 Soldaten.

\footnotetext{
37 BAdDEley, ebd., S. 209-220.; vgl. auch Hill-Paulus, Spatharij, S. 103ff.

38 MANCALL, Russia and China, S. 142ff.

39 Klaus HelLER, Der russisch-chinesische Handel von seinen Anfängen bis zum Ausgang des 19. Jahrhunderts, Erlangen 1980; vgl. auch ders., Der russisch-chinesische Handel in Kjachta. Eine Besonderheit in den außenwirtschaftlichen Beziehungen Russlands im 18. und 19. Jahrhundert, in: Jahrbücher für Geschichte Osteuropas N.F. 29 (1981), S. 515-536.
} 
Doch bestand die russische Seite, diesmal erfolgreich, auf der Gleichheit der Verhandlungspartner, die die chinesische Seite nach einigem Zögern akzeptierte. Symbolisches Handeln stand zunächst im Vordergrund. Soldaten paradierten und die Gesandten sowie ihre Begleitung erschienen in den entsprechenden Gewändern. Bei der ersten Begrüßung redeten beide Seiten gleichzeitig. Im Plenum trafen sich die Delegationen nur dreimal, verhandelt wurde durch nachgeordnete Beamte, die zwischen den beiden Lagern hin- und her pendelten. So zogen sich die Verhandlungen über die Grenzziehung und den Handel, an dem die Chinesen nicht sonderlich interessiert waren, einige Zeit hin und wurden mit Hilfe der Jesuiten in lateinischer Sprache geführt, denn das direkte Gespräch erwies sich aufgrund der mangelnden Qualität der Dolmetscher beider Seiten als unmöglich. Schließlich wurde am 27. August 1689 russischer Zeitrechnung der Vertrag von Nerčinsk geschlossen, von dem je eine Fassung in lateinischer und russischer Sprache sowie eine in Mandschu ausgefertigt wurde, wobei die lateinische Version gemeinhin als die zuverlässigste gilt und auch die verbindliche Fassung war ${ }^{40}$.

Der Vertrag legte den Grenzverlauf zwischen China und Russland am Argun fest, von dort nördlich bis zum Kamm des Stanovoj-Gebirges, um schließlich in östlicher Richtung hinunter zum Ochotskischen Meer dem Gebirgszug zu folgen. Nerčinsk blieb russisch, doch musste die Festung Albazin aufgegeben werden. Den Russen wurden Handelsrechte eingeräumt, die ihnen den chinesischen Markt öffneten ${ }^{41}$. Was allerdings nicht gelang, war die von den Russen angestrebte Monopolisierung des Handels. Weder Nerčinsk noch späterhin, ab 1727, Kjachta wurden zur Drehscheibe des europäischen China-, geschweige denn des Asienhandels. Unmöglich war es zugleich, den inoffiziellen Handel zu kontrollieren, der nach vorsichtigen Schätzungen den offiziellen erheblich übertraf ${ }^{42}$. Dennoch legte dieser Vertrag die Grundlage für eine lange Friedenszeit zwischen den beiden Mächten, die erst um die Mitte des 19. Jahrhunderts endete. Die chinesische Seite erhielt das Recht, durch Grenzsteine mit einer eingemeißelten Inhaltsangabe des Vertragstextes den genauen Grenzverlauf festzulegen.

\footnotetext{
40 Die Verträge zwischen Russland und China 1689-1881. Faksimile der 1889 in St. Petersburg erschienenen Sammlung mit den Vertragstexten in russischer, lateinischer, französischer sowie chinesischer, mandschurischer und mongolischer Sprache, hg. und eingel. von Michael WeIERS, Bonn 1979, S. 1-10; Reinhard WitTRAM, Peters des Großen Interesse an Asien, in: Nachrichten der Akademie der Wissenschaften in Göttingen aus dem Jahre 1957. Philologisch-Historische Klasse, Göttingen 1957, S. 1-25.

41 Wittram, Peters Interesse an Asien, S. 2.

42 Heller, Russisch-chinesischer Handel, S. 11.
} 
Im Kontext dieses Vertrages ist die Mission von Eberhard Isbrand Ides und Adam Brand nach China zu sehen. Ides stammte aus einer ursprünglich niederländischen Familie, war aber 1657 in Glückstadt an der Elbe geboren worden. Er war Kaufmann und handelte seit 1677 über die Nordmeerroute von Amsterdam und Hamburg aus mit Russland. Zwischen 1687 und 1690 ließ er sich in der Moskauer Deutschen Vorstadt nieder und gehörte dort zu den führenden Persönlichkeiten, der auch den jungen Zaren Peter I. in seinem Haus als Gast empfing. 1691 allerdings stand Ides vor dem Bankrott und bat den Zaren um eine Handelserlaubnis nach China. Peter I. erteilte ihm nicht nur die Genehmigung dafür, sondern machte ihn 1692 zum offiziellen Gesandten »Ihrer Majestäten«, denn der Chinahandel versprach auch für den russischen Staat lukrative Einnahmen. Zudem bestand nach dem gerade geschlossenen Vertrag von Nerčinsk politischer Handlungsbedarf. Wie die Vorgänger auch, so scheiterte die Mission diplomatisch, war aber für Ides ökonomisch ein voller Erfolg. Bald nach seiner Rückkehr verlagerte er seine Geschäftsinteressen vom Handel auf die Unternehmertätigkeit, war auch darin äußerst erfolgreich und genoss das Wohlwollen des Zaren. Ides' Bericht verdankt sich im wesentlichen dem nicht nur in Russland, sondern auch im westlichen Europa stetig wachsenden Interesse an China. Sein Hin- und Rückweg führte ihn auch durch Sibirien, wo er sich längere Zeit aufhielt. So ist es auch einer der ersten Berichte über Sibirien, das noch unbekannter war als China. Ein erster Druck seiner Mitteilungen über die Gesandtschaftsreise erschien in holländischer Sprache 1704 in Amsterdam und enthielt eine längere Widmung an Zar Peter I. Es folgten 1706 eine englische Ausgabe in London und 1707 in Frankfurt eine deutsche Ausgabe. Danach folgten weitere Gesamt- oder Teilausgaben, bis am Ende des 18. Jahrhunderts auch eine russische Übersetzung erschien ${ }^{43}$. Dem Stil der Zeit entsprechend enthielten die holländische und die deutsche Erstausgabe zahlreiche Kupferstiche, die holländische zudem eine große Karte von Sibirien.

$\mathrm{Zu}$ den Begleitern des Isbrand Ides gehörte der wahrscheinlich aus Lübeck stammende Kaufmann Adam Brand, über dessen Leben vor und des-

43 E. Ysbrant Ides, Driejaarige Reize naar China, te landen gedann door den Moskovischen Afgezant E. YsBrant IDES, von Moskau af, over Grot Ustiga, Siriania, Permia, Sibirien, Daour, Groot Tartaryen to in China [...], Amsterdam 1704; deutsche Fassung: Dreyjährige eise nach China, von Moscau ab zu lande durch groß Ustiga, Siriania, Permia, Sibirien, Daour, und die große Tartary; gethan durch den Moscowitischen Abgesandten Hrn. E. Yßbrants Ides [...], Franckfurt 1707; kommentierte Neuausgabe mit einer ausführlichen Einleitung: Beschreibung der dreijährigen Chinesischen Reise. Die russische Gesandtschaft von Moskau nach Peking 1692 bis 1695 in den Darstellungen von Eberhard IsBRANT IDES und Adam BRAND, hg., eingel. und kommentiert von Michael Hundt, Stuttgart 1999, S. 75f.: der Bericht von IDES, S. 109-364; vgl. auch Georg HENNING, Die Reiseberichte über Sibirien von Herberstein bis Ides, in: Mitteilungen des Vereins für Erdkunde zu Leipzig 1905, S. 245-394, hier S. 316ff. 
sen Funktion während der Reise wenig bekannt ist. Er verließ Russland unmittelbar nach der Rückkehr aus China und ließ sich in Lübeck als Kaufmann nieder. Nach einem Bankrott ging er 1707 nach Berlin und danach nach Königsberg. Der preußische König ernannte ihn schließlich zum Kommerzienrat, nach 1720 verliert sich seine Spur endgültig. Auch über die Umstände der Entstehung seines Berichts ist nichts bekannt. Seine »Beschreibung der Chinesischen Reise« erschien erstmals 1698, sechs Jahre vor dem Werk von Ides. Nach dieser ersten Auflage erschien 1712 in Berlin eine erweiterte Fassung, der 1723 eine dritte und 1734 eine vierte Auflage folgten ${ }^{44}$.

Insgesamt war die Gesandtschaft zwei Jahre und neun Monate unterwegs. Für die Hinreise brauchte man 18 Monate, hielt sich dann dreieinhalb Monate in Peking auf und benötigte schließlich elfeinhalb Monate für die Rückreise. Der Reiseweg verlief von Moskau über Solikamsk, Tobol'sk, Irkutsk und Nerčinsk, wo die Grenze überschritten wurde, bis nach Peking.

Reiseberichte waren schon in der Antike ein beliebtes Genre. Seit dem Beginn der europäischen »Entdeckungen« am Ende des 15. Jahrhunderts steigerte sich das Interesse noch und erlebte seit dem Ende des 17. und im Verlauf des 18. Jahrhunderts einen wahren Boom. Je exotischer die Gebiete waren, umso größer war das Interesse der Leserschaft, von deren Bildung generell auszugehen ist. Sibirien und China passten als terrae incognitae ausgezeichnet in diesen Kontext. Beide Territorien, China aber vor allem, fanden das große Interesse der europäischen Gelehrten der Zeit, so etwa von Leibniz, der nach dem Erscheinen von Brands Bericht ein Exzerpt anfertigte, von dem noch zu reden sein wird.

Ides konzentrierte sich in seiner Darstellung stärker auf die Reise und die Durchquerung Sibiriens und schilderte ausführlich Sitten und Gebräuche der dortigen Ethnien. In China interessierte ihn besonders die Hauptstadt, während er über die diplomatischen Geschäfte kaum berichtete. Worauf Ides seinen Bericht stützte, lässt sich nachträglich nicht mehr rekonstruieren. In jedem Falle liegen bei ihm diverse Datierungsfehler vor, während Brand sich auf eigene Tagebuchaufzeichnungen stützen konnte ${ }^{45}$. Brand schrieb eher persönlich und lebendiger, während Ides meist sachlich und

\footnotetext{
44 Adam BRAND, Beschreibung der Chinesischen Reise Welche vermittelst Einer Zaaris. Gesandtschaft Durch Dero Ambassadeur, Herrn Isbrand Ao. 1693. 94 und 95. von Moscau in Groß=Ustiga, Siberien, Dauren und durch die Mongalische Tartarey verrichtet worden [...], Hamburg 1698; Adam Brands, Seiner Königl. Majestät in Preussen Commercien=Raths, Neu vermehrte Beschreibung seiner grossen Chinesischen Reise [...], Berlin 1712, 3. Aufl., Lübeck 1723, 4. Aufl., Lübeck 1734; die folgenden Zitate entstammten dieser vierten, gegenüber der zweiten unveränderten Auflage. Abgedruckt bei HundT (Hg.), Beschreibung der dreijährigen Reise, S. $107-189$.

45 HundT (Hg.), Beschreibung der dreijährigen Reise, Einleitung, S. $70 f$.
} 
erklärend schreibt, manchmal sogar durchaus akademisch, wodurch der Erzählfluss unterbrochen wird.

Recht ausführlich schilderte Brand den Weg von der Grenze nach Peking, berichtete über die Freundlichkeit des chinesischen Offiziellen, der die Gesandtschaft begleitete, und von den Essgewohnheiten mit »Stöcklein «, die die Chinesen »in sonderbarer Geschwindigkeit« benutzten ${ }^{46}$. Die »Große Mauer« beeindruckte ihn durchaus, vor allem aber die zahlreichen Tempel und Pagoden mit den »heßlichen und grausahm« anzusehenden Göttern ${ }^{47}$. Umfassend schilderte er die diplomatischen Begegnungen, die zahlreichen Essen und Zusammentreffen mit den chinesischen Offiziellen. Deutlich wird dabei, dass Brand nur in untergeordneter Stellung an der Gesandtschaft teilnahm, denn einen wichtigen Teil der Verhandlungen, in denen es um die Rangordnung zwischen den Mächten ging, fehlen bei ihm. Erneut war, wie bei den russischen Gesandten zuvor, die entscheidende Frage, Einvernehmen über den Ablauf des diplomatischen Zeremoniells und über die Ausübung des Kotau vor dem chinesischen Kaiser zu erzielen; insbesondere aber ging es um das Problem der Gleichrangigkeit der beiden Staaten. Für die Chinesen handelte es sich um eine Tributgesandtschaft, die entsprechend untergebracht wurde und die zunächst ihre Geschenke und ihr Beglaubigungsschreiben zu überreichen hatte, um festzustellen, ob es überhaupt für erforderlich gehalten wurde, den Gesandten mit seiner Begleitung zu einer Audienz beim Kaiser zuzulassen. Ides versuchte mit aller Beredsamkeit und Verweisen auf die Beziehungen der europäischen Staaten miteinander oder auch zu den islamischen Ländern, die Gesten der Unterwerfung und der Ungleichheit zu vermeiden. Doch bestanden die Chinesen darauf und drohten damit, gar keine Audienz zu gewähren und Ides unverrichteter Dinge wieder zurückzuschicken ${ }^{48}$.

So unterwarf sich denn Ides mit seiner Begleitung den gewünschten Praktiken, ohne dadurch irgendwelche diplomatischen oder politischen Vorteile zu erlangen. Stattdessen beschwerte sich der chinesische Minister, wie schon im Fall von Spatharij, darüber, dass der russische Gesandte keine genügend qualifizierten Dolmetscher mitgebracht hatte, so dass sich die Kommunikation als schwierig erwies. Man hatte noch nicht einmal daran gedacht, einen Dolmetscher mit ausreichenden Lateinkenntnissen mitzubringen, um mit Hilfe der jesuitischen Missionare zu verhandeln ${ }^{49}$. Offensichtlich waren die rund zwanzig Jahre zurückliegenden Berichte Spatharijs schon wieder in Vergessenheit geraten.

\footnotetext{
46 Ebd., Text Brand, S. 153.

47 Ebd., S. 158.

48 ManCALl, Russia and China, S. 188-194; HundT (Hg.), Beschreibung der dreijährigen Reise, Einleitung, S. 49ff.

49 HundT (Hg.), Beschreibung der dreijährigen Reise, Einleitung, S. 57.
} 
Diplomatisch betrachtet war die Reise, wie die vorherigen auch, ein Fehlschlag. Immerhin ließ der chinesische Kaiser durch einen Jesuiten mitteilen, dass sich China an den Vertrag von Nerčinsk halten werde, was auch tatsächlich eintrat ${ }^{50}$. Ökonomisch betrachtet war die Gesandtschaft sowohl für Ides als auch für die russische Staatskasse dagegen ein voller Erfolg, für Brand hingegen weniger, denn die chinesische Seite erlaubte den Mitgliedern der Gesandtschaft, in Peking unbeschränkt zu handeln. Ides wurde reich, und erhielt nach seiner Rückkehr mehrere Ämter vom Zaren, darunter den Posten eines »Kommissars der Admiralitätskanzlei« und eines Verwalters der Exportzölle in Archangel'sk. Darüber hinaus genoss er zahlreiche Privilegien des Zaren ${ }^{51}$.

Beeindruckt zeigten sich Ides und Brand von der Hauptstadt Peking und waren sehr angetan von der Fülle der Waren auf den zahlreichen Märkten. Beeindruckt waren beide auch von der Größe des Landes, von dem sie allerdings nicht viel gesehen hatten. Angetan waren sie zudem von der chinesischen Oper, deren Stücke ihnen mehrmals vorgeführt wurden und die sie als »Comödie« bezeichneten. Am Ende seines Berichtes versuchte Ides ein kurze Einschätzung Chinas und seiner Bewohner zu geben. $\mathrm{Zu}-$ nächst hielt er den Unterschied zwischen den Chinesen und den mandschurischen Eroberern fest und hielt jene für »aufrichtiger«, für »reinlich und nett«, da sie »ein mäßiges und nüchternes leben « führten ${ }^{52}$. Die im 17. Jahrhundert unter den Gelehrten und Gebildeten vorherrschende Meinung über die »grosse weißheit, künste und wissenschaften« in China hielt Ides für ein Fehlurteil. Die Chinesen seien vom Verstand her und von »denen wissenschafften « den Europäern unterlegen ${ }^{53}$. Zudem seien sie, das sehe man an ihren Gesetzen, »barbarisch und unmanierlich $\aleph^{54}$.

Immerhin waren die Nachrichten von Brand und Ides so neu, dass Leibniz ein Exzerpt aus Brands Buch anfertigte und darauf hoffte, dass auch Ides, der »Envoye«, einen Bericht vorlegen werde. Das Exzerpt macht deutlich, dass auch dieser Gelehrte zunächst einmal an Sachinformationen interessiert war, die er entsprechend notierte: wer wo und auf welche Art und Weise wohnte, welche Religion die Menschen hatten, wie hoch und breit die chinesische Mauer war, dass in den Tempeln »Abgotzen« von »abscheulicher Gestalt« standen, von denen einige acht bis zehn Klafter hoch waren und der chinesische Kaiser etwa 45 Jahre alt war und »wohl von Gestalt $\ll^{55}$. Grundsätzlich aber zeigte sich der Gelehrte enttäuscht von Brands Werk, denn es enthielt kaum neue Informationen über die chinesische Kul-

50 ManCALL, Russia and China, S. 193.

51 HundT (Hg.), Beschreibung der dreijährigen Reise, Einleitung, S. 4.

52 Hundt (Hg.), Beschreibung der dreijährigen Reise, Text Ides, S. 338.

53 Ebd., S. 340.

54 Ebd., S. 339. 
tur oder über die Ethnien Sibiriens und dessen Geographie ${ }^{56}$. Vor allem mangelte es wohl in Leibniz' Verständnis daran, dass beide Werke nichts zu seiner Idee einer "gegenseitig nutzbringenden Kooperation zwischen zwei gleichrangigen wissenschaftlichen Welten" - als solche sah Leibniz die chinesische Gelehrtenwelt durchaus - beitrugen ${ }^{57}$.

Brand versuchte noch nicht einmal, ein Fazit seiner Reise zu ziehen oder einige generelle Sätze über China zu schreiben. Am Ende der Reise schien er wohl nur noch froh darüber zu sein, alles heil und gesund überstanden zu haben. Er dankte am Ende Gott, dass er frisch und gesund wieder nach Moskau zurückgekehrt war: »Woselbst wir unsere matten Glieder und Leiber mit einer angenehmen und vergönnten Ruhe wieder zu rechte brachten, nachdem wir auf dieser Chinesischen Land-Reise 3. Jahr weniger 6. Wochen zugebracht hatten $\ll^{58}$.

Aufschlussreicher als die Ausführungen über China waren die Darstellungen der beiden Autoren über ihre Reise durch Sibirien. Da der Bericht Spatharijs über seine Reise durch Sibirien nicht gedruckt worden war, lagen damit die ersten westeuropäischen, aus eigener Anschauung gewonnenen Ausführungen über dieses weitgehend unbekannte und riesige Gebiet vor. Kurz zuvor war mit dem Werk »Noord en Oost Tartarye« des holländischen Diplomaten und Kaufmanns Nicolaas Witsen die erste ausführliche Beschreibung des Subkontinents erschienen ${ }^{59}$. Doch hatte er Sibirien nicht bereist, sondern während eines längeren Aufenthalts in Russland entsprechendes Material für sein Buch und eine Karte Sibiriens gesammelt ${ }^{60}$.

Bemerkenswert an den Schriften von Brand und Ides ist die große Fülle ethnologischer Beobachtungen. In zahlreichen Details und manchmal in

55 Hundt (Hg.), Beschreibung der dreijährigen Reise, druckt S. 347-349 Leibnizens »Kurze Relation von des Herrn Brandts Reise und Gesandtschafft aus Moscau nacher China, und von den Völkern so Er unter Wegs angetroffen« und »Relation aufs kürtzeste wie der Envoyé Extr. Isbrand seinen Weg nacher China genommen und was Vor Nation Völker angetroffen« aus dem Nachlaß ab.

56 Ebd., Einleitung, S. 70; Otto Franke, Leibniz und China, in: Gottfried Wilhelm Leibniz. Vorträge aus Anlaß seines 300. Geburtstages, Hamburg 1946, S. 97-109; Kurt Müller, Gottfried Wilhelm Leibniz und Nicolaas Witsen, in: Sitzungsberichte der Deutschen Akademie der Wissenschaften zu Berlin. Klasse für Philosophie, Geschichte, Staats-, Rechts- und Wirtschaftswissenschaften, Nr. 5, Berlin 1955, S. 3-45, hier S. 21 f.

57 Jürgen OSTERHAmmEL, Die Entzauberung Asiens. Europa und die asiatischen Reiche im 18. Jahrhundert, München 1998, S. 174.

58 HunDT, Beschreibung der dreijährigen Reise, S. 189.

59 Nicolaas Witsen, Noord en Oost Tartarye [...], Amsterdam 1692, 2. Aufl., Amsterdam 1705, 3. Aufl., Amsterdam 1785. Die letzte ist gegenüber der zweiten Auflage kaum verändert. Das Tagebuch der Reise Witsens durch Russland erschien erst im 20. Jahrhundert: Th.J.G. LOCHER / P. DE BuCK (Hg.), Nicolaas Witsen, Moscovische Reyse 1664-1665. Journaal en Antekeningen, 3 Teile, Den Haag 1966/67. Vgl. dazu Gudrun Bucher, »Von Beschreibung der Sitten und Gebräuche der Völker«. Die Instruktionen Gerhard Friedrich Müllers und ihre Bedeutung für die Geschichte der Ethnologie und der Geschichtswissenschaft, Stuttgart 2000, S. 60-62. 
Form von Momentaufnahmen wurde das Leben dieser Ethnien beschrieben. Sehr intensiv beobachteten sie das religiöse Leben und versuchten, das Fremdartige daran zu erfassen. Immer wieder werden Vergleiche angestellt, häufiger zu den Sprachen, und nach Verwandtschaftsbeziehungen zwischen den sibirischen Ethnien gesucht.

Sibirien allerdings war nicht ihr Thema, sondern ergab sich für diese beiden Autoren ebenso wie für Spatharij eher aufgrund ihres Reiseweges. Doch interessierte dies die damalige gelehrte Welt kaum. Sie sahen das Reich der Mitte sowohl mit Blick auf den dortigen Stand der Wissenschaften als auch in Bezug auf die Handelsbeziehungen als weitaus wichtiger an. Dieses Chinabild haben indes sowohl Ides als auch Brand nicht in vollem Umfang bedient. Von den Chinesen, so glaubten sie im Unterschied zu Leibniz und anderen europäischen Gelehrten, konnten die Europäer nichts lernen. Die europäische Kultur sahen sie in fast jeder Hinsicht als überlegen an und ließen, wie Brand, höchstens den Fleiß der Chinesen und deren Agrarwirtschaft gelten ${ }^{61}$. Von jeder Form eines Kulturrelativismus waren sie weit entfernt.

60 Nicolaas Witsen, Nieuwe lantkaarte van het Noorder en Ooster deel von Asia en Europa, Strekkende van Nova Zemla tot China [...], Amsterdam 1687. Vgl. dazu Baddeley, Russia, Mongolia, China, Bd. 1, S. 148ff.

61 HundT (Hg.), Beschreibung der dreijährigen Reise, Einleitung, S. 63f. 


\title{
Eugenia Massold
}

\section{»Völker in der Großen Finsterniß ihres Verstandes...»}

\author{
Ethnologische Forschungen im Altaj im 18. und in der \\ ersten Hälfte des 19. Jahrhunderts ${ }^{1}$
}

Die tragende Rolle bei der wissenschaftlichen Erforschung Sibiriens im 18. und 19. Jahrhundert spielte die Regierung des Russischen Reiches. Ohne die staatliche Finanzierung wäre die Erforschung der gewaltigen nordasiatischen Gebiete des Reiches nicht möglich gewesen. Sibirien war das erste Objekt der wissenschaftlichen Untersuchungen, die im Russischen Reich seit dem 18. Jahrhundert stattfanden. Die Regierung unterstützte diese Unternehmen vorrangig aus kommerziellen Gründen. Es sollte ermittelt werden, welche Ressourcen außer den kostbaren Pelzen in Sibirien vorhanden waren. Gleichzeitig sollte die Infrastruktur für den Handel mit den östlichen Nachbarn ausgebaut werden. Ebenso bedeutend waren die Bestrebungen der Regierung, durch die Etablierung der Wissenschaften nach westeuropäischen Vorbildern und die Gründung höherer Lehranstalten Russlands Ansehen in Westeuropa auf ein höheres Niveau zu heben. Grundlegend für diese Entwicklung war die Gründung der Akademie der Wissenschaften in St. Petersburg im Jahre 1725, die für die nächsten 120 Jahre als einzige Forschungseinrichtung im Russischen Reich für die Koordinierung und Systematisierung der Sibirienforschung zuständig sein sollte. Bedeutende westeuropäische und russische Gelehrte bereisten im Auftrag der Akademie der Wissenschaften die nordasiatischen Gebiete des Russischen Reiches und machten dabei einzigartige landeskundliche und ethnologische Entdeckungen ${ }^{2}$.

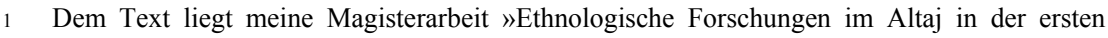
Hälfte des 19. Jahrhunderts « zugrunde, die 2006 an der Abteilung für Osteuropäische Geschichte der Rheinischen Friedrich-Wilhelms-Universität Bonn unter Betreuung von Prof. Dr. Dittmar Dahlmann entstanden ist.

2 Wieland HinTZSChE / Thomas NickOL (Hg.), Die Große Nordische Expedition. Georg Wilhelm Steller (1709-1746). Ein Lutheraner erforscht Sibirien und Alaska, Gotha 1996; Wieland HinTZSCHE u.a. (Hg.), Quellen zur Geschichte Sibiriens und Alaskas aus russischen Archiven; die Bände erscheinen in einer deutschen und russischen Fassung; bisher sind fünf Bände der deutschund zwei Bände der russischsprachigen Fassung erschienen: Georg Wilhelm STELLER. Briefe und Dokumente 1740, Halle 2000; Georg Wilhelm STELLER / Stepan KRAŠENINNIKOV / Johann Eberhard FISCHER. Reisetagebücher 1735-1743, Halle 2000; Georg Wilhelm STELLER. Briefe und Dokumente 1739, Halle 2001; Dokumente zur 2. Kamčatkaexpedition 1730-1733. Akademiegruppe, Halle 2004; Dokumente zur 2. Kamčatkaexpedition Januar - Juni 1734. Akademiegruppe,
} 
Die Route der großen sibirischen Forschungsreisen im 18. Jahrhundert sowie zahlreicher kleinerer Expeditionsmannschaften im 19. Jahrhundert führte die Wissenschaftler häufiger auch in die Altajregion. Das erzreiche Gebiet hatte für das Russische Reich eine wichtige handelspolitische Position als Landbrücke zu den östlichen Märkten. Das Bemühen um noch intensivere Handelsbeziehungen mit China und den mongolischen Chanen hatte in der russischen Handelspolitik einen sehr hohen Stellenwert. Bereits am Anfang des 17. Jahrhunderts wurden Erkundungsexpeditionen und später auch die ersten Botschafter nach China über das Gebiet der Westmongolen geschickt ${ }^{3}$.

Administrative Dokumente, Kosaken- sowie Reiseberichte über geschäftliche, diplomatische und wissenschaftliche Reisen und schließlich ethnologische Abhandlungen oder Publikationen von so genannten »Ethnographieenthusiasten« stellen die Quellen dar, in denen ethnographische Nachrichten über die Altajer enthalten sind. Diese über Jahrhunderte andauernde Kontinuität der Erforschung der Altajregion stellt eine besondere Chance dar, an diesem Fallbeispiel die Expansion des Russischen Reiches nach Nordosten und in deren Folge die wirtschaftliche und wissenschaftliche Erschließung Sibiriens sowie die Interessen der Auftraggeber genauer zu untersuchen.

Besonders die Beschreibungen anderer, bisher unbekannter Lebensweisen eröffnen uns einen Zugang zur Selbst- und Fremdwahrnehmung in der offiziellen Sichtweise der russischen Regierung, ihrer Beamten und Militärs sowie der Weltwahrnehmung der »europäischen« gelehrten Welt. Im Sinn von Michael Harbsmeier, der davor warnt, die Reiseberichte ausschließlich als reine Informationsträger zu behandeln, gelten hier diese schriftlichen Ergebnisse der Altaj-Erforschung in erster Linie als Zeitzeugnisse ${ }^{4}$.

Die ersten Informationen über den Altaj gelangten zunächst auf Umwegen über Zentralasien und den arabischen Osten nach Europa. Bereits vor dem Eroberungszug des Kosaken Ermak Timofeevič im 16. Jahrhundert

Halle 2006; Viland CHINTCŠE u.a. (Hg.), Georg Vil'gelm Šteller. Pis'ma i dokumenty 1740, Moskau 1998; Natal'ja OCHOTINA-LIND / Peter Ul'f MËLLER (Hg.), Vtoraja Kamčatskaja Ėkspedicija. Dokumenty 1730-1733. Čast' 1: Morskie otrjady, Moskau 2001.

3 Handbuch der Geschichte Russlands, Bd. 2,1: 1613-1856. Vom Randstaat zur Hegemonialmacht, hg. von Klaus ZeRNACK, Stuttgart 1986, S. 366f.; N. F. Demidova / V. S. MJASNIKOV (Hg.), Russko-kitajskie otnošenija v XVII veke. Materialy i dokumenty v dvuch tomach, Bd. 1: 1603-1683, Moskau 1969, S. 7ff.; Gert RoBel, Die Eroberung Sibiriens, in: Erich DonNeRT (Hg.), Europa in der Frühen Neuzeit, Bd. 6, Köln u.a. 2002, S. 873-885, hier S. 874; David N. ColbIns, The Altai. Fortified Resource Frontier on the Marches of Tsarist Russia, in: Eva-Maria Stolberg (Hg.), The Siberian Saga. A History of Russian's Wild East, Frankfurt/M. u.a. 2005, S. $29-42$, hier S. 30.

4 Michael HarbsmeIER, Wilde Völkerkunde. Andere Welten in deutschen Reiseberichten der Frühen Neuzeit, Frankfurt/M. u.a. 1994, S. $7 \mathrm{ff}$. 
fanden sich spärliche Angaben über den Altaj und den Oberlauf des Flusses Ob' auf manchen westeuropäischen geographischen Karten. So wurde der Altaj auf einer venezianischen Karte des Jahres 1457 verzeichnet, obgleich Sibirien nur eine enge Landverbindung zwischen dem Altaj und dem Arktischen Ozean darstellte ${ }^{5}$. Die altajschen Berge werden erst in der Karte von Nikolaj Spafarij, der 1675 als russischer Botschafter über Sibirien nach China gereist war, angegeben ${ }^{6}$. Neben beiläufigen Erwähnungen in Nachrichten und Karten von Botschaftsreisen lieferten die Kosakenberichte (kazač $i$ otpisi) ausführlichere historische und geographische Daten zu dieser Region und den dort lebenden Menschen. Die Berichte wurden aus Kundschafterberichten der Kosakentrupps und Nachrichten anderer Kundschafter, den so genannten zemleprochodcy, von den Voevoden angefertigt ${ }^{7}$.

Den Kosaken des 16. und 17. Jahrhunderts folgten im 18. und 19. Jahrhundert die Forschungsexpeditionen ${ }^{8}$. Zunächst waren es die universal gebildeten und interessierten Wissenschaftler des Zeitalters der Aufklärung wie Gerhard Friedrich Müller und Johann Georg Gmelin, die der Route der Zweiten Kamčatka-Expedition folgend das Altajvorland erforschten. Peter Simon Pallas sowie der deutsche Botaniker und Chemiker Johann Gottlieb Georgi reisten im Rahmen der Akademie-Expeditionen durch die Altajregi-

5 Michail F. Rozen, Verchnjaja Ob' i Altaj na kartach XVI-XIX vekov, Barnaul 1988, S. 3; Aleksandr N. PYPIN, Istorija russkoj ètnografii, Bd. 4, St. Petersburg 1892, S. 201.

6 John F. BADDEley, Russia, Mongolia, China. Being Some Record of the Relations Between Them From the Beginning Of the XVIIth Century To the Death Of the Tsar Alexei Mikhailovich A.D. 1602-1676 [...], Bd. 2, New York 1919, S. 207.

7 Leonid P. PotAPOV, Očerki po istorii Altajcev, 2. erg. Aufl., Moskau / Leningrad 1953, S. 23f.; A. I. ANDREEV, Očerki po istočnikovedeniju Sibiri, Bd. 1: XVII vek, 2. bericht. und erg. Aufl., Moskau 1960, S. 19ff.; A. P. OKLADNIKov u.a. (Hg.), Istorija Sibiri, Bd. 2: Sibir' v sostave feodal'noj Rossii, Leningrad 1968, S. 153f.

8 Han F. Vermeulen, Anthropology in Colonial Contexts. The Second Kamčatka Expedition (1733-1743) and the Danish-German Arabia Expedition (1761-1767), in: Ders. / Shimizu, Akitoshi (Hg.), Anthopology and Colonialism in Asia and Oceania, Richmond / Surrey 1999, S. 13-39; ders., Early History of Ethnography and Ethnology in the German Enlightenment. Anthropological Discourse in Europe and Asia, 1710-1808, Leiden 2008; Yuri SLEZKINE, The Sovereign's Foreigners: Classifying the Native People in Seventeenth-Century Siberia, in: Russian History 19 (1992), S. 475-485; Lothar MAIER, Wissenschaft und Staatsinteresse zur Zeit Peters des Grossen. Die Erschließung Sibiriens und des Nordpazifik durch wissenschaftliche Expeditionen, in: Österreichische Osthefte 4 (1978), S. 435-449; Marita HüBNER, Christliche Aufklärung und Staatsinteresse im Spiegel der Forschungsreise von Daniel Gottlieb Messerschmidt (16851735) nach Sibirien in den Jahren 1720-1727, in: Erich DonNERT (Hg.), Europa in der Frühen Neuzeit. Festschrift für Günter Mühlpfordt, Bd. 7, Köln u.a. 2008, S. 697-711; Marcus RoHN, Die Expedition Alexander Th. Middendorfs (1842-1845) und die Folgen, Münster 2004 [Magisterarbeit, unveröffentlichtes Manuskript]; Gert ROBEL, Deutsche Gelehrte und ihr Beitrag an der Erforschung Sibiriens 1700-1850, in: Boris MEISSNER / Alfred EISFELD (Hg.), Der Beitrag der Deutschbalten und der städtischen Russlanddeutschen zur Modernisierung und Europäisierung des Russischen Reiches im 18. und in der ersten Hälfte des 19. Jahrhunderts, Köln 1996, S. 257-282, hier S. $272 f$. 
on'. Ihnen folgte zu Beginn der 1780er Jahre der französische Mineraloge Eugène-Melchior Louis Patrin, Korrespondierendes Mitglied der Russischen Akademie der Wissenschaften, der zu jener Zeit in enger Beziehung zu Pallas stand ${ }^{10}$. Schließlich unternahm auch Alexander von Humboldt im Jahre 1829 auf Kosten der russischen Regierung eine kurze, aber dennoch überaus bedeutende Expedition an die Grenzen des Russischen Reiches, die ihn auch durch das Altajvorland führte ${ }^{11}$.

Neben den Regierungsbehörden, auf deren Initiative und Finanzierung Wissenschaftler in Begleitung kleiner Mannschaften gezielt in die Altajregion entsandt wurden, und der Petersburger Akademie der Wissenschaften beteiligte sich im 19. Jahrhundert auch die Universität Dorpat (heute Tartu) an der Erforschung des russischen Binnenlandes. Die wissenschaftliche Untersuchung des Russischen Reiches durch Expeditionen und die Auswertung der Ergebnisse wurde an der Universität Dorpat von Anfang an als einer der Forschungsschwerpunkte festgelegt ${ }^{12}$. Die Liste der Absolventen der Universität Dorpat, die Sibirien erforschten, umfasst bedeutende Wissenschaftler: Alexander von Bunge, von dem später noch die Rede sein wird, Alexander Theodor von Middendorff, Ernst Hofmann und Alexander Gustav Schrenk. Jedoch bleibt der Beitrag der Universität Dorpat zur Erforschung Sibiriens und Russland bis heute ein Forschungsfeld. Die erste bedeutende Expedition in die Altajregion fand auf Initiative von Professor Carl Friedrich Ledebour statt, der im Jahre 1825 dem Rat der Universität Dorpat seinen Plan einer zweijährigen Expedition in den Altaj vorlegte und diese im Jahr darauf verwirklichen konnte. Eine besondere Rolle in Dorpat spielte Alexander von Humboldt, der zwischen 1804 und 1850 eine rege Korrespondenz mit zahlreichen Mitgliedern des Lehrkörpers der Physika-

\footnotetext{
9 Folkwart Wendland, Peter Simon Pallas (1741-1811). Materialien zu einer Biographie, Berlin / New York 1992, S. 80ff.

10 Eugène-Melchior Louis PATRIN, Relation d'une voyage aux montes d'Altaice en Sibérie, fait en 1781, St. Petersburg 1783. Patrin war Botaniker und Mineraloge, der außer dem Altaj auch noch andere Teile Sibiriens in den 1780er Jahren bereiste. WendLand, Peter Simon Pallas, S. 176f. und 199ff.

11 Hanno BECK (Hg.), Alexander von Humboldts Reise durchs Baltikum nach Russland und Sibirien 1829, Stuttgart u.a. 1983; Jörg STADELBAUER, Alexander von Humboldt und Russland, in: Dittmar DAHLMANN / Wilfried POTTHOFF (Hg.), Deutschland und Russland. Aspekte kultureller und wissenschaftlicher Beziehungen im 19. und frühen 20. Jahrhundert, Wiesbaden 2004, S. $29-58$.

12 Stefan FISCH, Forschungsreisen im 19. Jahrhundert, in: Peter J. BRENNER (Hg.), Der Reisebericht. Die Entwicklung einer Gattung in der deutschen Literatur, Frankfurt/M. 1989, S. 383-405, hier S. 390; Erik AMBURGER, Die Bedeutung der Universität Dorpat für Osteuropa. Untersucht an der Zusammensetzung des Lehrkörpers und der Studentenschaft in den Jahren 1802-1889, in: Gert von PISTOHLKORS u.a. (Hg.), Die Universitäten Dorpat / Tartu, Riga und Wilna / Vilnus 15791979. Beiträge zu ihrer Geschichte und ihrer Wirkung im Grenzbereich zwischen West und Ost, Köln / Wien 1987, S. 163-181, hier S. 164; Erich DONNERT, Die Universität Dorpat-Jur'ev 18021918. Ein Beitrag zur Geschichte des Hochschulwesens in den Ostseeprovinzen des Russischen Reiches, Frankfurt/M. u.a. 2007.
} 
lisch-Mathematischen Fakultät führte. Humboldt erhielt 1827 die Ehrendoktorwürde der Dorpater Universität, die er auf seiner Reise nach Russland auch besuchte, und war in den 1840er Jahren an zahlreichen Berufungen beteiligt ${ }^{13}$.

Vor allem sind es jedoch die sogenannten »Arbeitsenthusiasten«, Missionare und Regierungsbeamte, die als Pioniere der ethnologischen Untersuchungen der turksprachigen Ethnien Altajs gelten. Im Unterschied sowohl zu den Wissenschaftlern des 18. Jahrhunderts, welche den Altaj lediglich während einer Durchreise sahen, als auch zu den Forschern aus der ersten Hälfte des 19. Jahrhunderts, welche die ethnographische Forschungen neben ihren eigentlichen naturwissenschaftlichen Studien betrieben haben, basierten die ethnologischen Daten der Regierungsbeamten und Missionare auf ihren langjährigen Beobachtungen der Lebensumstände der Altajer. Jedoch erschienen ihre Arbeiten zerstreut und zumeist in Zeitschriften außerhalb der Zentren, weshalb sie der westeuropäischen Forschung ihrer Zeit unzugänglich blieben. So erschien 1840 eine bedeutende ethnologische Untersuchung ${ }^{14}$ des Bijsker Kreispolizeichefs und Hobbyethnologen Aleksandr Michajlovič Gorochov in der Zeitschrift des Ministeriums für Innere Angelegenheiten. Dieses Periodikum ist bis heute in keiner deutschen Bibliothek verzeichnet.

Die pelzreiche Tajgagegend am Fuße der altajschen Gebirgskette war über Jahrhunderte eine der wichtigsten Quellen für Tierfelle für verschiedene asiatische Herrscher. Im 13. Jahrhundert musste die Bevölkerung Dschingis-Chan Abgaben in Form von Pelzen leisten ${ }^{15}$. Der Name Altaj, der in den mongolischen und den Turksprachen »Gold« bedeutet, lieferte für lange Zeit den Anlass, in dieser Region außerordentliche Edelmetallvorkommen zu vermuten. Heute ist das Gebiet des Altaj auf vier Staaten aufgeteilt: Russland, die Mongolei, Kasachstan und China. Traditionell wird vom russischen, mongolischen und Gobi-Altaj gesprochen. Der in Kasachstan liegende Teil wird in russischen Publikationen als Erzaltaj (rudnyj Altaj) bezeichnet ${ }^{16}$. Die Bezeichnung »Altajer« ist eine geogra-

13 Stadelbauer, Alexander von Humboldt in Russland, in: Dahlmann / Potthoff (Hg.), Deutschland und Russland, S. 51ff.

14 Kratkoe ètnografičeskoe opisanie bijskich ili altajskich kalmykov, sostavlennoe iz zapisok byvšego zemskogo ispravnika Bijskogo uezda Tomskoj gubernii gr. Gorochova, in: Žurnal Ministerstva vnutrennich del, Nr. 11, St. Petersburg 1840, S. 201-228. Angabe aus Ajžan A. IRKITOVA / Tamara K. MAJČIKOVA, Issledovateli Gornogo Altaja (XVII-seredina XX v.). Biobibliografï̈ceskij spravočnik, Gorno-Altajsk 2003, S. 35. Allgemein zum Leben und Werk von Gorochov: Aleksej. D. SERGEEv, G. I. Gorochov - ètnografy altajcev, in: Izvestija Altjaskogo otdelenija Geografičeskogo obščestva SSSR, Vyp. 9 (1969), S. 108-121.

15 Vgl. POTAPOV, Očerki po istorii Altajcev, S. 166.

16 Vgl. Conradin A. Burga / Frank KLÖTZLI / Georg GrabHerR (Hg.), Gebirge der Erde. Landschaft, Klima, Pflanzenwelt, Stuttgart 2004, S. 144f. 
phische Sammelbezeichnung für ein Konglomerat turksprachiger Ethnien verschiedener Herkunft, die im Altajgebirge und den unmittelbar anschließenden Territorien leben. Sie gehören zu der autochthonen sibirischen Bevölkerung, die bis zum 18. Jahrhundert teils eigenständig, meist aber unter der Herrschaft westmongolischer und anderer Chane lebte ${ }^{17}$. Heute werden zwei kulturell eigenständige Gruppen unterschieden, die nach ihren Siedlungsgebieten als nördliche und südliche Gruppe bezeichnet werden. Bereits die russische Administration im 17. und 18. Jahrhundert differenzierte zwischen den Nord-Altajern als Bewohnern der nördlichen waldigen Gebiete und den Süd-Altajern als Bergbewohnern. Zu den Nord-Altajern zählen Tubalaren, Čelkanen, Kumanden und Šoren, deren Dialekte im allgemeinen zur ujgurischen Gruppe der Turksprachen gehören. Die Süd-Altajer setzen sich aus den eigentlichen Altajern (auch Altaj-kiži genannt), Telengiten, Telesen und Teleuten zusammen und werden wie die Kirgizen, Kasachen und Baškiren zur kipčakischen Gruppe der Turksprachen gezählt. Die Bezeichnung der Ethnien wurde in den meisten Fällen auf die Selbstbezeichnungen zurückgeführt. Jede der aufgezählten Ethnien besteht aus mehreren Sippen (Verwandtschaftsgruppen). Innerhalb einiger Sippen herrscht auch heute noch eine strenge Exogamie $^{18}$. Bei den nomadisierenden Süd-Altajern war die Zugehörigkeit zu einem Stamm/Ethnie vorrangig mit Ansprüchen auf bestimmte Weidegebiete verbunden ${ }^{19}$.

Die ethnische Verschiedenheit ist dadurch bedingt, dass die Süd-Altajer Wanderhirten und die Nord-Altajer Jäger und Sammler, teilweise sesshafte Jäger waren, die auch Feldbau mit Hacken betrieben haben. Beide Gruppen unterschieden sich sehr deutlich in ihren Bräuchen, der Kunst, der Ernährung, der Art der Behausung und ihrer Bekleidung sowie in ihrer Religion. Die Altajer sind Anhänger schamanistischer Naturreligionen, wobei die Viehzüchter des Südaltajs eine Himmelsgottreligion und die Nord-Altajer eine Erdgottreligion praktizieren. Der Schamane wird in den Turksprachen als kam bezeichnet ${ }^{20}$. Im Laufe des 19. Jahrhunderts wurde

17 Vgl. Rudolf A. MARK, Die Völker der ehemaligen Sowjetunion. Die Nationalitäten der GUS, Georgiens und der baltischen Staaten. Ein Lexikon, 2. neubearb. und erw. Aufl., Opladen 1992, S. 38; Omeljan PRITSAK, Das Altaitürkische, in: Jean DENY (Hg.), Philologiae Turcicae fundamenta, Bd. 1, Wiesbaden 1959, S. 569-580, hier S. 658f., 572f.; Narody Rossii. Ėnciklopedija, Moskau 1994, S. 82.

18 Vgl. Leonid P. POTAPOV, Ėtničeskij sostav i proischoždenie Altajcev. Istoriko-ètnografičeskij očerk, Leningrad 1969, S. $21 \mathrm{ff}$. Deutsche Bezeichnung nach MARK, Die Völker der ehemaligen Sowjetunion.

19 Vgl. V. A. Koceev (Hg.), Istočniki po istorii respubliki Altaj, Grono-Altajsk 1997, S. $55 \mathrm{ff}$.

20 Vgl. P. W. Schmidt, Der Ursprung der Gottesidee. Eine historisch-kritische und positive Studie, Bd. 9: Die asiatischen Hirtenvölker. Die primären Hirtenvölker der Alt-Türken, der Altaj- und der Abakan-Tataren, Freiburg u.a. 1949, S. 71-454, besonders S. 96f., 216-227. 
ein Teil der Altajer christianisiert. Die Süd-Altajer wurden im Russischen Reich zusammenfassend als »Kalmücken« bezeichnet, wahrscheinlich weil sie äußerlich den Westmongolen ähnlich sahen. Daneben aber wurden die anders aussehenden Nord-Altajer als »Tataren« bzw. černevye tatary benannt ${ }^{21}$. Die Bezeichnung »Tataren« ist inhaltlich sehr diffus und wurde im Russischen Reich ebenso wie in der europäischen Wissenschaft allgemein für turksprachige Ethnien oder Bevölkerungsgruppen verwendet ${ }^{22}$.

Trotz der umfangreichen Quellenbasis zur Erforschung Sibiriens sind epochenübergreifende Untersuchungen aus mentalitätsgeschichtlicher Sicht und in Bezug auf die Kulturbegegnungen noch sehr selten. Die deutschsprachige Sibirienforschung konzentriert sich vorrangig auf Fallstudien, die Untersuchung einzelner Expeditionen oder auf das Wirken bestimmter Wissenschaftler mit dem Schwerpunkt auf dem 18. Jahrhundert. Ansätze zu epochen- und autorenübergreifenden Untersuchungen zur Erforschung Sibiriens bieten fast ausschließlich die Aufsätze von Gert Robel ${ }^{23}$ und Dittmar Dahlmann ${ }^{24}$. Einen hervorragenden Streifzug durch die jahrhundertelange Erforschung Sibiriens bietet die Habilitations-

21 Vgl. Pritsak, Das Altaitürkische, S. 569; Potapov, Ėtničeskij sostav, S. 20; Ders. / M. G. LEVIN (Hg.), Narody Sibiri, Moskau / Leningrad 1956, S. 329.

22 Vgl. Henning BAuER / Andreas KAPPElER / Brigitte Roth (Hg.), Die Nationalitäten des Russischen Reiches in der Volkszählung von 1897, Bd. A: Quellenkritische Dokumentation und Datenhandbuch, Stuttgart 1991, S. 237; The Encyclopeaedia of Islam, New Edition, Bd. 10, Leiden 1998, S. 370f.

23 Gert RoBel, Der Wandel des deutschen Sibirienbildes im 18. Jahrhundert, in: CanadianAmerican Slavic Studies 14 (1980), S. 406-426; ders., Die Sibirienexpeditionen und das deutsche Russlandbild im 18. Jahrhundert. Bemerkungen zur Rezeption von Forschungsergebnissen, in: Erik Amburger / M. CieŚLA / L. SzIKLAY (Hg.), Wissenschaftspolitik in Mittel- und Osteuropa. Wissenschaftliche Gesellschaften, Akademien und Hochschulen im 18. und beginnenden 19. Jahrhundert, Essen 1987, S. 271-294; ders., Berichte über Russlandreisen, in: Mechthild KELLER (Hg.), Russen und Russland aus deutscher Sicht. Bd. 2: 18. Jahrhundert, Aufklärung, München 1987, S. 216-247; ders., Das ferne Reich des Nordens - Russlandsreisen, in: Hermann BAUSINGER / Klaus BEYRER / Gottfried KORFF (Hg.), Reisekultur. Von der Pilgerfahrt zum modernen Tourismus, München 1991, S. 249-255; ders., Deutsche Gelehrte und ihr Beitrag.

24 Dittmar DahlmanN, Von Kalmücken, Tataren und Itelmenen. Forschungsreisen in Sibirien im 18. Jahrhundert, in: Eva-Maria AUCH / Stig FöRSTER (Hg.), »Barbaren« und »Weiße Teufel«. Kulturkonflikte und Imperialismus in Asien vom 18. bis zum 20. Jahrhundert, Paderborn 1997, S. 19-44; ders., Die »fremden Völker« Alaskas und Sibiriens in deutschsprachigen Reisebeschreibungen des 18. und frühen 19. Jahrhunderts, in: Erich DONNERT (Hg.), Europa in der Frühen Neuzeit, Bd. 6, Köln u.a. 2002, S. 1011-1016; ders., Die Eroberung und Erforschung Sibiriens vom 16. bis zum Ende des 18. Jahrhunderts, in: Geschichte Russlands und der Sowjetunion, Kurseinheit 4, Fernuniversität Hagen, Hagen 1999, S. 1-115; ders., Gelehrte auf Reisen, in: Mathias BeER / Dittmar DAhLmann (Hg.), Über die trockene Grenze und über das offene Meer. Binneneuropäische und transatlantische Migrationen im 18. und 19. Jahrhundert, Essen 2004, S. 119-132; russ. Übersetzung: Učenye-putešestvenniki, in: Nemcy v Rossii. Tri veka naučnogo sotrudničestva, St. Petersburg 2003, S. 46-61. 
schrift von Peter P. Schweitzer, welche die Geschichte der sibirischen Ethnologie zum Thema hat ${ }^{25}$.

Auch in Russland liegen systematische Quellenuntersuchungen über Sibirien bereits einige Jahrzehnte zurück. Seitdem Aleksandr N. Pypin vor über einhundert Jahren eine epochenübergreifende Geschichte der ethnologischen Erforschung Sibiriens gewagt hatte, hat sich kein anderer russischer Wissenschaftler mehr dieser Aufgabe gestellt ${ }^{26}$. Allerdings werden in diesem Werk lediglich die historischen Hintergründe, biographische Angaben zu den einzelnen Forschern und kurze inhaltliche Skizzen ihrer Werke geboten. Ebenso unterbleibt in Sergej Tokarevs Standardwerk zur Geschichte der russischen »Ethnographie« die inhaltliche Auseinandersetzung mit den Werken ${ }^{27}$. Im 20. Jahrhundert tat sich auf diesem Gebiet Aleksandr I. Andreev besonders hervor ${ }^{28}$. Er gilt bis heute als der beste Kenner der historischen Quellen über Sibirien ${ }^{29}$. Daneben steht eine Arbeit, die ausländische Berichte über Sibirien vom 13. bis zum 17. Jahrhundert zum Gegenstand hat. Schon in seiner Einleitung bemängelt der Herausgeber M. P. Alekseev jedoch, dass die Nachrichten über die ansässige Bevölkerung »einfältig und oft wenig interessant" seien ${ }^{30}$. Eine systematische Erfassung von Quellen über Sibirien für das 18. Jahrhundert wurde von Ėrvin P. Zinner vorgenommen, der sein Werk als Fortsetzung von Andreevs Arbeiten versteht ${ }^{31}$. Der größte Teil der schriftlichen Zeugnisse bleibt jedoch bis heute immer noch ungenügend und vor allem auch ungleichmäßig erforscht, wobei zudem viele der existierenden Monographien längst eine Revision der Untersuchungsmethoden benötigen.

Schließlich ist die Geschichte und Eroberung der Altajregion in der deutschsprachigen Sibirienforschung nur marginal vertreten. Neben spärlichen Erwähnungen in den Gesamtdarstellungen der Geschichte Sibiriens lassen sich weder selbständige wissenschaftliche Publikationen noch Aufsätze in Sammelbänden oder in Zeitschriften zur Geschichte des

25 Peter P. Schweitzer, Siberia and Anthropology. National Traditions and Transnational Moments in the History of Research, Wien, Univ., Habil., 2001 [Maschinenschrift].

26 Aleksandr N. PYPIN, Istorija russkoj ètnografii, Bd. 4, St. Petersburg 1892, S. 177-452, vgl. dazu Demitri B. SHIMKIN, Siberian Ethnography. Historical Sketch and Evaluation, in: Arctic Anthropology 27 (1990), S. 36-51.

27 Sergej A. TOKAREV, Istorija russkoj ètnografii (dooktjabr'skij period), Moskau 1966.

28 A. I. ANDREEV, Očerki po istočnikovedeniju Sibiri, Bd. 1: XVII vek, 2. bericht. und erg. Aufl., Moskau 1960; Bd. 2: XVIII vek (pervaja polovina), Moskau 1965.

29 Vgl. N. Ochotina-Lind, A. I. Andreev i nesostojavšiesja »Beringiany«, in: dies. / Peter Ulf Möller (Hg.), Under Vitus Bering's Command. New Perspectives on the Russian Kamchatka Expeditions, Aarhus 2003, S. 179-222.

30 Michail P. AlekseEv, Sibir' v izvestijach zapadno-evropejskich putesestvennikov i pisatelej. Bd. 1: XIII - XVIII vv., Irkutsk 1932, S. LI.

31 Ėrvin P. ZINNER, Sibir' v izvestijach zapadnoevropejskich putešestvennikov i učenych XVIII veka, Irkutsk 1968; auch ders., Putešestvie dlinnoju v tri stoletija, Irkutsk 1973. 
Altaj nachweisen ${ }^{32}$. In der englischsprachigen Sibirienforschung werden bestimmte Ereignisse aus der Geschichte der Altajregion von David N. Collins $^{33}$ in einigen Aufsätzen behandelt, die jedoch in ihren Fußnoten überwiegend auf russische Publikationen verweisen. Knappe Angaben zur Altajregion finden sich noch in dem Werk von James Forsyth ${ }^{34}$. Grundsätzlich sind die Arbeiten russischer Historiker zu diesem Thema auch bis heute noch maßgebend. Hier öffnet sich ein weites Feld für umfangreiche und detaillierte Untersuchungen zum Thema der Geschichte und Erforschung des Altaj ${ }^{35}$.

Der Grund für den unzulänglichen Zustand der deutsch- und englischsprachigen Sibirienforschung ist vorrangig in den politischen Ereignissen des 20. Jahrhunderts zu suchen, denn seit den 1930er Jahren bis zum Zusammenbruch der Sowjetunion war der Zugang westeuropäischer Wissenschaftler zu den russischen Archiven sehr stark eingeschränkt. Daher blieb die Beschäftigung mit der Ethnologie der sibirischen Völker überwiegend den sowjetischen Wissenschaftlern vorbehalten. Erst seit den 1990er Jahren verbesserte sich zunehmend die Lage für die Forschung und den Austausch zwischen den Wissenschaftlern aus dem westeuropäisch-angelsächsischen Raum und aus der ehemaligen Sowjetunion. Besonders für die Ethnologen eröffnete sich nach der politischen Wende die Möglichkeit, Feldarbeit und Untersuchungen unmittelbar vor Ort zu betreiben, was bereits zu zahlrei-

32 Vgl. dazu und allgemein zur Geschichte Sibiriens: DAHLMANN, Die Eroberung und Erforschung Sibiriens; Andreas KAPPELER, Russland als Vielvölkerreich. Entstehung, Geschichte, Zerfall, München 2000; Bruce W. LinCOLN, Die Eroberung Sibiriens, München / Zürich 1994; Ludmila THOMAS, Geschichte Sibiriens. Von den Anfängen bis zur Gegenwart, Berlin(Ost) 1982.

33 David N. Collins, The Altai. Fortified Resource Frontier on the Marches of Tsarist Russia, in: Eva-Maria Stolberg (Hg.), The Siberian Saga. A History of Russian's Wild East, Frankfurt/M. u.a. 2005, S. 29-42; ders., Colonialism and Siberian Development. A Case-Study of the Orthodox Mission to the Altay, 1830-1913, in: Alan WoOD (Hg.), The Development of Siberia. People and Resources, New York 1989, S. 50-71; ders., The Role of the Orthodox Missionary in the Altai. Archimandrite Makarii and V. I. Verbitskii, in: Geoffrey HoskING (Hg.), Church, Nation and State in Russia and Ukraine, Basingstoke 1990, S. 96-107.

34 James Forsyth, A History of the Peoples of Siberia. Russia's North Asian Colony 15811990, Cambridge u.a. 1992. Ferner vgl. dazu Alan Wood (Hg.), The History of Siberia. From Russian Conquest to Revolution, London / New York 1991; ders. / R. A. FrENCH (Hg.), The Development of Siberia. Peoples and Resources, New York 1989.

35 Eine Auswahl: Jurij S. Bulygin, Bibliografija istorii Altaja (èpocha feodalizma), Barnaul 1986; Michail F. RozEN, Bibliografija Altaja: geografičeskie, geologičeskie i pročie issledovanija dosovetskogo perioda, Barnaul 1992; ders., Očerki ob issledovateljach i issledovanijach Altaja: XVII - načalo XX veka, Barnaul 1996; Aleksej D. SERGEEV / Nikolaj KAMBALOv, Pervootkryvateli i issledovateli Altaja, Barnaul 1968; M. L. BorCOVA (Hg.), Issledovateli Altajskogo kraja: XVIII - načalo XX veka. Biobibliografičeskij slovar', Barnaul 2000; IRKITOVA / MAJČIKOVA, Issledovateli Gornogo Altaja. Siehe allgemein zu Geschichte Sibiriens die Akademieausgabe A. P. OKLADNIKOV u.a. (Hg.), Istorija Sibiri. S drevnejšich vremen do našich dnej. V pjati tomach, Leningrad 1968/69. 
chen Dissertationen und Aufsätzen geführt hat ${ }^{36}$. Daraus ist die Arbeit von Gudrun Bucher besonders hervorzuheben. Sie stellt die Frage nach der Herausbildung der Ethnologie als eigenständige Wissenschaft neu und führt die Anfänge des Fachs auf die Arbeit der Akademie der Wissenschaften in St. Petersburg sowie vor allem auf das Wirken von Gerhard Friedrich Müller zurück ${ }^{37}$.

Die strenge staatliche Überwachung der Forschungen und des Austauschs in der Sowjetunion bedeutete ebenso für viele sowjetische Wissenschaftler eine massive Behinderung ihrer Arbeit. Die Inhalte und Theorien hatten sich den Veränderungen der politischen Konjunktur anzupassen ${ }^{38}$. Besonders nach dem Zweiten Weltkrieg galt es in Bezug auf die Expansion des Russischen Reiches nach Sibirien grundsätzlich von einer friedlichen und freiwilligen Eingliederung zu sprechen.

Auch die Begrifflichkeit musste dementsprechend modifiziert werden: Bezeichnungen wie »Eroberung « (zavoevanie) oder »Unterwerfung « (pokorenie) passten nicht in das Konzept ${ }^{39}$. Um eine eindeutige Charakterisierung der Aneignung Sibiriens zu umgehen, wurde in den 1960er Jahren von einigen sowjetischen Historikern der eher neutrale Begriff »Angliederung « (prisoedinenie) eingeführt, der bis heute noch in Gebrauch ist. Andrej Zuev beklagt für die postsowjetischen Untersuchungen das Fehlen jeglicher Methodik - also historischer Modelle und einer klar ausdifferenzierten Begrifflichkeit - bei der Behandlung der Frage nach der russischen Expansion im Allgemeinen, darunter auch in Sibirien ${ }^{40}$. Grundsätzlich sollte in der russischen und westlichen Forschung bei der Bewertung der Eroberung Sibiriens stärker auf die einzelnen Regionen eingegangen werden, denn der Raum Sibirien ist ein zu komplexes Geflecht aus unterschiedlichen ethnischen Gruppen, Lebensweisen, geographischen und politischen Gegebenheiten, um den Charakter der »Angliederung« dieses Raumes eindeutig bestimmen

36 Vgl. Patty Gray / Nikolai Vakhtin / Peter Schweitzer, Who Owns Siberian Ethnography? A Critical Assessment of a Re-Internationalized Field, in: Sibirica 3 (2003), S. 194-216, hier S. 213, Fn. 11, 12.

37 Gudrun BuCHER, 'Von Beschreibung der Sitten und Gebräuche der Völker'. Die Instruktionen Gerhard Friedrich Müllers und ihre Bedeutung für die Geschichte der Ethnologie und der Geschichtswissenschaft, Stuttgart 2002. Vgl. dazu auch Han F. VERMEULEN, Origins and Institutionalization of Ethnography and Ethnology in Europe and the USA 1771-1845, in: VERMEULEN, Han F. / Arturo Alvarez Roldan (Hg.), Fieldwork and footnotes. Studies in the history of European anthropology, London 1995, S. 39-59; ders., Early History of Ethnography, S. 99ff.

38 Vgl. dazu Svetlana ČERvonNAJA, Geschichtswissenschaft Russlands in den 1990er Jahren. Problematik, Methodologie, Ideologie, in: Osteuropa 6 (2001), S. 695-715.

39 Vgl. Dahlmann, Die Eroberung und Erforschung Sibiriens, S. 9.

40 Vgl. Andrej S. ZUEV, Charakter prisoedinenija Sibiri v novejšej otečestvennoj istoriografii, in: Evrazija: kul'turnoe nasledie drevnich civilizacij. Vyp. 1: Kul'turnyj kosmos Evrazii, Novosibirsk 1999, S. 124-136; auch ders., »Konkvistadory imperii«. Russkie zemleprochodcy na severovostoke Sibiri, in: Ab Imperio 4 (2001), S. 81-108. 
zu können. Dies stellt schon bei der Untersuchung der Altajregion ein schwieriges Unterfangen dar.

Die Präzisierung der Begrifflichkeit ist auch in Bezug auf die Bezeichnung von Nicht-Russen im Russischen Reich notwendig. Hier spiegelten sich besonders die Wahrnehmung und der Status der nichtrussischen Bevölkerung wider, die in administrativen Dokumenten und in der Forschungsliteratur der vorrevolutionären Zeit zum Ausdruck kommen. Andreas Kappeler beklagte vor einigen Jahren den Mangel an »umfangreicher Untersuchung solcher Schlüsselbegriffe wie imperija [Imperium; hier und im Folgenden Anm. E.M.], narod [Volk], narodnost [Volkstümlichkeit oder volksverbundener Patriotismus], nacija [Nation], inozemcy [Fremdländer], inovercy [Andersgläubige, Fremdgläubige] « ${ }^{41}$. Diese Liste kann beliebig fortgeführt werden, auch für die Bezeichnungen in der sowjetischen und postsowjetischen Ära, wie aborigeny (Aborigines), korennoe naselenie (ansässige Bevölkerung), tuzemcy (Diesländer), inorodcy (Fremdstämmige, Fremdgeborene). Vor allem der Begriff inorodcy ist sehr umstritten. In der Bol'šaja Sovetskaja Énciklopedija wird dieser Begriff in keiner der drei Auflagen erwähnt ${ }^{42}$.

Der »Russozentrismus«, der in dieser Begrifflichkeit zum Ausdruck kommt, war kennzeichnend für die offizielle Sichtweise der Sowjetunion auf die russische Expansion und kommt bei der Behandlung und Interpretation der Archivdokumente sowie bei der Darstellung der historischen Ereignisse in vielfältiger Weise zum Ausdruck. Seit der Stalinzeit wurden in ethnologischen Darstellungen fast ausschließlich die Bauern als Träger der »Segnungen der russischen Kultur« dargestellt. Die negativen Seiten der Begegnungen der sibirischen Völker mit den Rusen wurde auf das habgierige und gewaltsame Verhalten der zarischen Beamten zurückgeführt ${ }^{43}$.

Die einseitige Bewertung der historischen Ereignisse ist auch in neuere russische Publikationen eingeflossen. In einem Schulbuch von 1995 über die Geschichte der Altajregion gibt es zum Beispiel kein eigenes Kapitel zur Kultur und Lebensweise der indigenen Bevölkerung ${ }^{44}$. In einem Sammelband von 1998 zur Ethnologie der Altajregion findet sich ein Aufsatz, in dem bestimmte Eigenschaften der Mentalität der indigenen Bevölkerung

\footnotetext{
41 Andreas KAPPELER, »Rossija - mnogonacional'naja imperija«. Nekotorye razmyšlenija vosem' let spustja posle publikacii knigi, in: Ab Imperio 1 (2000), S. 9-22, hier S. 20. Vgl. zum »Imperium« jetzt Jürgen OsteRHAMmEL, Russland und der Vergleich zwischen Imperien. Einige Anknüpfungspunkte, in: Comparativ 18 (2008), H. 2, S. 11-26.

42 Bol'šaja sovetskaja ènciklopedija, 51 Bde., Moskau 1926-1945; 2. Aufl., 51 Bde., Moskau 1949-1960; 3. Aufl., 30 Bde., Moskau 1970-1978. Vgl. dazu auch unten, Anm. 93.

43 PotaPOV, Očerki po istorii Altajcev, S. 181f.

44 A. P. ANAŠKIN u.a. (Hg.), Istorija Altaja. Čast' I: S drevnejšich vremen do 1917 goda, Barnaul 1995.
} 
Südsibiriens wie Ehrlichkeit, Sparsamkeit und Edelmut auf den kulturellen Einfluss der Russen zurückgeführt werden ${ }^{45}$.

Die Ansicht vom absoluten Wertprimat einer »christlichen « und sesshaften Lebensweise wurzelt tief in der »europäischen « Geistesgeschichte ${ }^{46}$. Der herrschenden Elite, nicht nur im Russischen Reich, lieferte das Bild von einem »unterentwickelten, armseligen Wilden« eine ausgezeichnete Rechtfertigung für die koloniale Expansion. Das Verhältnis der herrschenden und gebildeten Schichten des Russischen Reiches zu seinen »inneren Fremden« weist viele Parallelen zu sozialen Spannungen im westlichen Europa auf. Ebenso benutzte die russische Elite den sibirischen Raum als Projektionsfläche für unterschiedliche gesellschaftspolitische Visionen. In mehreren Untersuchungen zeigte Mark Bassin den Wandel des Sibirienbildes in Bezug auf imperiale und nationale Ideologien der gebildeten und herrschenden Elite $^{47}$. Die Lebensweise der in Sibirien ansässigen Bevölkerung war unter anderem ein willkommenes Kontrastbeispiel, um die eigene Fortschrittlichkeit nach europäischen Maßstäben hervorzuheben und die eigene Sonderstellung als Vermittler zwischen »Europa« und »Asien« zu demonstrieren. Fallstudien von Dittmar Schorkowitz ${ }^{48}$, Yuri Slezkine ${ }^{49}$ und Jürgen Osterhammel $^{50}$ zeigen deutlich, dass die erste Hälfte des 19. Jahrhunderts eine epochale Übergangsphase in der Kontaktgeschichte mit der indigenen Bevölkerung Sibiriens darstellte.

Denn anfänglich war die offizielle Sichtweise Russlands hinsichtlich Sibiriens in erster Linie vom pragmatischen Interesse an regelmäßiger Tributabgabe und einer stabilen politischen Situation geprägt. In dieser Zeit war jasačnye ljudi (Tributpflichtige) die gängigste Bezeichnung für die sibirische Bevölkerung. Im 18. Jahrhundert reisten die ersten westeuropäischen

45 A. V. CIRKIN, Kul'turnoe vlijanie russkich na mental'nost' korennogo naselenija Južnoj Sibiri v XVIII-XIX vv., in: M. A. DEMIN / T. K. ŠČEgLOVA (Hg.), Ėtnografija Altaja i sopredel'nych territorij, Barnaul 1998.

46 Vgl. Dahlmann, Von Kalmücken, Tataren und Itelmenen.

47 Mark BASSIN, Imperialer Raum, nationaler Raum. Sibirien auf der kognitiven Landkarte Russlands im 19. Jahrhundert, in: Geschichte und Gesellschaft 28 (2002), S. 378-403; ders., Imperial Visions. Nationalist Imagination and Geographical Expansion in the Russian Far East, 1840-1865, Cambridge 1999. Ferner vgl. dazu auch Klaus HeLLER, Russland zwischen Tradition und Verwestlichung, in: Reinhard C. MeIER-WaLSER / Bernd Rill (Hg.), Russland. Kontinuität, Konflikt und Wandel, Grünwald 2002, S. 23-32; Carsten GOEHRKE, Das »andere« Russland: Zu Sibiriens Stellenwert in der russischen Geschichte, in: Berliner Jahrbuch für osteuropäische Geschichte 2 (1995), S. 123-150; I. V. ZELENEVA, Geopolitika i geostrategija Rossii, XVIII - pervaja polovina XIX veka, St. Petersburg 2005, S. $122 \mathrm{f}$.

48 Dittmar Schorkowitz, Staat und Nationalitäten in Russland. Der Integrationsprozess der Burjaten und Kalmücken, 1822-1925, Stuttgart 2001.

49 Yuri SlezkINE, Arctic Mirrors. Russia and the Small Peoples of the North, Ithaca / London 1994.

50 Jürgen Osterhammel, Die Entzauberung Asiens. Europa und die asiatischen Reiche im 18. Jahrhundert, München 1998. 
Wissenschaftler durch die Gebiete hinter dem Ural. Diese kamen bereits mit ihren Vorkenntnissen und bestimmten Erwartungen nach Sibirien. Abgesehen von vereinzelten Berichten über Russlandreisen konnten die westeuropäischen Gelehrten des ausgehenden 17. Jahrhunderts auf eine umfangreiche Reiseliteratur zurückgreifen.

Reisen und Reiseberichte haben in Westeuropa eine lange Tradition. Neben unbekannten Pflanzen und Tieren waren die Menschen, ihr Aussehen und ihre Bräuche eines der beliebtesten Beschreibungsobjekte. Seit der Entdeckung des amerikanischen Kontinents verbreitete sich in Westeuropa in den Berichten über die »Neue Welt« die Beschreibung der indigenen Bevölkerung neu entdeckter Landstriche, wobei diese ausschließlich als »Wilde« bezeichnet wurden. In den folgenden Jahrhunderten wurde diese Bezeichnung auf die indigenen Völkerschaften Afrikas, Ozeaniens und Australiens ausgeweitet. Im selben Zuge bildete sich nach »Hellenen« und »Barbaren«, »Christen« und »Heiden« das neue Gegensatzpaar der »Zivilisierten « und der »Wilden« heraus. Der »Wilde« wurde zum »Naturmenschen $\ll^{51}$. Daher ist mit hoher Wahrscheinlichkeit davon auszugehen, dass die Wissenschaftler mit der Erwartung in die nordasiatischen Gebiete gereist sind, dort auch $»$ Wilden $«$ zu begegnen ${ }^{52}$.

Nach der Emanzipation des wissenschaftlichen Denkens vom Primat der Theologie und dem damit verbundenen Aufschwung der Naturwissenschaften beschäftigte die Frage nach dem Wesen des Menschen die Denker der westeuropäischen Welt mit neuer Intensität. Neue Vergleichsebenen wurden von den Gesellschaftstheoretikern herangezogen. Neben der Antike und der chinesischen Kultur verwandelten sich für viele Gelehrte die ethnographischen Nachrichten aus den neu entdeckten Landstrichen über andere, der europäischen Kultur und Lebensweise so unterschiedliche Völker zunehmend in ein philosophisch-politisches Problem. Die Rezeption der Reiseberichte durch die daheim gebliebenen Theoretiker führte zu einer kritischen Besinnung, ob die europäischen Formen von Kultur, Staat und Ge-

51 Vgl. Karl-Heinz KoHL, Ethnologie - die Wissenschaft vom kulturell Fremden. Eine Einführung, 2. erw. Aufl., München 2000, S. 17ff.; Peter J. BRENNER, Die Erfahrung der Fremde. Zur Entwicklung einer Wahrnehmungsform in der Geschichte des Reiseberichts, in: ders. (Hg.), Der Reisebericht. Die Entwicklung einer Gattung in der deutschen Literatur, Frankfurt/M. 1989, S. 1449, hier S. 18ff.; Sergio MoraviA, Beobachtende Vernunft. Philosophie und Anthropologie in der Aufklärung, aus dem Italienischen von E. Piras, München 1973, S. 173f. Allgemein zum europäischen Asien-Bild im 18. Jahrhundert vgl. OSTERHAMMEL, Die Entzauberung Asiens.

52 Vgl. Dahlmann, Von Kalmücken, Tataren und Itelmenen, S. 26. M. O. Kosven betont jedoch, dass in ethnographischen Schriften der Zweiten Kamčatka-Expedition die indigene Bevölkerung nicht als »dikari« (dt. Wilde), sondern ausschließlich nur mit Begriffen wie »inozemcy« oder »inozemčeskie narody« bezeichnet wurde. Vgl. M. O. KosvEN, Ėtnografičeskie rezul'taty Velikoj Severnoj èkspedicii 1733-1743 gg., in: Sibirskij ètnografičeskij sbornik 3 (1961), S. 167212, hier S. 212. 
sellschaft tatsächlich die besten oder einzig möglichen seien. Vor diesem Hintergrund schwankte die Beschreibung und Bewertung der »Wilden« stark zwischen Idealisierung und Verachtung ${ }^{53}$. Dabei standen europäische Werte und Lebensweisen im Zentrum der Welterklärungsmodelle und waren der Maßstab der Bewertungen. Diese Sichtweise wird heute allgemein als »eurozentristisch « charakterisiert, wobei Osterhammel in diesem Punkt nachdrücklich zwischen einer »inklusiven« und einer »exklusiven Europazentrik « unterscheidet:

»Wer im 18. Jahrhundert von der weltgeschichtlichen Überlegenheit des modernen Europa überzeugt war [...], der mußte dies nicht zwangsläufig mit der Ablehnung und Abwertung anderer Zivilisationen verbinden. [...] Die Beschränkung des eigenen Horizonts auf die abendländische `Culturwelt` des weißen Mannes wurde das Markenzeichen erst des 19. Jahrhunderts « ${ }^{54}$.

Gmelin bringt in seinem Reisebericht eine deutlich bemitleidende Haltung gegenüber den sibirischen Ethnien zum Ausdruck:

»So wie nun hieraus zu sehen ist, daß diese Völker in der Großen Finsterniß ihres Verstandes leben; also kan man auch in allem ihrem übrigen Betragen ihren unglückseeligen Zustand erkennen; und meiner Meinung nach können wir, denen ein besseres bekannt ist, kein überführenderes Zeugniß von dem Guten, das uns Gott erweiset, haben, als wenn wir den Zustand solcher unglückseeliger Völker anschauen « ${ }^{55}$.

Sein vierbändiges Werk Johann Georg Gmelins Reise durch Sibirien, von dem Jahr 1733 bis 1743 erschien ungeachtet der russischen Regierungsanordnung über die strikte Geheimhaltung der Ergebnisse der Expedition um die Mitte des 18. Jahrhunderts in Göttingen, was großen Unmut bei der Petersburger Akademie auslöste. Denn seit 1727 stand Gmelin im russischen Dienst an der Akademie der Wissenschaften. Zuvor hatte er in seiner Heimatstadt Tübingen Naturwissenschaften und Medizin studiert. 1730 erhielt er an der Akademie die Stelle eines ordentlichen Professors der Che-

53 Vgl. Bucher, »Von Beschreibung...«, S. 195ff.; Jürgen OSTERHAMmEL, Distanzerfahrung. Darstellungsweisen des Fremden im 18. Jahrhundert, in: Hans-Joachim KöNIG / Wolfgang ReINHARD / Reinhard WENDT (Hg.), Der europäische Beobachter außereuropäischer Kulturen. Zur Problematik der Wirklichkeitswahrnehmung, Berlin 1989, S. 9-42; Wilhelm E. MüHLMANN, Geschichte der Anthropologie, 2. verb. und erw. Aufl., Frankfurt a. M. / Bonn 1968, S. 40ff.; KarlHeinz KoHL, Entzauberter Blick. Das Bild vom Guten Wilden und die Erfahrung der Zivilisation, Berlin 1981; MORAVIA, Beobachtende Vernunft, S. 120ff.; Handbuch der Europäischen Geschichte, Bd. 4: Europa im Zeitalter des Absolutismus und der Aufklärung, hg. von Fritz WaGNER, Stuttgart 1968, S. 136-141, 162f.; Wolfgang MARSCHALL, Verfremdung und autonome Konstitution. Zur Kategorie der Fremden im Denken des aufgeklärten Jahrhunderts, in: Meinhard SChusTer (Hg.), Die Begegnung mit dem Fremden. Wertungen und Wirkungen in Hochkulturen vom Altertum bis zur Gegenwart, Stuttgart / Leipzig 1996, S. 245-261.

54 OSterhammel, Die Entzauberung Asiens, S. 62.

55 Johann Georg Gmelins Reise durch Sibirien, von dem Jahr 1733 bis 1743, Vier Theile, Göttingen 1751/1752, hier 1, 1751, S. 286. 
mie und der Naturgeschichte. Nach seiner Rückkehr nach St. Petersburg ließ Gmelin sich - nicht ohne Probleme - in die Heimat beurlauben, kehrte jedoch, nachdem ihm die Professur für Botanik und Chemie in Tübingen übertragen worden war, nicht mehr zurück ${ }^{56}$.

Sein Werk erlangte besondere Bedeutung dadurch, dass es den ersten vollständigen Reisebericht über eine mehrjährige Forschungsreise im 18. Jahrhundert darstellt ${ }^{57}$. Der Reisebericht ist nicht thematisch, sondern chronologisch aufgebaut. Viel Raum lässt Gmelin der Beschreibung der indigenen Bevölkerung, ihrer Wohnungen und deren Einrichtung, der Bekleidung, den Essensgewohnheiten sowie ihren Bräuchen und stellt auch Vergleiche zwischen den Ethnien an. Gmelin beschreibt ferner seine Begegnungen mit den Teleuten und den »abnizischen« Tataren, die heute als Vorfahren der Šoren gelten. Die besondere Aufmerksamkeit Gmelins galt den Schamanen. In jeder von ihm besuchten Siedlung ließ er den $\mathrm{Kam}^{58} \mathrm{zu}$ sich rufen und bat ihn um eine Séance oder unterhielt sich einfach mit ihm. Seine beliebteste Frage war, wieso sich denn der Kam nicht zu Gott, sondern zum Teufel wende ${ }^{59}$.

Auf die »neue" sibirische Welt ließ sich Gmelin offensichtlich nicht unvoreingenommen ein. Bei all seinem Interesse und seiner Neugier für die Bräuche und die Lebensweise der sibirischen indigenen Bevölkerung bleiben seine Schilderungen nur der äußeren Form der Erscheinungen verhaftet. Dem inneren Sinn der von ihm beobachteten Abläufe forscht er nicht nach. Die Altajer fragt er nicht nach ihrer Herkunft oder nach dem Namen ihrer Götter. Seine abfällige Haltung kann exemplarisch an den Adjektiven gezeigt werden, welche Gmelin während seiner Reise im nördlichen Altajvorland bei der Beschreibung der dort lebenden Menschen und ihres Tuns verwendet. So empfindet er die teleutischen Frauen als »nicht schön«, die Wohnräume bei den »abnizischen Tataren« »etwas schweinischer « als bei den Teleuten, die Verstellungsweise des Gesichts und des Leibes des Kam während der Vorführung seines Rituals als »fürchterlich« und schließlich den Zustand »dieser Völker« als »unglückseelig ${ }^{60}$. An dieser Stelle sollte an die Feststellung von Gabriele Scheidegger erinnert werden, dass »die eigene kulturelle Prägung bewusst und vor allem unbewusst die Wahrnehmung einer fremden Wirk-

\footnotetext{
56 Vgl. Helmut Dolezal, Gmelin, Johann Georg, in: Neue Deutsche Biographie (im Folgenden NDB), Bd. 6, Berlin 1964, S. 479.

57 Vgl. Dahlmann, Einleitung, in: Johann Georg Gmelin, Expedition ins unbekannte Sibirien, hg., eingeleitet und erläutert von Dittmar DAHLMANN, Sigmaringen 1999, S. 7-84, hier S. 59ff.

58 Bezeichnung der Schamanen in den Turksprachen.

59 Gudrun BUCHER, Wahrnehmung und Beschreibung des Schamanismus durch Gelehrte des 18. Jahrhunderts, in: Periplus. Jahrbuch für Außereuropäische Geschichte 17 (2007), S. 104-134.

60 Gmelins Reise durch Sibirien, S. 276-286.
} 
lichkeit ganz wesentlich beeinflusst« und dass »die Maßstäbe der eigenen Kultur « sich nicht »ablegen « lassen ${ }^{61}$. Wichtige Impulse für diese Denkrichtung liefert die Reiseforschung bei der Untersuchung der ständig wiederkehrenden Thematik der Begegnung mit dem »Fremden« in der Reiseliteratur. Peter Brenner bringt die Wahrnehmungsform des Reisenden auf den Punkt, dass das $\gg$ Fremde als Relationsbegriff historisch, kulturell und individuell variabel aufgefasst werden muss ${ }^{62}$. Jürgen Osterhammel spricht in diesem Zusammenhang vom »Bild« des Fremden, welches jeder Reisende vor der unmittelbaren Begegnung mit dem »Objekt seiner Beobachtung « bereits im Kopf mitführt ${ }^{63}$.

Einen der wichtigsten Bezugspunkte stellte für den Pietisten Gmelin sicherlich sein christlicher Glaube dar, was besonders in seiner Haltung gegenüber den religiösen Vorstellungen der sibirischen Ethnien zum Ausdruck gebracht wird. In den Augen Gmelins, eines Wissenschaftlers des Aufklärungszeitalters, kam Europa als dem Hort des Christentums, einer »vernünftigen Religion« und einer höherwertigen Kultur ein absoluter Werteprimat $\mathrm{zu}^{64}$.

Neben der Religion war ebenso die Lebensform ein weit verbreitetes Abgrenzungskriterium. Bereits in der Antike wurde zwischen Sammlern, Jägern, Viehzüchtern und Ackerbauern unterschieden. Auch in der Aufklärung diente die Lebensform neben den physischen Merkmalen und der Sprache als Klassifikationskriterium für fremde Völker. Dominiert von französischen und schottischen soziokulturellen Theorien, wurde Fortschritt zum leitenden Prinzip der Entwicklungsgeschichte der Menschen erklärt. Die teleologisch-universalhistorischen Entwürfe der Spätaufklärung sahen in zeitgenössischen »wilden « Gesellschaften die Vorstufen der Gattungsgeschichte. Das Telos der Entwicklung wandelte sich unter dem Eindruck der »Triumphe« der Naturwissenschaft und der Technik und dem Vertrauen in die Kraft menschlicher Vernunft vom christlichen in ein zivilisatorisches um. Die »Vervollkommnung« des Menschen und seiner Fähigkeiten war in der zweiten Hälfte des 18. Jahrhunderts ein zentrales Anliegen des Ge-

\footnotetext{
61 Gabriele SCHEIDEgGer, Das Eigene im Bild vom Anderen. Quellenkritische Überlegungen zur russisch-abendländischen Begegnung im 16. und 17. Jahrhundert, in: Jahrbücher für Geschichte Osteuropas 37 (1987), S. 339-335, hier S. 340.

62 BRENNER, Der Reisebericht, S. $15 \mathrm{f}$.

63 OSTERHAMMEL, Distanzerfahrung, S. 9-42, hier S. 41.

64 Vgl. Dahlmann, Einleitung, S. 81. Ferner vgl. zu Gmelins Reisebericht: ders., Von Kalmücken, Tataren und Itelmenen; ders., Die »fremden Völker« Alaskas; ders., Johann Georg Gmelin and the Second Kamchatka Expedition, in: Peter U. MöLlER / Natascha Okhotina LIND (Hg.), Under Vitus Bering's Command. New Perspectives on the Russian Kamchatka Expeditions, Aarhus 2003, S. 113-128; RoBeL, Der Wandel; J. L. BLACK, J.-G. Gmelin and G.-F. Müller in Siberia, 1733-43. A Comparison of their Reports, in: Alan Wood / R. A. French (Hg.), The Development of Siberia. People and Resources, New York 1989, S. 35-49;
} 
schichtsdenkens und der gesellschaftlichen Bildungspolitik ${ }^{65}$. Im Lichte der neuen Fortschrittsidee wurden Stillstand und Zufriedenheit im Sinn einer Bedürfnislosigkeit zu Untugenden ${ }^{66}$.

Die Fortschrittsperspektive spiegelt sich deutlich in Georgis Beschreibung aller Nationen des Russischen Reichs, ihrer Lebensart, Religion, Gebräuche, Wohnungen, Kleidungen und übrigen Merkwürdigkeiten ${ }^{67}$ bei der Bewertung der Teleuten. Ebenso spricht Georgi in der Einleitung über »Stuffen von Rohen zu Feinen«, über »Graden des Übergangs« von »dem Stande der Natur nahe[n] Welt« zu »der heutigen feinen kenntniß- und bedürfnißreichen Welt $\iota^{68}$. Georgi wirft den Teleuten vor, dass ihre Antworten »immer so kurz, wie möglich « seien, und interpretiert das als Zeichen ihres »stumpfen Verstandes«. »Ihre Wünsche schränken sich auf Vieh, Korn, Kinder und faule Ruhe ein [...] « $\ll^{69}$. Der Gebrauch des Verbs »einschränken« impliziert die Annahme höherer Ansprüche. »Ruhe« wird kurzerhand als »faul« charakterisiert.

Georgi hatte zur Zeit seiner Berufung an die Petersburger Akademie bereits ein ausgedehntes Studium der Chemie, Pharmazie, Biologie und Mineralogie an den Universitäten von Stettin und Uppsala durchlaufen und unterhielt eine eigene Apotheke im heimatlichen Pommern. 1770 folgte er der Berufung nach St. Petersburg und wurde noch im selben Jahr Mitglied der Akademie-Expeditionen. Die Akademie-Expeditionen von 1768 bis 1774 wurden in drei Hauptgruppen unterteilt: in die Astronomische Expedition und zwei »physikalische « Expeditionen, die Orenburg- und die Astrachan'Expeditionen. Kein geringerer als Peter Simon Pallas war Leiter einer der drei Untergruppen der Orenburger Expedition. Während seiner sechsjährigen Reise, deren Route weit über das im Namen der Expedition erwähnte Gebiet hinausging, bereiste er zwischen Juli und November 1771 auch die Altajregion. Bei diesen Expeditionen stand ebenso die Entdeckung und Nutzung neuer Ressourcen Sibiriens im Vordergrund $^{70}$.

65 Vgl. Bucher, »Von Beschreibung ...«, S. 198f.; Werner Petermann, Die Geschichte der Ethnologie, Wuppertal 2004, S. 223ff.; Hans SCHLEIER, Kulturgeschichte der Völker als Evolution und Vervollkommnung des Menschen. Deutsche Kulturhistoriker Ende des 18. Jahrhunderts, in: Erich DONNERT (Hg.), Europa in der Frühen Neuzeit, Bd. 4, Weimar u.a. 1997, S. 619-642; KoHL, Entzauberter Blick, S. 129ff.; Emil ANGEHRN, Geschichtsphilosophie, Stuttgart u.a. 1991, S. 67ff.; Ulrich MUHLACK, Geschichtswissenschaft im Humanismus und in der Aufklärung. Die Vorgeschichte des Historismus, München 1991.

66 Vgl. Osterhammel, Die Entzauberung Asiens, S. 400.

67 St. Petersburg 1776.

68 GeORGI, Beschreibung aller Nationen, S. IIIf.

69 GeORGI, Beschreibung aller Nationen, S. 241

70 Vgl. Georgi, Beschreibung aller Nationen, S. 97-99; Kambalov / SERGEev, Pervootkryvateli, S. 20. Vgl. dazu Peter Simon Pallas, Reise durch verschiedene Provinzen des Russischen Reiches, Vorwort von Dietmar Henze, 3 Bde. und Tafelband, Graz 1967 [Photomech. Nachdr. der Ausg. St. Petersburg 1771-1776], hier Bd. 2, S. 580ff. 
Georgi bereiste zunächst unter der Leitung von Johann Peter Falck die kirgisische Steppe und Westsibirien, schließlich wechselte er im Jahre 1772 zu Pallas. Nach seiner Rückkehr nach St. Petersburg wurde Georgi 1776 zum Adjunkten für Chemie an der Akademie gewählt ${ }^{71}$. Ihm kommt das Verdienst zu, als erster eine zusammenfassende Beschreibung - eine Art Handbuch - aller im Russischen Reich lebenden »Nationen« verfasst zu haben. In seiner Beschreibung aller Nationen werden insgesamt 65 unterschiedliche ethnische Gruppen beschrieben. Das Buch wurde auf Deutsch in vier Teilen herausgegeben, wobei die ersten drei Teile zur gleichen Zeit auch auf Russisch und Französisch erschienen. Tokarev resümiert, dass sich damals »kein anderes Land der Welt« einer ähnlichen Arbeit rühmen konnte. Vielleicht hatte Georgi ein gutes Gespür für die Bedürfnisse des gelehrten und lesenden Publikums; seine Literaturverweise im Vorwort zeugen von einer guten Kenntnis des bis dahin in Russland gesammelten umfangreichen ethnographischen Materials. Auch Gmelins Reisebericht wird als Quelle aufgeführt.

Ebenso gingen Georgis eigene Beobachtungen, die er während der Reise mit der Akademie-Expedition gesammelt hatte, in seine Beschreibung aller Nationen ein, wobei er aber die Herkunft der Informationen in den jeweiligen Abhandlungen über ethnische Gruppen nicht gesondert kennzeichnet. Georgis Beschreibung aller Nationen darf nicht als eine individuelle Untersuchung aller dort beschriebenen ethnischen Gruppen gesehen werden, eher als ein Kompendium des damaligen Standes des ethnologischen Wissens ${ }^{72}$. Die im Werk enthaltenen Abhandlungen über einige altajsche Ethnien stellten zu dem Zeitpunkt die ersten systematischen ethnographischen Beschreibungen dar ${ }^{73}$.

In Übereinstimmung mit Gmelin und Georgi sprach auch Grigorij Ivanovič Spasskij Jahre später von der »Beschränktheit« der Wünsche der Teleuten, die sich seiner Meinung nach nur auf das Nötigste erstreckten. Spasskij wird in den Publikationen zu Forschungen im Altaj als bedeutender Historiker, Archäologe und Ethnograph charakterisiert ${ }^{74}$; jedoch kommt sein Name in der Sowjetischen Historischen Enzyklopädie ${ }^{75}$ (Sovetskaja istoričeskaja ėnciklopedija) nicht vor. Er hat nie eine Stelle an einer Lehr-

\footnotetext{
71 Vgl. Natascha AstrinA, Johann Gottlieb, Georgis Schriften über Russland, in: Dittmar DahlmanN (Hg.), Die Kenntnis Russlands im deutschsprachigen Raum im 18. Jahrhundert. Wissenschaft und Publizistik über das Russische Reich, Göttingen 2006, S. 179-200; Olaf HeIN, Georgi, Johann Gottlieb, in: NDB, Bd. 6, S. 242f.

72 Vgl. TOKAREV, Istorija russkoj ètnografii, S. 103ff.; SCHWEITZER, Siberia and Anthropology, S. 75.

73 Vgl. Potapov, Očerki po istorii Alajcev, S. 26.

74 Vgl. Kambalov / SergeEv, Pervootkryvateli, S. 42.

75 Vgl. Sovetskaja istoričeskaja énciklopedija, Bd. 13, Moskau 1971.
} 
oder Forschungsanstalt bekleidet, abgesehen von der Wahl zum korrespondierenden Mitglied der Petersburger Akademie im Jahre 1810. Geboren im Rjazan'er Gouvernement in der Familie eines Priesters, erwarb er seine Allgemeinbildung im Kolomensker geistlichen Seminar (Kolomenskaja duchovnaja seminarija). Ab 1803 arbeitete er erst in Tomsk, dann in Bijsk und Kuzneck im Bezirksgerichtshof (uezdnyj sud). Über acht Jahren verbrachte Spasskij in der Altajregion, bis er schließlich in das Kabinett ${ }^{76}$ nach St. Petersburg versetzt wurde.

Seine Arbeit erlaubte es ihm, viel in der Region zu reisen, wobei er die Gelegenheit nutzte, umfangreiche Daten zu Linguistik, Geographie und Geschichte zu sammeln. In St. Petersburg gab er von 1818 bis 1827 eine monatliche Zeitschrift Sibirskij vestnik heraus, die 1825 in Aziatskij vestnik umbenannt wurde. Neben seinen eigenen Abhandlungen wurden in der Zeitschrift Informationen aus alten Reisebeschreibungen zu Sibirien und den Nachbargebieten sowie Ergebnisse einiger aktueller sibirischer Expeditionen erstmalig publiziert ${ }^{77}$. Deshalb kommt Spasskij auch das Verdienst zu, die Kenntnisse über Sibirien einem breiteren Publikum nahe gebracht zu haben.

Seine ethnologischen Arbeiten wurden vorrangig im Auftrag höherer Beamter durchgeführt, denen daran gelegen war, die Kenntnisse über die schwach erforschte Region zu vermehren. Auch die Akademie der Wissenschaften legte Spasskij mehrere Fragen vor. Seine Abhandlungen über die Altajer basieren sehr stark auf eigenen Beobachtungen, denn seine Arbeit als Bezirksrichter ermöglichte ihm gute Einblicke in das alltägliche Leben und die Bräuche der Menschen. Außerdem erlaubte ihm seine berufliche Position, auch Archivmaterialien in die Untersuchungen einzubeziehen. Spasskij berichtet über die Herkunft, die Sitten und das Alltagsleben, die Religion und die Zeitrechnung. Seine Abhandlung Teleuty ili belye kalmyki ist klar strukturiert, wobei er sich stark an Georgi anlehnte und viele Angaben unter Erwähnung Georgis übernahm. Jedoch kritisierte er an einigen Stellen wiederum Georgis Ausführungen als nicht sachgetreu $^{78}$.

Spasskij beschrieb und bewertete die Teleuten ebenso deutlich aus der Fortschrittsperspektive, griff jedoch zu härteren Adjektiven. Die Teleuten werden als »faul, streitsüchtig, dickköpfig und gefühllos« und in Bezug auf

76 Gemeint ist die Verwaltung des Kronbesitzes, darunter der Altajschen Bergwerke (ehemals Kolyvano-Voskresensker Werke). Vgl. Erik AMBURGER, Geschichte der Behördenorganisation Russlands von Peter dem Großen bis 1917, Leiden 1966, S. 103, 241.

77 Vgl. G. V. NAUMOv, Russkie geografičeskie issledovanija Sibiri v XIX - načale XX v., Moskau 1965, S. 10f.; TOKAREV, Istorija russkoj ètnografii, S. 171; BorCOVA u.a. (Hg.), Issledovateli Altajskogo Kraja, S. 200f.

78 Vgl. Sergeev, G. I. Spasskij i A. M. Gorochov - ètnografy altajcev; PotAPOV, Očerki, S. 32. 
ihren Verstand als »einfältig und dumm « beschrieben ${ }^{79}$. Das Gefühl der Überlegenheit gegenüber den Teleuten schlug bei Spasskij in schiere Überheblichkeit um. Während Georgi den »stumpfen « Verstand der Teleuten auf ihre Ungeübtheit zurückführte, wurden die Teleuten bei Spasskij kurzerhand als »dumm« abgestempelt. Wahrscheinlich rührt Spasskijs Überheblichkeit nicht unwesentlich auch aus seiner Position als Beamter des Russischen Reiches her, als Repräsentant der Macht und eines Lebensstandards, dem die autochthone Bevölkerung Altajs zumindest in militärischer und technologischer Hinsicht eindeutig unterlegen war. Dieser Begründung der eigenen Vormachtstellung aus der militärischen Überlegenheit heraus wird sich später auch Čichačev in seinem Reisebericht bedienen.

Neben dem Stand der Technik kann sich der Zivilisationsbegriff nach der Definition von Norbert Elias auf sehr verschiedene Fakten beziehen: »auf die Art der Manieren, auf die Entwicklung der wissenschaftlichen Erkenntnis, auf religiöse Ideen und Gebräuche « ${ }^{80}$. Offensichtlich stellte die Zugehörigkeit zu einer monotheistischen Religion für Georgi das wichtigste »Zivilisierungsmerkmal« dar. In der Abhandlung über die Teleuten werden permanent Vergleiche zwischen den »heidnischen « und »muhamedanischen" Teleuten gezogen, wobei letztere zusammenfassend als die "gesittesten ${ }^{81}$ charakterisiert werden. Dennoch bleibt der christliche Glaube bzw. die russische Lebensform das Maß oder gegebenenfalls die Vergleichsebene:

»Gegenwärtig bauen sie freystehende Wohnungen, die heidnischen Teleuten den Barabinzischen ganz ähnlich, schlecht, klein und mit einer Vorhalle oder Schauer nämlich, die muhamedanischen aber die ihre heidnischen Brüder an Klugheit, Fleiß, Wohlstande und Vermögen weit übertreffen, den rußischen Dorfhäusern bis auf die, den Tataren eigene breite Banke und den Kammin gleich $\aleph^{82}$.

Allerdings erkennt Georgi den »unaufgeklärten Brüdern « ${ }^{83}$ durchaus ein Potential zur Entwicklung zu. In seiner Vorrede spricht er von Völkern, die »neben der herrschenden Nation in milderen Gegenden wohnen« und »sich durch Nachahmung immer mehr von ihren alten Sitten« entfernen, »die den christlichen Glauben annehmen« und sich somit allmählich zu »guten Landsleuten « entwickeln ${ }^{84}$.

Von einer verhältnismäßig toleranten Haltung hat sich auch Michail Michajlovič Speranskij bei der Entwicklung seines Statut über die Verwaltung

79 Vgl. Grigorij SPASSKIJ, Teleuty ili belye kalmyki, in: Sibirskij vestnik, 1821, Teil 13-14, S. 1-8 (7-14), hier bes. S. 5 (11).

80 Norbert EliAS, Über den Prozess der Zivilisation. Soziogenetische und psychogenetische Untersuchungen, Bd. 1, Frankfurt/M. 1976, S. 1.

81 GEORGI, Beschreibung aller Nationen, S. 246.

82 GeORGI, Beschreibung aller Nationen, S. 243.

83 GeORGI, Beschreibung aller Nationen, S. XII.

84 GEORGI, Beschreibung aller Nationen, S. IIf. 
der inorodcy ${ }^{85}$ leiten lassen. Das Statut und die im Jahre 1822 in Kraft getretene neue Verwaltungsordnung für Sibirien wurden im Wesentlichen von Speranskij entwickelt, der von 1819 bis 1821 den Posten des Generalgouverneurs Sibiriens innehatte. Er war ein Mann von herausragender Bildung und gehörte als bedeutender Staatsmann vor seinem Dienst in Sibirien zum engsten Kreis um Alexander I. Auch an die Aufgabe der Reformierung der Verhältnisse in Sibirien ist er sehr gründlich herangegangen. Speranskij hatte den sibirischen Verwaltungsbeamten aufgetragen, umfassende Daten über die aktuellen Lebensverhältnisse der autochthonen Bevölkerung Sibiriens zu sammeln. Tokarev spricht in diesem Zusammenhang von der »ersten systematischen Aufnahme des Gewohnheitsrechts der Völker Sibiriens und des Nordens«. Allerdings wurden diese Daten, nachdem Auszüge daraus bereits am Ende des 19. Jahrhunderts erschienen waren, erst während der Sowjetzeit vollständig herausgegeben ${ }^{86}$. Die bedeutendste Neuerung in rechtspolitischer Hinsicht war die Schaffung einer legalen Grundlage für den neuen Stand der inorodcy.

Für Speranskij waren Aufklärung und Bekehrung die einzig annehmbaren Methoden, um die autochthone Bevölkerung der nordasiatischen Gebiete des Russischen Reiches auf eine höhere Ebene der »Zivilisation« zu heben. Ein "guter Landsmann" sollte nach Speranskij ein sesshaftes Leben führen und ein Christ sein. Jene inorodcy, die diesen Anforderungen entsprachen, seien »von den Russländern durch keine gesonderte Bezeichnung $\mathrm{zu}$ unterscheiden $\aleph^{87}$. Ferner erklärte er den $»$ freiwilligen Wunsch « der inorodcy zur notwendigen Bedingung, um ihren rechtlichen Status zu ändern und sie in einen anderen Stand soslovie aufzunehmen ${ }^{88}$. Generell sollten die inovercy, also die Andersgläubigen oder jene, die keine orthodoxen Christen sind, »Glaubensfreiheit und Gottesdienst nach alter Sitte « genießen ${ }^{89}$.

Bei aller Toleranz waren es die Religionszugehörigkeit und die Lebensform, die als Hauptkriterien für die Bestimmung der rechtlichen Lage des Einzelnen zu Grunde gelegt wurden. Der Leitgedanke der russischen Nationalitätenpolitik war ein zivilisatorisches Programm, das im Statut über die Verwaltung der inorodcy zum ersten Mal eine offizielle Legitimation bekam.

85 Vgl. Polnoe Sobranie zakonov Rossijskoj imperii (im Folgenden PSZRI), Serie I: 1649-1825, Bd. 38, St. Petersburg 1930, Nr. 29.126, S. 394-417. Mehr zum Statut von 1822 sowie zu Speranskij bei Marc RAEFF, Siberia and the Reforms of 1822, Seattle 1956.

86 TOKAREV, Istorija russkoj ètnografii, S. 174.

87 PSZRI, Nr. 29.126, S. 395, § 12.

88 PSZRI, Nr. 29.126, S. 396, § 25.

89 PSZRI, Nr. 29.126, S. 397, § 53, S. 410, § 286. Vgl. SLEZKINE, Arctic Mirrors, S. 83ff.; SCHORKOwITZ, Staat und Nationalitäten in Russland, S. 173f. 
Juristisch gesehen wurde die unter der Bezeichnung inorodcy erfasste nicht-christliche indigene Bevölkerung Sibiriens hierarchisch unter die sesshaften Christen gestellt. Ferner wurden die »natürlichen « Bewohner der nordasiatischen Gebiete mit der Bezeichnung inorodcy wortwörtlich zu Fremden im eigenen Land erklärt. Außerdem ersetzte der nun offizielle Begriff inorodcy die bis dahin gängigen Bezeichnungen inozemcy, inovercy und jasačnye ljudi.

Der Begriff inorodec $^{90}$ tauchte am Anfang des 17. Jahrhunderts in schriftlichen Quellen auf ${ }^{91}$. Diese Benennung wurde noch im 18. Jahrhundert synonym zu inozemec oder inoplemennik (Andersstämmiger) für die Bezeichnung der Ausländer gebraucht ${ }^{92}$. Am Ende des 18. Jahrhunderts wurde dieser Begriff durch die von Katharina II. einberufene gesetzgebende Kommission in die Amtssprache eingeführt. Die ursprüngliche amtliche Bedeutung bezog sich lediglich auf die Bezeichnung ethnischer Gruppen Sibiriens. Bereits in der zweiten Hälfte des 19. Jahrhunderts jedoch definierte Vladimir Dal' in seinem Bedeutungswörterbuch der lebendigen großrussischen Sprache den inorodec als einen »Abkömmling aus einem anderen, fremden Volk « ${ }^{93}$.

Seit Peter I., der seine Vision, sein Herrschaftsgebiet nach »europäischem « Vorbild umzugestalten, unnachgiebig zu verwirklichen suchte, vollzog sich in der Herrschaftsideologie und in der Kultur der Elite eine deutliche und anhaltende Hinwendung zu Westeuropa. Eine der Konsequenzen dieser Entwicklung war die Verschiebung der geographischen Grenze zwischen Europa und Asien, die bis dahin am Fluss Don verlaufen war und nun von dem Geographen und Historiker Vasilij Tatiščev sowie von Peter Simon Pallas in das Uralgebirge verlegt wurde. Somit wurde das westlich des Ural gelegene Territorium zu Europa erklärt, darunter die ursprünglich russischen Gebiete. In einem Statut ließ Katharina II. nun offiziell verkünden, dass Russland eine europäische Macht und das russische Volk ebenso ein europäisches Volk sei ${ }^{94}$.

\footnotetext{
90 Singular; $»$ inorodcy $«=$ Plural.

91 Slovar' russkogo jazyka XI-XVII vv., Bd. 6, Moskau 1976, S. 242.

92 Slovar' russkogo jazyka XVIII veka, Bd. 9, Leningrad 1997, S. 99.

93 Vladimir I. DAL', Tolkovyj slovar' živogo velikorusskago jazyka, St. Petersburg / Moskau 1880-1882, Bd. 2, S. 46. Ferner vgl. KAPPELER, Russland als Vielvölkerreich, S. 140f.; John W. SLOcum, Who, and When, Were the Inorodtsy? The Evolution of the Category of "Aliens" in Imperial Russia, in: The Russian Review 57 (1998), S. 173-190.

94 BASSIN, Imperialer Raum, nationaler Raum; HELleR, Russland zwischen Tradition und Verwestlichung; GoEHRKE, Das »andere« Russland; ZelENEVA, Geopolitika i geostrategija Rossii, S. 122f.; Trude MAURER, »Russland ist eine europäische Macht«. Herrschaftslegitimation im Zeitalter der Vernunft und der Palastrevolten, in: Jahrbücher für Geschichte Osteuropas 45 (1997), S. 577-596.
} 
Der »asiatische« Teil Russlands erhielt den Status einer kolonialen Peripherie, in der die Russen die Möglichkeit bekamen, als Zivilisationsträger aufzutreten. Somit konnte sich Russland als Kolonialmacht und kultureller »Erzieher« mit dem Westen vergleichen ${ }^{95}$. Wahrscheinlich wurde die von Georgi während der Regierungszeit Katharinas II. publizierte Beschreibung aller Nationen mit diesem Hintergedanken sogleich in mehreren Sprachen herausgegeben. Es galt, der westeuropäischen Elite den hohen Entwicklungsstand der russischen Kultur zu verdeutlichen, war doch Russland noch bis ins 18. Jahrhundert hinein in ihrem Urteil ein »seltsames« und nicht selten »barbarisches« Land ${ }^{96}$.

Ebenso wurde die Wissenschaft im Russischen Reich bis ins 19. Jahrhundert hinein von westeuropäischem Gedankengut bestimmt. Das wissenschaftliche Personal - die Akademiker und Professoren an den Universitäten und der Akademie - bestand zum größten Teil aus Ausländern, die meistens aus deutschen Ländern oder aus einem deutsch geprägten Umfeld kamen. Der erste bedeutende Bericht über die Altajer im 19. Jahrhundert wurde von dem deutschstämmigen Wissenschaftler Alexander von Bunge verfasst. Er entstammte einer adligen Familie und wurde in Kiev geboren, studierte Medizin in Dorpat und trat 1826 als Arzt in den Dienst der Kolyvano-Voskresensker Werke ${ }^{97}$. Nach der Empfehlung durch Carl Friedrich Ledebour wurde er neben Karl Anton Meyer als Gehilfe in die Expedition im Jahre $1826^{98}$ aufgenommen. Jeder reiste auf eigener Route und arbeitete selbständig, wobei Ledebour das ganze Unternehmen leitete ${ }^{99}$. Ledebour gehörte zusammen mit M. von Engelhardt und dem Astronomen W. Struve zu den wichtigsten Gesprächspartnern Alexander von Humboldts in Dorpat ${ }^{100}$.

\footnotetext{
95 BASSIN, Imperialer Raum, nationaler Raum, S. $391 \mathrm{ff}$.

96 Gabriele ScheIDEgGer, Perverses Abendland - barbarisches Russland. Begegnungen des 16. und 17. Jahrhunderts im Schatten kultureller Missverständnisse, Zürich 1993.

97 Im Jahre 1729 nahm der Unternehmer und Besitzer mehrerer metallverarbeitender Betriebe im Ural, Akinfij Nikitič Demidov, das erste Bleischmelzwerk im Altaj unter dem Namen KolyvanoVoskresenskij in Betrieb. Bald darauf wurden Kupferlager, Silber- und Polymetallvorkommen entdeckt. Nachdem die Nachrichten über die Entdeckung von Silbervorkommen im Altaj zu Kaiserin Elisabeth vorgedrungen waren, wurde Demidov im Jahre 1747 gezwungen, seine Werke in Kronbesitz zu übergeben. Vgl. Viktor T. MišČENKO u.a. (Hg.), Ėnciklopedija Altajskogo Kraja, Bd. 1, Barnaul 1996, S. 113f.

$98 \mathrm{Zu}$ der Expedition s. o.

99 Irkitova / MajČIKOVA, Issledovateli Gornogo Altaja, S. 22f.; KAMBAlov / SERGEev, Pervootkryvateli, S. 43ff.

100 Stadelbauer, Alexander von Humboldt und Russland, in: Dahlmann / Potthoff (Hg.), Deutschland und Russland, S. 52. Nicht nur unter diesem Gesichtspunkt wäre es ein lohnendes Forschungsprojekt, die Bedeutung der Universität Dorpat für die russische Wissenschaftsgeschichte herauszuarbeiten. Hinweise dazu ebd., S. 53f.
} 
Bunges Reisetagebuch erschien im zweiten Band der Aufzeichnungen Ledebours und enthielt neben botanischen und landeskundlichen Beschreibungen viele Informationen über die ansässige Bevölkerung. Er verbrachte sehr viel Zeit mit Gesprächen und Teezeremonien, interessierte sich für jedes Detail der Sitten und Gebräuche und gab Einblicke in die soziale Struktur der Altajer:

»Alles, was ich an ihnen bemerkte, war mir neu und interessierte mich um so mehr, da der größte Theil meiner ${ }^{101}$ Reise durch Gegenden führen sollte, die von diesem Volke bewohnt waren, mit dem ich mich genau bekannt machen wollte «102.

Damit fasst Bunge den Stand der Forschung über die Süd-Altajer präzise zusammen. Trotz großangelegter Expeditionen im 18. Jahrhundert existierten noch erhebliche »weiße Flecken « auf der Karte des Russischen Reiches, über die es nur verstreute Informationen gab. Allein die Tatsache, dass Bunge die indigene Bevölkerung des Bergaltaj als kalmyki bezeichnet, zeugt von mangelnder Kenntnis über die südaltajschen Ethnien. Trotz umfassender Vorbereitung auf die Reise durch die Lektüre von Pallas, Falck und Georgi blieb es Bunge verborgen, dass die Süd-Altajer turkprachig sind, so dass die Bezeichnung der Altajer als kalmyki, also Angehörige eines mongolischen Stammes, falsch ist. Die Teilnahme an dieser Expedition war ein Sprungbrett für Bunges wissenschaftliche Karriere. Es folgten weitere Expeditionen im Auftrag der Akademie der Wissenschaften. Seine Sammlungen wurden in einem Ergänzungsband der Flora Altaica verarbeitet; später arbeitete er als Professor für Botanik und Direktor des Botanischen Gartens an der Universität Dorpat ${ }^{103}$.

Bei seinen Ausführungen bilden eindeutig die »europäischen« Maßstäbe seine Bezugsgröße, zum Beispiel wenn es um die Schönheit der »kalmückischen« Frauen geht:

»Ihre ältere Tochter Erko, welche durch auffallend regelmäßige Gesichtszüge und die bei den Kalmücken höchst seltene Weiße der Haut selbst unter Europäerinnen den Namen einer Schönheit verdient hätte $[\ldots] \ll^{104}$.

Ebenso wie bereits Georgi und Spasskij kritisierte Bunge die Lebensweise der Süd-Altajer eindeutig aus der Fortschrittsperspektive heraus. Auch er betonte die »Bedürfnislosigkeit« des »kalmückischen« Lebens:

101 Vgl. PotaPOV, Očerki po istorii Altajcev, S. 9ff.

102 Alexander v. Bunge's Reise im östlichen Theil des Altaj-Gebirgs, in: Ledebour's Reise, Zweiter Theil, Berlin 1830, S. 3-170, hier S. 21.

103 Vgl. Ludwig StiedA, Bunge Alexander von, in: Allgemeine Deutsche Biographie, Bd. 47, Leipzig 1903, S. 363.

104 Bunge's Reise, S. 94. 
»Da das ganze Geschäft der Kalmücken, besonders im Sommer [...] nur darin besteht, die Heerden (Tabunen) zu besehen, weil die Frauen alle häusliche Arbeiten [...] verrichten, so bringen sie die meiste Zeit damit hin, von einer Jurte zur andern zu reiten, um zu zechen und zu schmausen $\aleph^{105}$.

Insgesamt reagiert Bunge jedoch deutlich aufgeschlossener auf die Altajer und ihre Bräuche, als es zum Beispiel bei Gmelin der Fall gewesen war, der sich in seinen Beschreibungen überwiegend unangenehm berührt oder gar entsetzt gezeigt hatte. So schrieb Bunge von der »geronnenen käsigen Milch«, dass man ihr den Wohlgeschmack nicht absprechen könne, während Gmelin den einheimischen Speisen gänzlich abgeneigt gewesen war ${ }^{106}$. Bei einer »Kalmückin« sah Bunge während einer Unterhaltung »recht viel Verstand hervorleuchten« und sie habe »sogar Witz« gezeigt ${ }^{107}$. Während Gmelin dem Kam Anordnungen erteilt hatte, etwas vorzuführen ${ }^{108}$, legte Bunge Wert auf freundschaftliche Beziehungen $\mathrm{zu}$ den Einheimischen, führte Geschenke mit und bemühte sich, sein Verhalten ihren Bräuchen anzupassen. So schildert er in seinem Bericht, wie er während einer Aufenthaltspause einen Zajsan ${ }^{109}$ und seine Mutter zu sich ins Zelt einlud: » [...] und bewirtete nun ihn und seine Mutter, so gut ich es hatte ${ }^{110}$. Wenn es jedoch um den Schamanismus der Altajer ging, stimmten die Meinungen der beiden Mediziner Gmelin und Bunge überein. Auch Bunge bezeichnete einen Kam kurzerhand als einen Zauberer und sein Werkzeug als »Zauberstückchen « ${ }^{111}$.

Einen anderen und in Bezug auf die Beschreibung der Altajer ebenso neuen Zugang wählte Gregor von Helmersen. Er studierte in seiner Geburtsstadt Dorpat Naturwissenschaften. Nach seinen Forschungen im Ural, im Altaj und in den russischen zentralasiatischen Gebieten wurde er zunächst zum Professor der Geologie am Berginstitut in St. Petersburg berufen, wo er später Direktor und ab 1850 ordentliches Mitglied der Akademie der Wissenschaften wurde ${ }^{112}$.

Seine Reise, die im Jahre 1834 stattfand, führte Helmersen in bereits bekannte Gegenden, jedoch stand diesmal die geologische Erforschung im Vordergrund. Dieses Unternehmen wird als die erste geologische Expedi-

\footnotetext{
105 Bunge's Reise, S. 47.

106 Bunge's Reise, S. 32f.

107 Bunge's Reise, S. 94.

108 Gmelins Reise durch Sibirien, S. 283.

109 Bezeichnung aus mongolischen Sprachen; deutsch: Fürst, Oberhaupt eines Stammes / einer Verwandtschaftsgruppe. Der Titel wurde meist weitervererbt.

110 Bunge's Reise, S. 95.

111 Bunge's Reise, S. 46f.

112 Vgl. GnuČEva (Hg.), Materialy dlja istorii èkspedicij Akademii Nauk, S. 175ff.; BorCova u.a. (Hg.), Issledovateli Altajskogo kraja, S. 53f.; IRIKITOVA / MAJČIKOVA, Issledovateli Gornogo Altaja, S. 31f.; Walther FISCHER, Helmersen, Gregor von, in: NDB, Bd. 8, Berlin 1969, S. 496f.
} 
tion in das Gebiet des Telecker Sees betrachtet, denn bis dahin existierten nur beiläufige Untersuchungen von Forschern, die sich immer nur auf der Durchreise in diesem Gebiet aufgehalten hatten ${ }^{113}$. Das Ergebnis dieses Unternehmens war der Bericht Reise nach dem Altai, der allerdings erst zwölf Jahre nach der Reise erschien. Davor hatte Helmersen aber eine kurze Abhandlung Der Telezkische See und die Teleuten im östlichen Altai herausgebracht, in der er alles, was ihm seiner Ansicht nach »neu und für die Kenntnis des Altai am wichtigsten erschien«, zusammenfasste. Dort beschrieb Helmersen die ansässige Bevölkerung, die Teleuten, denen er am Telecker See begegnet war. Neben seinen persönlichen Erlebnissen schilderte Helmersen die »Entdeckungsgeschichte dieses Sees und die Geschichte seiner Anwohner«, wobei er sich auf Informationen aus Gmelins Reisebericht und aus Schriften der Expedition von Ledebour bezieht. Mit den Teleuten sind eigentlich die Kumandiner gemeint ${ }^{114}$. Die Abhandlung wurde in St. Petersburg 1838 auf Deutsch und zwei Jahre später im Gornyj žurnal ${ }^{115}$ auch auf Russisch publiziert.

Hier ist die geographische Eingrenzung ausschlaggebend. Sich selber bezeichnet Helmersen als einen »Europäer $~^{116}$. Unter den »Asiaten « werden vermutlich neben den Altajern die Ethnien Zentral-, Ost- und Nordasiens verstanden ${ }^{117}$. Ferner werden bestimmte typisch »asiatische « Charaktereigenschaften als Wesensmerkmale der »Asiaten« und somit auch der Altajer beschrieben.

»Ich habe nun ziemlich oft beobachtet, daß bei den örtlichen Bewohnern, wie auch bei vielen asiatischen Völkern, die Habsucht charakteristisch ist, und daß das Lob für die Mäßigung ihrer Sinnesgelüste, die den vielen Asiaten zugeschrieben wird, auf diese nicht zutreffend ist $\ll^{118}$.

Während die bisher analysierten Autoren grundsätzlich davon ausgegangen sind, dass die Altajer sich auf einer unteren Entwicklungsstufe befanden und sich durch Aufklärung und vorbildhafte Nachbarn »bessern« könnten, zeigte sich in Helmersens Abhandlung eine deutlich andere Haltung. Dem

113 Vgl. Kambalov / Sergeev, Pervootkryvateli, S. 57; Naumov, Russkie geografičeskie issledovanija, S. $15 \mathrm{ff}$.

114 Vgl. PotaPOV, Očerki po istorii Altajcev, S. 31.

115 G. GeL'Mersen, Teleckoe ozero i Teleuty vostočnogo Altaja, in: Gornyj žurnal, St. Petersburg 1840, č. 1, Buch 1, S. 41-61, Buch 2, S. 239-261, Buch 3, S. 421-446.

116 Reise nach dem Altai, im Jahre 1834 ausgeführt von G. von Helmersen, in: Beiträge zur Kenntniss des Russischen Reisches und der angrändzenden Länder Asiens, hrgs. von K. G. v. BAER und Gr. v. Helmersen, Vierzehntes Bändchen, S. 51 [Neudr. der Ausg. 1848, Osnabrück 1969]

117 Vgl. Werner Conze, Rasse, in: Geschichtliche Grundbegriffe, Bd. 5, Stuttgart 1994, S. 135178 , hier S. $142 \mathrm{ff}$.

118 GEL'MERSEN, Teleckoe ozero i Teleuty vostočnogo Altaja, S. 44. 
Stereotyp »der Asiate« wird nun »der Europäer« gegenübergestellt. Als Stereotypen lassen sich grob schematische Bilder, die in generalisierender Weise einer Gruppe von Menschen bestimmte Eigenschaften zu- oder absprechen, definieren. Sie stellen eine der Folgen des Versuchs dar, die menschlichen Erscheinungs- und Lebensformen zu systematisieren ${ }^{119}$. Die geographische Grenze zwischen »Europa« und »Asien« wird hier gleichzeitig als eine Scheidelinie zwischen zwei Kulturen definiert.

Der geographische und auch kulturelle Unterschied zwischen Europa und Asien wurde auch zum wesentlichen Beschreibungsmerkmal des Reiseberichtes von Petr Aleksandrovič Čichačev. Er wird zu den berühmtesten russischen Reisenden gerechnet. Čichačev war adeliger Abstammung, studierte an der Petersburger Universität und besuchte die Diplomatenschule beim Kolleg für auswärtige Angelegenheiten (Kollegija inostrannych del). Erfolgreiche Forschungsexpeditionen in Frankreich und Italien brachten Čichačev auch in seinem Heimatland große Anerkennung. Nach einem Empfehlungsschreiben Humboldts an den Finanzminister bekam Čichačev die Erlaubnis und finanzielle Unterstützung für die Organisation einer Expedition in den Altaj, die vom März bis Dezember 1842 dauerte. Das Ziel der Expedition war ziemlich weit gefasst, im Vordergrund standen jedoch geologische und geographische Untersuchungen. Für weite Strecken seiner Reise existierten noch keine geographischen Aufzeichnungen, auf die Čichačev hätte zurückgreifen können, auch die Wegführer kannten die jeweilige Umgebung nicht immer genau ${ }^{120}$. Insofern war einer der bedeutendsten Beiträge Čichačevs die erste geologische sowie detaillierte geographische Karte des Altajs, in die die bisher gesammelten Daten von Gmelin, Pallas, Ledebour und Humboldt mit aufgenommen wurden. In Jahre 1845 erschien auf Französisch in Paris Čichačevs Werk über seine Reise Voyage Scientifique dans L'Altai Oriental. Erst zu Sowjetzeiten wurden einige Abschnitte seiner Arbeit auf Russisch publiziert ${ }^{121}$. Für diese Expedition bekam Čichačev von Nikolaj I. den Orden des Heiligen Vladimir vierten Grades.

Neben geographischen und landeskundlichen Aufzeichnungen widmete Čichačev auch der Ethnologie seine Aufmerksamkeit. In seinem Reisetagebuch, das in den ersten zwölf Abschnitten seines Buches untergebracht wurde, befinden sich Beschreibungen der ansässigen Bergbevölkerung, darunter einige Informationen zu einer der südaltajschen Ethnien, den Telengiten.

119 Vgl. Arnold Suppan, Einleitung. Identitäten und Stereotypen in multiethnischen europäischen Regionen, in: Valeria Heuberger u.a. (Hg.), Das Bild vom Anderen. Identitäten, Mentalitäten, Mythen und Stereotypen in multiethnischen europäischen Regionen, S. 9-20, hier S. 16.

120 Vgl. P. ČICHAČEV, Putešestvie v Vostočnyj Altaj, übers. aus dem Franz. und komm. v. V. Cybul'skij, Moskau 1974, S. 36.

121 ČICHAČEV, Putešestvie v Vostočnyj Altaj. 
Besonders deutlich kommt Čichačevs Einstellung im elften Kapitel seines Reiseberichts zum Ausdruck. Dort beschreibt er, wie er mit seiner Begleitung, darunter auch Altajern, die er als moi gorcy (meine Hinterwäldler oder meine Bergbewohner) bezeichnet, Rast in einem Kosakendorf machte:

»Zum Beispiel haben wir ihnen ausführlich erklärt, daß Häuser genauso wie Jurten sind, aber aus Holz gebaut werden. Sie aber [Altajer, E.M.] haben angenommen, daß Fenster als Eingang benutzt werden, und fingen an durch diese in das Haus zu klettern, wobei sie mit viel Krach in die Zimmer hineinfielen. Natürlich haben die Altajer es sich nicht nehmen lassen, zu bemerken, daß man in ihre Jurten viel einfacher hineingelangen könne. Die Besichtigung von Sachen, die sich im Zimmer befanden, rief bei ihnen große Verwunderung hervor. Für sie existierte kein Unterschied zwischen einem Tisch und einem Stuhl und sie nahmen mal auf dem Tisch mal auf dem Stuhl Platz. Ein Ofen erschien ihnen als eine vollkommen unglaubliche Anfertigung. Getrieben von dem Wunsch, diesen gründlich zu untersuchen, haben sie ihre Köpfe in den Ofen gesteckt und kamen mit von Ruß und Asche beschmutzten Gesichtern da heraus, was immer lautes Gelächter hervorrief « ${ }^{122}$.

Häuser und Betten bezeichnete Čichačev mit Wohlwollen als »europäischen Komfort" und freute sich, als er endlich unter einem Dach übernachten konnte. Die »europäischen« Gegenstände wie Tische und Stühle wurden von Čichačev und seinen Begleitern als selbstverständlich wahrgenommen und stellten Beweise für die Fortschrittlichkeit ihrer Lebensweise dar. Die Altajer wurden durch ihr »unangebrachtes« Verhalten und »falsches« Benutzen von Gegenständen ein Objekt der Belustigung. Jedoch liegt Čichačevs Überlegenheitsgefühl anscheinend nicht nur in seinem Zugehörigkeitsgefühl zur »europäischen Zivilisation«, sondern auch in der militärischen Überlegenheit seines Staates gegenüber den Altajern. Bei der ersten Erwähnung der Altajer schrieb er, dass diese sich in ein »friedliches und harmloses Volk « verwandelt hätten ${ }^{123}$.

An der Schwelle zur zweiten Hälfte des 19. Jahrhunderts setzte sich, durch wissenschaftlichen und militärischen Fortschritt beflügelt, der Gedanke vom ausschließlichen Werteprimat der »europäischen Zivilisation« durch, während dieser Gedanke in der russischen Öffentlichkeit kontroverse Reaktionen hervorrief. Beeinflusst von der Vorstellung, die »europäische" Kultur sei der Höhepunkt der moralischen und ästhetischen Entwicklung des Menschen, wurden im Auftrag ethnologischer Vereine und ethnographischer Museen Artefakte der »wilden « Völker gesammelt. Die ethnologischen Sammler des 19. Jahrhunderts verstanden sich selbst als »Retter« der Kunst, unterbrachen dabei jedoch gewaltsam die Tradition der Ethnien ${ }^{124}$.

122 ČICHAČEV, Putešestvie v Vostočnyj Altaj, S. 204f. Als »gorcy« wurden vor allem die Bewohner des Kaukasus seit dem ausgehenden 18. Jahrhundert bezeichnet.

123 Vgl. ČICHAČEV, Putešestvie v Vostočnyj Altaj, S. 34. 
In der russischen Bildungsschicht verstärkte sich währenddessen unter dem Einfluss der politischen Ereignisse in Westeuropa die Kritik am petrinischen Projekt der »Verwestlichung « Russlands. Vor allem die Vertreter der nationalen Idee waren darum bemüht, die Einzigartigkeit der russischen Kultur über die westlichen Wertvorstellungen zu stellen. Ihr Ziel war nun zu beweisen, in welchen Aspekten sich Russland von der europäischen Zivilisation unterschied ${ }^{125}$. Die einschränkende Toleranz der russischen Nationalitätenpolitik wich allmählich dem erwachenden Nationalismus und Russozentrismus der gesellschaftlichen Vorstellungen.

Im internationalen Kontext radikalisierte sich der Gedanke von der Fortschrittlichkeit der »europäischen« Lebensweise zur Überzeugung von einem ausschließlichen Werteprimat Europas gegenüber dem Rest der Welt. Diese Entwicklung spiegelt sich auch in den Urteilen über die Altajer wider. Das Bild von den »Unglückseeligen« oder »unaufgeklärten Brüdern« wandelte sich zu dem eines "gierigen Asiaten«. Schließlich wurden die Ethnien Altajs als »harmlos« und lächerlich »unterentwickelt« präsentiert. Aus heutiger Sicht legten die Wissenschaftler in ihren schriftlichen Zeugnissen bloß dar, dass die Lebenswelt der altajschen Ethnien für sie unzugänglich und weitgehend unverständlich geblieben ist.

124 Vgl. Fritz Kramer, Verkehrte Welten. Zur imaginären Ethnographie des 19. Jahrhunderts, 2. Aufl., Frankfurt/M. 1981, S. 78.

125 Vgl. BAssin, Imperialer Raum, nationaler Raum, S. 388. Siehe allgemein zum russischen Nationalismus F. GOLCZEWSKI / G. PICKHAN, Russischer Nationalismus. Die russische Idee im 19. und 20. Jahrhundert. Darstellung und Texte, Göttingen 1998. 


\title{
Diana Ordubadi
}

\section{»Brennendes Eis, jeden Traum verscheuchende Stürme und merkwürdige Fremde...«}

\author{
Carl Heinrich Merck und sein Beitrag zur Erforschung des russischen \\ Nordens im Rahmen der Billings-Saryčev-Expedition 1785-1795
}

Mit der Gründung der Russischen Akademie der Wissenschaften im Jahre 1724 durch Peter I. und ihrer ein Jahr später - schon nach dem Tode des Kaisers - erfolgten Eröffnung setzte in Russland eine umfassende wissenschaftliche Erforschung der asiatischen Gebiete des Landes ein. Erste Expeditionen waren bereits zuvor auf Anordnung Peters nach Sibirien und in den Fernen Osten entsandt worden ${ }^{1}$. Da die Gründung der Akademie der Wissenschaften auf Konzepte von Leibniz und späterhin von Christian Wolff zurückging, darüber hinaus das Zarenreich über fast keinen eigenen wissenschaftlichen Nachwuchs verfügte, stammte der überwiegende Teil der Wissenschaftler, die seit dem Ende der 1710er Jahre im kaiserlichen Auftrag die sibirischen und fernöstlichen Regionen untersuchten, aus Westeuropa und vor allem aus dem deutschsprachigen Raum ${ }^{2}$. Rasch setzte sich in Russland die Erkenntnis durch, dass die schnellstmöglichen wissenschaftlichen Erfolge und dadurch auch der gesellschaftliche Fortschritt am besten durch eine Zusammenarbeit auf zwischenstaatlicher Ebene zu erreichen seien. Die russische Regierung bediente sich gerne der ausländischen Spezialisten, wenn diese sich durch herausragende Fähigkeiten auszeichneten und bereit waren, in russische Dienste überzutreten.

$\mathrm{Zu}$ den bedeutendsten Gelehrten, die in dieser Epoche eine feste Tradition der deutsch-russischen Wissenschaftsbeziehungen mitbegründeten und prägten, gehören unter anderem Daniel Messerschmidt, Johann Georg Gmelin, Georg Wilhelm Steller, Gerhard Friedrich Müller und Peter Simon Pallas. Am Ende des 18. Jahrhunderts wurde diese Reihe durch einen weite-

\footnotetext{
1 Vgl. dazu als ersten Überblick Dittmar DahlmanN, Einleitung, in: ders. (Hg.), Johann Georg Gmelin, Expedition ins unbekannte Sibirien, Sigmaringen 1999, S. 7-84.

2 Dittmar Dahlmann, Gelehrte auf Reisen, in: Mathias BeER / Dittmar Dahlmann (Hg.), Über die trockene Grenze und über das offene Meer. Binneneuropäische und transatlantische Migrationen im 18. und frühen 19. Jahrhundert, Essen 2004, S. 119-132; russ. Fassung: Učenyeputešestvenniki, in: Galina I. Smagina (Hg.), Nemcy v Rossii. Tri veka naučnogo sotrudničestva, St. Petersburg 2003, S. 46-61.
} 
ren begabten deutschstämmigen Forscher bereichert. Der hessische Arzt Carl Heinrich Merck, der im Auftrag der russischen Regierung Ostsibirien und Alaska erkundete, übermittelte mit seinem Nachlass ein authentisches und faszinierendes Zeugnis aus der Epoche, als das wissenschaftliche Interesse keine staatlichen Grenzen mehr kannte und die Erforschung der entfernten Ecken der Erde die europäischen Weltmodelle intensiv zu verändern begann.

1785 entsandte die russische Kaiserin Katharina II. eine geheime Expedition zur Erforschung Ostsibiriens und Alaskas. Ziel der Reise war es zum einen, an die akademischen Erfolge der Zweiten Kamčatka-Expedition $(1733-1743)^{3}$ von Vitus Bering anzuknüpfen und die Erforschung des nordöstlichen Teils Russlands fortzusetzen. Zum anderen aber diente die Expedition dem streng geheimen politischen Ziel, alle bis dahin noch nicht besetzten Territorien dieser Region, unter anderem die Aleutischen Inseln und das Küstengebiet Alaskas, zum russischen Interessengebiet zu erklären, was in der Retrospektive einer der Gründe dafür gewesen ist, dass diese nordostpazifische Expedition in der wissenschaftlichen Literatur nur wenig thematisiert wurde.

Wie jede andere russische Regierungsexpedition, wurde auch die nordostpazifische Reise mit der bestmöglichen Besatzung und Ausstattung versehen. Mit ihrer Vorbereitung beschäftigte sich das St. Petersburger Admiralitätskollegium. Die wissenschaftliche Betreuung der Seefahrt übernahm Peter Simon Pallas (1741-1811)5, ein zu dem Zeitpunkt europaweit bekannter und einflussreicher Akademiker unter der persönlichen Obhut der russischen Kaiserin.

Zum Chef der Expedition wurde der Engländer Joseph Billings (17611806) ${ }^{6}$ bestimmt, der bereits an Cooks Dritter Weltumseglung (1776-1780) als astronomischer Gehilfe teilgenommen hatte. Als einer der wichtigen Führungsoffiziere trat zudem der russische Leutnant Gavriil Andreevič

3 Vgl. dazu ausführlich Dittmar DaHLMANN, Einleitung, in: ders. (Hg.), Expedition ins unbekannte Sibirien, S. 26-59; Wieland HintzSche, Die große Nordische Expedition. Georg Wilhelm Steller (1709-1746): ein Lutheraner erforscht Sibirien und Alaska, Gotha 1996; Doris PosselT (Hg.), Die große Nordische Expedition von 1733 bis 1743: aus Berichten der Forschungsreisenden Johann Georg Gmelin und Georg Wilhelm Steller, München 1990.

4 Ukaz Ekateriny II Admiraltejstv-kollegii ot 8 avgusta 1785 g. ob organizacii Severo-vostočnoj i astronomičeskoj èkspedicii pod komandovaniem kapitan-lejtenanta I. I. Billingsa dlja issledovanija i otkrytija novych zemel' v Severnom Ledovitom i Tichom okeanach, in: St. Petersburger Marine-Archiv (RGAVMF), fond 179, opis' 1, d. 131, Bl. 8ff.

5 Vgl. Folkwart WendLAND, Peter Simon Pallas (1741-1811). Materialien zu einer Biographie, 2 Bde., Berlin / New York 1992.

6 Vgl. zu Billings G. A. SARYČEv, Putešestvie po severo-vostočnoj časti Sibiri, Ledovitomu morju i Vostočnomu okeanu. Pod redakciej i so vstupitel'noj stat'ej N.N. Zubova, Moskau 1952, S. 297; deutsche Fassung: G. A. SARYTSCHEW, Reise durch den Nordostteil Sibiriens, das Eismeer und den Östlichen Ozean, Gotha 1954, S. 327. 
Saryčev (1763-1831) hervor. Schließlich, mehr oder weniger per Zufall, schloss sich außerdem Carl Heinrich Merck, ein deutscher Arzt in russischen Diensten, als Naturforscher der Expedition an.

Carl Heinrich Merck wurde am 19. November 1761 in Darmstadt als erster Sohn des Arztes Dr. Franz Christian Merck geboren. In den Jahren 1780-1784 führte er die Familientradition fort und studierte Medizin an den Universitäten Gießen und Jena.

Unmittelbar nach seinem Studienabschluss wurde Merck von der Kaiserin Katharina II. über einen Vermittler nach Russland eingeladen. Was ihn dazu motivierte, sich in Russland dienstlich zu betätigen, ist unbekannt. Vermutlich war es aber sein Onkel väterlicherseits, Johann Heinrich Merck (1741-1791), ein renommierter Schriftsteller, begabter Hobby-Paläontologe und persönlicher Freund Goethes ${ }^{8}$, der den Neffen bei dem Gedanken der Beschäftigung im Russischen Reich unterstützte. 1773 konnte Johann Heinrich Merck persönlich das Russische Reich kennen lernen. Damals kam er in die russische Hauptstadt als Zahlmeister und Rechnungsführer an der Seite der Gräfin Karoline von Hessen-Darmstadt. Die Gräfin brachte ihre drei Töchter nach St. Petersburg, um sie dort als potenzielle Ehepartnerinnen für den russischen Großfürsten Paul vorzustellen. Die Wahl der kaiserlichen Familie fiel auf die siebzehnjährige Augustine-Wilhelmine von Hessen-Darmstadt, die nach ihrem Übertritt zum russisch-orthodoxen Glauben und der Vermählung mit dem künftigen Zaren Paul I. den Namen Natal'ja Alekseevna führte ${ }^{9}$. Während dieses Besuches am russischen Hofe studierte Johann Heinrich Merck verschiedene Kabinette der Akademie der Wissenschaften und sammelte dort viele positive Erfahrungen, vor allem im paläontologischen Bereich.

Aus dem Jahre 1785 liegt ein Brief von Johann Heinrich Merck vor, der seine aktive Teilnahme am Schicksal des Neffen belegt. Das Schreiben ist mit dem 2. April 1785 datiert und richtet sich an Johann Peter Brinckmann (1746-1785) ${ }^{10}$, den damaligen Medizinaldirektor des Herzogtums JülichBerg. Im Frühjahr 1785 nahm Brinckmann einen Ruf als Hofmedicus nach St. Petersburg an. J. H. Merck, der Brinckmann persönlich kannte, nutzte

\footnotetext{
7 Vgl. A. I. AleKSEEv, Gavriil Andreevič Saryčev, Moskau 1966.

8 Zu Johann Heinrich Merck vgl. Marie-Theres FEDERHOFER, »Moi simple amateur«: Johann Heinrich Merck und der wissenschaftliche Dilettantismus im 18. Jahrhundert, Hannover 2001; Fritz EBNER, Johann Heinrich Merck (1741-1791). Ein Leben für Freiheit und Toleranz, Darmstadt 1991; Walter SCHÜBLER, Johann Heinrich Merck 1741-1791. Biographie, Weimar 2001.

9 Alexander FISCHER, Paul I., in: Hans-Joachim TORKE (Hg.), Die russischen Zaren 1547-1917, München 1999, S. 263-273, S. 265.

10 Vgl. August HIRSCH (Hg.), Biographisches Lexikon der hervorragenden Ärzte aller Zeiten und Völker, Bd. 1, Berlin 1929, S. 700; Karl SuDHOFF, Johann Peter Brinckmann, ein niederrheinischer Arzt im 18. Jahrhundert, in: Beiträge zur Geschichte des Niederrheins 16 (1902), S. 240-295.
} 
die Gelegenheit, um die Protektion eines neuernannten Hofmedicus für Carl Heinrich zu erbitten.

»Diesesmal ist es nicht für mich, sondern für einen jungen Menschen, der wie ich hoffe, sich nie Ihrer Güte unwürdig machen wird. Es ist mein Neveu, ein Doktor Merck, der eben absolvirt hat, und den ich mit gutem Winde nach Norden absegeln lassen will« - schrieb Johann Heinrich Merck und betonte: »Ich werde ihm von allen Orten her Empfehlungen zu verschaffen suchen; auf Ihre gütige Verwendung im Nothfall würde ich mich indessen mehr zählen, als auf die Versprechungen aller Russen, die ich die Ehre habe zu kennen $\aleph^{11}$.

Brinckmanns Antwort auf diese Zeilen ist unbekannt. Der Brief muss jedoch Wirkung gezeigt haben, denn bereits im Mai 1785 durfte Carl Heinrich Merck Brinckmann von Hamburg zur See nach St. Petersburg begleiten, wo sie am 5. Juni eintrafen ${ }^{12}$.

Im Sommer 1785 unterzog sich Carl Heinrich Merck in St. Petersburg einem erneuten und damals für alle ausländischen Mediziner verpflichtenden Examen zur Bestätigung seiner ärztlichen Kompetenzen. Nach der erfolgreichen Anerkennung seiner Qualifikation reiste er dann einige Wochen später nach Irkutsk, um dort die Stelle eines Hospitalarztes anzutreten ${ }^{13}$.

Bereits etwa sechs Monate später, im Februar 1786, traf Joseph Billings zusammen mit seiner Mannschaft in Irkutsk an. Hier sollte sich der französische Botaniker Eugène-Melchior Louis Patrin der Expedition als Naturforscher anschließen. Aufgrund gesundheitlicher Probleme verweigerte er jedoch die Teilnahme an der Reise. An seine Stelle schlug der damalige Generalgouverneur von Irkutsk und Kolyvan' Ivan Varfolomeevič Jakobi die Kandidatur des Bergwerkbeamten Erik Gustavovič Laxmann vor. Die Wahl von Billings fiel jedoch auf Dr. Carl Heinrich Merck, den der Kapitän als einen dafür besonders geeigneten »Kenner der Naturwissenschaften und der Botanik $\ll^{14}$ bezeichnete.

Der Jahreslohn für Merck wurde für die Dauer der Expedition auf 800 Rubel bestimmt ${ }^{15}$. Wie alle anderen Expeditionsoffiziere erhielt er also im Laufe der Reise ein doppeltes Gehalt. Außerdem stand ihm nach sei-

\footnotetext{
11 Brief 735: An Johann Peter Brinckmann, in: Ulrike Leuschner (Hg.), Johann Heinrich Merck. Briefwechsel, Bd. 4, Göttingen 2007, S. 694f.

12 Ebd., S. 695.

13 J. BRONŠTEJN / N. ŠNAKENBURG, Zapiski doktora K. Merka - učastnika èkspedicii BillingsaSaryčeva v 1785-1792 gg., in: Sovetskaja Arktika (1941), Nr. 4, S. 76-88, S. 79; MERCK, Karl Heinrich (Christianov), in: Regensburger / vormals Münchener Amburger-Archiv »Personendatenbank zur Migration ins vorrevolutionäre Russland «, Akte Nr. 62511.

14 Zit. nach F. Herrmann, Karl Heinrich Merck, Kaiserlicher Russischer Hofrat, und seine Nachkommen, in: Mercksche Familienzeitschrift 12 (1931), S. 14-21, S. 16.

15 HerrmanN, Karl Heinrich Merck, Kaiserlicher Hofrat, S. 16.
} 
ner Rückkehr eine lebenslange Pension in Höhe eines einfachen Gehalts zu. Ferner wurden die Offiziere nach Erreichen bestimmter Stationen um jeweils einen Rang befördert. Als graduierter Mediziner wurde Merck anfangs in die achte Rangklasse (Kollegienassessor) eingestuft, die auf Grund der russischen Rangtabelle von 1721 einen erblichen Adelsstatus vermittelte. Bereits im Jahre 1787 erhielten alle Expeditionsteilnehmer den nächsthöheren Rang, was für Merck bedeutete, dass er nun zum Kaiserlichen Hofrat ernannt wurde ${ }^{16}$.

Vor dem Hintergrund all dieser Privilegien, die Merck als Expeditionsnaturforscher erfuhr, ist ein gehässiges Urteil über ihn seitens des abgewiesenen Naturforschers Laxmann nicht verwunderlich. In einem Brief aus Irkutsk vom 10. Mai 1786 bezeichnete Laxmann Merck als einen »zu nichts geeigneten Nichtstuer ${ }^{17}$, der sich nur $»$ durch seine Jugend und die Fähigkeit meisterlich Grog zu trinken $\aleph^{18}$, die Stelle innerhalb der Expedition erschlichen habe. Diese Bewertung steht jedoch im Widerspruch zu den Äußerungen anderer Zeitgenossen von Merck. Kapitän Saryčev zum Beispiel erwähnte in seinen Aufzeichnungen Mercks »eifervolle Bemühungen ${ }^{19}$. Der Expeditionsarzt Rohbeck nannte ihn einen Mann, der »mit seltenen Kenntnissen eine beinahe in Furchtsamkeit ausartende Bescheidenheit verband $\ll^{20}$.

Noch vor der Abreise aus Irkutsk erhielt Merck aus den Händen von Billings eine durch Pallas persönlich verfasste Instruktion, die strenge wissenschaftliche Belehrungen für den Naturforscher enthielt ${ }^{21}$. In zwölf Punkten regelte die Instruktion den Gegenstand und die Methoden der bevorstehenden Forschungen. So wurde Merck zur Führung eines ausführlichen Journals verpflichtet, in dem er nicht nur seine Aufzeichnungen über die Pflanzen- und Tierwelt festhalten sollte, sondern auch die meteorologischen, ethnographisch-linguistischen und topographischen Beobachtungen. Dar-

16 Ebd., S. 16.

17 Zit. nach Naum M. RASKIN / Ilarion I. ŠAFRANOVSKIJ, Erik Gustavovič Laksman: vydajuščijsja putešestvennik i naturalist 18 veka, Leningrad 1971, S. 141.

18 Ebd., S. 141.

19 G. A. SARYČEV, Putešestvie po severo-vostočnoj časti Sibiri, S. 27.

20 Zit. nach Arnold JACOBI, Der Forschungsreisende Carl Heinrich Merck und sein Tagebuch, in: Mercksche Familienzeitschrift 15 (1937), S. 46-51, S. 49.

21 Peter Simon Pallas, Instruction für Doctor Merck, der an Stelle des Assessors Patrin den Capitain Billings auf der Expedition als Naturforscher und Reisebeschreiber begleiten sollte, in: St. Petersburger Filiale des Archivs der Russischen Akademie der Wissenschaften (Archiv RAN), fond 37, opis' 1, Nr. 5. Eine Abschrift dieser Instruktion aus dem Jahr 1786 schenkte außerdem Georg Thomas Baron von Asch der Göttinger Akademie der Wissenschaften. Heute wird diese Abschrift im Archiv der Universitätsbibliothek zu Göttingen aufbewahrt (Cod. Ms. Asch 228). Abgedruckt wurde die Instruktion bereits bei WENDLAND, Peter Simon Pallas, S. 823-829; in russischer Übersetzung veröffentlicht bei Danara A. ŠIRINA, Peterburgskaja Akademija Nauk i Severo-Vostok 1725-1917, Novosibirsk 1994, S. 263-270. 
über hinaus wurde ihm auferlegt, die Krankheiten der Eingeborenen und indigene Heilverfahren aus ärztlicher Sicht zu notieren.

Nach der Regelung aller Formalitäten verließ Billings mit seiner Crew Mitte Mai 1786 Irkutsk und erreichte im Juli die Stadt Ochotsk. In den darauf folgenden Jahren führten die Reisenden eine Fülle von Forschungen in Ostsibirien und im Fernen Osten durch ${ }^{22}$. Die größte messbare Errungenschaft war schließlich die Konsolidierung der politischen Zarenherrschaft über die bereisten Territorien der Aleutischen Inselkette, der Südküste von Alaska sowie der Halbinsel Čukotka. Als erste Europäer schafften es nämlich die Expeditionsteilnehmer, in die inneren Landgebiete der Halbinsel Čukotka vorzudringen und darüber umfassende Beschreibungen niederzulegen. Außerdem sind der Expeditionsarbeit die ersten korrekten Karten der Küstengebiete des Nordpolarmeeres, des Ochotskischen und des Beringmeeres über Kamčatka und die Aleuten bis hin zum amerikanischen Kontinent zu verdanken. Darüber hinaus setzte die Expedition die Suche nach der Nordostpassage im kleinerem Rahmen fort, indem sie sogar einen doppelten Versuch unternahm, den Seeweg zwischen dem Ostsibirischen Meer und dem Pazifischen Ozean über die Beringstraße zu erkunden. Da diese Meeresfahrt jedoch wegen der undurchdringlichen Eisfelder unmöglich erschien, bemühte sich die Mannschaft, so wie es auch durch die Anweisung des Admiralitätskollegiums vorgesehen war $^{23}$, auf dem Landwege um die Erkundung der ostsibirischen Küste, aber auch der Flüsse und Gebirgsmassive. So erhielt die Akademie der Wissenschaften zahlreiche Klima-Studien sowie viele teilweise erstmalige ethnographische, zoologische und botanische Beschreibungen der gesamten bereisten Territorien.

Während der Fahrt erwies sich der Naturforscher Merck als besonders gewissenhaft und fleißig. Unter den schweren klimatischen Bedingungen des russischen Nordens bemühte er sich um die genaue Erkundung der sibirischen und fernöstlichen Flora und Fauna sowie um das Sammeln der entsprechenden Naturalien, welche er laut Pallas' Instruktion in Kisten verpackte und nach St. Petersburg verschickte. Alle wissenschaftlichen Beobachtungen hielt Merck präzise in seinem sogenannten sibirisch-amerikanischen Reisetagebuch ${ }^{24}$ fest. Außer den Beobachtungen der Pflanzen-

22 Zu dem Verlauf der Expedition vgl. Erich DONNERT, Die Billings-Saryčev-Expedition in den Nordostpazifik 1785-1793 und der Naturforscher Carl Heinrich Merck, in: Erich DONNERT (Hg.), Europa in der Frühen Neuzeit. Festschrift für Günter Mühlpfordt, Bd. 6: Mittel-, Nord- und Osteuropa, Weimar / Köln / Wien 2002, S. 1023-1036, S. 1026f.

23 Anweisung des staatlichen Admiralitätskollegiums für den Herrn Kapitänleutnant der Flotte Joseph Billings, Leiter der geographischen und astronomischen Expedition in die nordöstlichen Teile Russlands, in: G. A. SARYTSCHEW, Reise durch den Nordostteil Sibiriens, S. 300-324, S. 311,322 .

24 Carl Heinrich MercK, Sibirisch-Amerikanisches Reisetagebuch 1788 biß 1791, in: Firmenarchiv der Familie Merck, Darmstadt, Sign. MA A 80. 
und Tierwelt widmete er sich auch umfassend den geographischen, geologischen und meteorologischen Phänomenen. So finden sich im Merck'schen Tagebuch unter anderem erstmalige systematische Beschreibungen des Viljuj-Flußtals in Ostsibirien, Aufzeichnungen zum Vulkanismus und den Thermalquellen auf Kamčatka sowie mehrere Wetterbeobachtungen auf den Aleuten und auf den Inseln St. Matthäus und St. Laurenz im Norden des Beringmeeres. Detailliert und präzise, aber genauso umfassend beschrieb Merck alles, was er sah, entdeckte oder vorgeführt bekam, ganz gleich ob es um ein präpariertes Tier ging bzw. um die Maße seiner inneren Organe oder um die Aleuten, also deren Äußeres, Charakterzüge und Bräuche. Alles um Merck herum hatte für ihn einen besonderen Wert. Kein Gegenstand seiner Forschung wurde dem anderen unmittelbar untergeordnet oder vorgezogen, was manchmal die Lesbarkeit seines Tagebuches ziemlich erschwert. Ohne jeglichen stilistischen Übergang können auf seinen Seiten die Erläuterungen der aleutischen Bestattungsbräuche sowie deren Jagdrituale durch eine präzise Darstellung der lokal verbreiteten Tierarten abgelöst werden. Eine Fülle von spannenden wissenschaftlichen Beobachtungen fand ihren Niederschlag im Tagebuch des Naturforschers genauso spontan und unerwartet, wie diese neuen Eindrücke in das Leben von Merck selbst stürmten. Die Zeit zum Systematisieren seiner Notizen fand der Forscher kaum, was seinen Expeditionsnachlass zu einer unverfälschten historischen Quelle aus der Epoche der russischen Entdeckungsreisen macht.

Besonders interessant erscheinen aus der heutigen Sicht seine vielseitigen und teilweise erstmaligen Beschreibungen von Kultur und Lebensart der indigenen Ethnien der bereisten Region. Vor allem die Sitten der Kamčadalen und der aleutischen Eingeborenen rücken in den Vordergrund in seinem Tagebuch. Während seine Beschreibungen der indigenen Jagdart und einiger Alltagsbräuche auf Kamčatka eine schöne Vervollständigung der entsprechenden ethnologischen Daten aus dem frühen 18. Jahrhundert bieten, fallen die Aufzeichnungen zu den Aleuten von den Inseln Kadjak, Andrejanovskie und Unalaška besonders wertvoll aus. Merck bemühte sich um eine möglichst vorurteilsfreie und genaue Darstellung des Kulturkontaktes mit den Indigenen und verzichtete dabei völlig auf die eigene Auswertung des Beschriebenen. An manchen Stellen erscheint diese Befangenheit mehr als erstaunlich. So beschrieb er im Juni 1790 die Bestattungsbräuche der Aleuten auf Unalaška in folgender nüchterner Weise:

»Sie begraben die Leichen in ihren Kleidungen. Den männlichen legen sie ihre Kähne, Pfeile und Angeln etwas zerbrochen mit bei. Sie verscharrn die Leichen sitzend, wie, besonders ihre Weibsen, meist Tags durch sitzen: die Knie gebeugt, die Fersen dem Gesäß bei. So binden sie selbe den mit Riemen oder Tangschnüren zusammen in einen Sack oder Matte. Sie decken die Leiche mit einem Robbenfel, die auf gleichem liegt. Sie nehmen die Eingeweide aus und stopfen den Unterleib mit Heu aus, begra- 
ben selbige den nächst der Leiche in eine gleiche Grube. Zum Andenken hängt der Mann wohl die Leiche seines Weibs, die Eingeweide ausgenommen, mit Moos ausgestopft über seine Schlafstelle; eben so die Leichen kleiner Kinder biß die Mutter ein anderes gebiert. Doch fangen sie ihre Gebräuche schon zu vergessen an $\aleph^{25}$.

Ein solcher Umgang mit Verstorbenen konnte keinen gläubigen Christen des 18. Jahrhunderts unberührt lassen. Und trotzdem fügte Merck der Beschreibung keinen eigenen Kommentar hinzu. Anscheinend ist es ein Versuch gewesen, völlig sachlich und neutral zu bleiben, um den Grundregeln der Wissenschaft zu entsprechen. Merck fasste seine Notizen zu der Zeit $a b$, als sich gerade die Tendenz in der europäischen Reiseforschung entwickelte, die Naturvölker nicht mehr als einen Bestandteil der Tierwelt zu betrachten, sondern diese als Urformen der menschlichen Zivilisation anzuerkennen. Der Umgang mit fremden Kulturen erforderte von den europäischen Reisenden auf einmal die Einhaltung von moralischen Werten und Normen. Das »wilde« Objekt ihrer Betrachtung verwandelte sich plötzlich aus einem animalischen Wesen in einen Menschen, den es als solchen zu behandeln galt. Die Tatsache jedoch, dass sich die indigenen Ethnien in ihrer Lebensweise, ihren Verhaltensmustern und ihrer Weltvorstellung gravierend von der Kultur der Europäer unterschieden, verursachte eine aktive Suche nach möglichst effektiven Methoden des Kulturkontaktes und der gegenseitigen Verständigung. Als eine der Methoden zum wissenschaftlichen Erkenntnisgewinn, der Merck zweifellos streng folgte, etablierte sich die Form von Feldforschung, bei der die Person des Datensammlers - seine Einschätzungen und Gefühle - gar keine Rolle spielen und eine nüchterne detaillierte Darstellung des faktisch Erlebten nicht trüben durfte.

Andererseits ging Merck vermutlich davon aus, dass die beschriebenen Tatsachen - nicht nur in dem Fall der angeführten Passage, sondern in seinem ganzen Tagebuch - gut genug für sich selbst sprächen und keinerlei Kommentierungen bedürften. Zudem wäre es möglich, dass Mercks bereits erwähnte Bescheidenheit seine Art der Notizenführung beeinflusste. Immerhin hatte er vor der Reise ausdrücklich betont, kein Experte auf dem naturwissenschaftlichen und ethnographischen Gebiet zu sein ${ }^{26}$. Und wenn man berücksichtigt, mit welcher Genauigkeit er in seinen Briefen an Pallas bezüglich der einen oder anderen Formalität bei der Aufzeichnung seiner Forschungen nachfragte, liegt die Vermutung nah, dass Merck sich in manchen Fällen einfach nicht traute, eigene schriftliche Auswertungen vorzunehmen oder naheliegende Schlüsse aus dem Beobachteten zu ziehen.

25 Ebd., S. 50.

26 WeNDLAND, Pallas, S. 653. 
Die Tendenz zur Objektivierung der Darstellungsweise bleibt allgemein kennzeichnend für die Reiseberichte aus dem späten 18. Jahrhundert. Sie markiert einen entscheidenden wissenschaftsmethodischen Fortschritt im Bereich der Völkerbeschreibung. Dank Mercks teilnehmender Beobachtung stellen seine Aufzeichnungen über die indigenen Ethnien des Nordens bis heute eine wichtige historische Quelle für die kulturwissenschaftliche und ethnopsychologische Erforschung dieser Völker dar. Bei der Beschreibung der indigenen Folklore, Grabkultur oder Jagdbräuche lieferte der deutsche Arzt authentische und faszinierende Bilder. So kann sein Tagebuch zum Beispiel in die Tanz- und Festriten der Aleuten auf der Insel Unalaška detailliert einweihen:

»Bei ihren Tanzen erleuchten sie die Hütte den Seiten hin mit mereren Tranlampen auf Stützen. Jüngere Mansen sitzen auf Stroh Matten zusammen, jeder mit einer Handpaucke, (Einem zu anderthalb Zol breiden Reif mit einem Stiel dran ist eine Walfischblase übergespant; ihr Schlägel vorn mit Alken Daun), so wie ihre Mädchen ohne selbe. Zu erst tanzen die Mannsen, Knaben nackt. Ältere binden ihre Vogelparken die Quere um die Schamgegend. Sie hüpfen den, zu eintzlen sich abwechselnd, eine Handpaucke schlagend, mit beiden Füßen zu gleich, die Knie etwas vorn hin aufwarts, vor sich oder schraglich der Hütte hin und so zurück. Dabei schlagen die übrigen ihre Handpauken und singen nicht unangenehm dazu, so wie die Mädchen, die teils den Daumen unterm Kinn beigedruckt, mit den Fingern feinere Töne vortrillern. Den tanzen die Weibsen, gleichfals zu eintzlen, wenn's sein kan, in beßeren Parcken. Sie springen, die Füße sich beigedruckt, die Hütte hin und sich umdrehend wieder zurück, gerade aufwärts. Teils haben welche in jeder Hand eine aufgeblasene längliche Seelöwenblase, worin Steinchen oder Zähne, die sie die Quere den Lenden anhalten, als ein Beweiß daß ihre Männer im Jagen fertig, deßen Lob die übrigen besingen. Auch tanzen sie mit Masken. Sie sind von Holz « ${ }^{27}$.

Einige Passagen später wird der Leser mit den aleutischen Alltags- und Haushaltsabläufen vertraut gemacht:

»Wer einen Walfisch mit dem ersten Pfeil aufschießt hat das Recht, von selbem die Hauth von Zunge und Leber zu nehmen, wie den größten Teil der Gedärme, und von den Floßen. Auch einen Teil mer als die von den Rückensehnen, woraus sie ihre Gürtel, Stricke und Schnüre flechten. Ihre Arbeiten sind alle langsam, besonders ihr feines Nahwerk. An einem Regenhemd arbeitet ein Weibsen zwei Monathe, und an einer Strohmatte flechtet sie den ganzen Winter über « ${ }^{28}$.

Auch weitere Stellen im Text bestätigen die Annahme, dass Merck die »Wilden«, wie er die Bevölkerungsgruppen nannte, nicht nur oberflächlich beobachtete, sondern viel Zeit mit ihnen verbrachte, bei ihnen wohnte und auch um ihre Sprache bemüht war. Sein Tagebuch enthält mehrere Begriffe

27 C. H. MERCK, Sibirisch-Amerikanisches Reisetagebuch 1788 biß 1791, S. 46.

28 Ebd., S. 48. 
aus der aleutischen und jakutischen Sprache. Merck versuchte die innere Bedeutung der naturnahen Lebensweise der Aleuten zu begreifen und war offenbar von dem geheimen Expeditionsziel entfernt, sibirische Ethnien zu bekehren oder der russischen Herrschaft zu unterwerfen. Sie interessierten ihn in ihrer reinen Natürlichkeit, welche er zu erfassen suchte, ohne irgendetwas verändern zu wollen.

Ein großes Interesse zeigte Merck auch an der Religion und den religiösen Bräuchen der Indigenen. Die entsprechenden Passagen in den Aufzeichnungen ermöglichen trotz Mercks ganzer Objektivitätsbemühungen die Auseinandersetzung mit der Frage nach den mentalitätsgeschichtlichen Schwierigkeiten, welche die europäischen Forscher beim Kontakt mit indigenen Kulturen hatten. Im Juli 1790 schrieb Merck über die Bewohner der Insel Kadjak Folgendes auf:

»Von einer Gottheit, einem Wesen, dem so alles sein Dasein dankt, felt ihnen jede Vorstellung. Jeder Umschweif ihnen einen Begrif davon zu erwecken, diente zu nichts. Alles Forschen blieb fruchtlos. Auch keine Benennung wußten sie uns zu sagen. Und da wir ob deß Nahmens ihnen öfter zusezten, so machte ihre Antwort, »Er ist nicht, wie sol man ihn den nennen? « unsre lezte Hofnung dieses Zwecks nicht zu verfehlen, scheiternd. Was ein bößes Wesen anlangt, so sagen sie, daß ihre Schamanne Teufel (Fack) in ihrer Begeisterung sehen, und daß sie in der Erde wohnten ${ }^{29}$.

Die Entwicklung der Religion und das Gottesverständnis bei den Indigenen stellten für die europäischen Reiseforscher ein sensibles und wichtiges Thema dar. Oft wurden diese als Kriterium benutzt, um den Grad kultureller Entwicklung des jeweiligen Stammes zu beurteilen. Trotz der ganzen Offenheit dem Fremden gegenüber fällt auch Merck unbewusst auf seine christlich geprägten Weltmodelle zurück und kann zumindest seine Verwunderung über die fehlende Gottesvorstellung der Indigenen nicht verbergen. Es schien aus der europäischen Sicht sehr schwer begreiflich, dass eine Ethnie ein klares Bild vom Bösen haben kann und gleichzeitig nicht einmal eine verschwommene Ahnung vom Guten und Warmherzigen. Zumal der Weg der ablehnenden Verurteilung für Merck als einem aufgeklärten Wissenschafter - wie er sich zumindest wahrnehmen sollte - nicht in Frage kam, musste er sich, ähnlich wie viele andere seiner zeitgenössischen Kollegen, mit der Frage nach methodischen Ansätzen beschäftigen, um eine derartige Haltung der Eingeborenen zu reflektieren. In der modernen Ethnologie ist dieses Phänomen aus den Anfängen der Disziplin gut bekannt, als die Begegnung mit dem Fremden zum Anlass wurde, über die Formen des Kulturkontakts und über das eigene Kulturverständnis neu nachzudenken und zugleich mehr oder weniger wissenschaftliche Strategien zur Verarbei-

29 Ebd., S. 70. 
tung der neuen Erfahrung zu entwickeln ${ }^{30}$. Merck löste dieses Problem auf die bereits erwähnte Weise, indem er auf die Kommentare der indigenen Fremdartigkeit verzichtete und die Auswertung der geschilderten Fakten seinen Lesern überließ. Dadurch stellte er seine Notizen in eine ganze Reihe anderer Reisebeschreibungen seiner Zeit, deren Verfasser dazu neigten, die Eigenart fremder Ethnien zu betonen, um die Besonderheit der eigenen Kultur kritisch davon abzuheben, was in Bezug auf die sogenannten "primitiven« Völker oft eine Bestärkung des europäischen Überlegenheitsgefühls bedeutete $^{31}$. Wenn jedoch zum Beispiel Georg Forster ${ }^{32}$ vor der Vermittlung eines solchen Gefühls in seinen Reisebeschreibungen zumindest nicht zurückscheute ${ }^{33}$, so kann von einer derartigen Absicht bei Merck keine Rede sein. Seine ganze penible Tagebuchführung und seine intensive Bemühungen, die Lebensart der Indigenen zu durchdringen, zeugen vielmehr davon, dass die manchmal zwischen den Zeilen durchleuchtende Skepsis nur eine vorübergehende Emotion sei, die der tüchtige Forscher bei besonders ungewöhnlichen Erkenntnissen nicht sofort unterdrücken konnte. So stellt sein Tagebuch ein klassisches Zeugnis seiner Zeit dar, in dem das aufklärerische Interesse an fremden Kulturen zwischen dem Bedürfnis, bestehende kulturelle Identitäten durch Abgrenzung zu festigen, und dem Wunsch, das gegebene Selbst- und Weltverständnis durch exotische Erfahrung zu erweitern, balanciert ${ }^{34}$.

Als Billings 1791 das Kommando über das Schiff an Saryčev übergab und mit einer kleinen Mannschaftsgruppe an Land ging, um als einer der ersten Europäer die Halbinsel Čukotka zu untersuchen, folgte der neugierige Naturforscher Merck seinem Kapitän. Die Wissenschaftler schlossen sich einer Gruppe von Rentierčukčen an. Ihr Weg führte von der St. Laurenz-Bucht bis zu der Kolyma-Mündung. Während ihrer beschwerlichen Reise konnten Billings und seine Gefährten erstmalig Aufzeichnungen über die Sitten und Bräuche der Indigenen anfertigen. Merck hielt seine dortigen Beobachtungen wohl für so wichtig, dass er sie nicht in seinem allgemeinen Expeditionstagebuch aufschrieb, sondern ein neues eigenes Journal dafür anfing. Das entstandene Werk mit dem Titel Beschreibung der Tschuktschi.

\footnotetext{
30 Peter J. BRENNER, Der Reisebericht in der deutschen Literatur, Ein Forschungsüberblick als Vorstudie zu einer Gattungsgeschichte, Tübingen 1990, S. 243.

31 Reinhard HeINRITZ, »Andre fremde Welten«. Weltbeschreibungen im 18. und 19. Jahrhundert, Würzburg 1998, S. 16.

32 Georg FORSTER, Reise um die Welt. Mit einem biografischen Essay von Klaus Harpprecht, 5. Aufl., Frankfurt/Main 2008.

33 Hans Erich BöDEKER, Aufklärerische ethnologische Praxis: Johann Reinhold Forster und Georg Forster, in: ders. / Peter Hanns Reill / Jürgen Schlumbohm (Hg.), Wissenschaft als kulturelle Praxis 1750-1900, Göttingen 1999, S. 227-253, S. 235.

34 HeINRITZ, »Andre fremde Welten«, S. 17.
} 
Von ihren Gebräuchen und Lebensart ${ }^{35}$ gilt heute als das erste und ausführlichste Dokument des 18. Jahrhunderts zur Ethnographie dieses sibirischen Volkes. Es enthält wertvolle Details über die sozialen Strukturen der Čukčen, ihr Familienleben, religiöse Bräuche, Feste usw. Indem die Expeditionsgruppe Tag und Nacht mit den Indigenen verbrachte, mit ihnen reiste, speiste und übernachtete, bekam Merck sehr ausführliche Einblicke in den Lebensstil dieses Stammes, einschließlich intimer Einzelheiten:

»Männer, die sich miteinander verstehen und sich als Freunde anerkennen, wechseln auch ihre Frauen. Gewöhnlich suchen sie dazu die Einwilligung derselben, die, wahrscheinlich sich aus Artigkeit, dieses Gesuch selten abschlagen. Sind beide Theile darüber einverstanden, so wird dieser Weiberwechsel jedes Mal, so oft sie einander nahe kommen, (...), wiederholt « ${ }^{36}$.

Als Arzt notierte Merck zudem auch diverse Heilverfahren und äußerte sich zu dem Phänomen des Schamanismus:

»Die Rennthiertschuktschen haben, gegen das Einbringen der Krankheiten von Fremden, folgende sonderbare Gebräuche eingeführt, wie wir es selbst erfuhren. (...) Nachdem wir ans Land gestiegen waren, und unser Gepäck ausgeladen hatten, so stellten sich alle entgegen gekommenen Tschuktschen vor das Feuer und die Weiber warfen einzelne Stückchen von einer Masse, die sie aus Rennthierfett, Weidenblättern, (...) und Wallroßdärmen geknetet hatten, in die Flamme. Hierauf ging zuerst der Wirth und dann unser Befehlshaber zwischen den beiden Feuern durch, wobei sie mit den Händen eine Bewegung machten, als strichen sie sich etwas daran Haftendes ab. Endlich folgten auch wir, nebst der uns begleitenden Menge von Eingeborenen, unter gleichen Gebräuchen, nach $\ll^{37}$.

Auch architektonische Details, wie z.B. čukčische unterirdische Behausungen, weckten das Interesse von Merck und wurden von ihm als von einem Augenzeugen beschrieben, was um so wichtiger war, da die späteren Erforscher nur noch Ruinen und Überreste antrafen und auf eine nachträgliche Rekonstruktion angewiesen waren ${ }^{38}$.

Die Čukotka-Handschrift ist noch sachlicher verfasst als der Expeditionsbericht. Hier tritt die Person des Verfassers endgültig zurück. Die wenigen Passagen, die Merck als Menschen charakterisieren, finden sich nur im sibirisch-amerikanischen Tagebuch. Dieses enthält zwar keine Emotionen von Merck, keine persönlichen Gedanken, es sind nicht einmal Bemerkun-

\footnotetext{
35 Carl Heinrich MercK, Beschreibung der Tschuktschi. Von ihren Gebräuchen und Lebensart, in: Russische Nationalbibliothek, Handschriftenabteilung, fond F 4, Nr. 173.

36 C. H. MERCK, Nachrichten von den Sitten und Gebräuchen der Tschuktschen, gesammelt von

Dr. K. H. Merck auf seinen Reisen im nördlichen Asien, in: Journal für die neuesten Landund Seereisen 17 (1814), S. 45-71, S. 54.

37 Ebd., S. 56f.

38 Vgl. BRONŠTEJN / ŠNAKENBURG, Zapiski doktora K. Merka, S. 82ff.
} 
gen über seinen Gesundheitszustand während der ganzen Reise vorzufinden. Worauf Merck aber nicht verzichten konnte, waren Gebete. Der Wissenschaftler vertraute seinem Tagebuch die Appelle an den Allmächtigen im Fall einer großen Gefahr oder nach einem erfolgreichen Unternehmen an. Und genau diese erlauben wenigstens einen kurzen Einblick in die Gefühlswelt eines deutschen Arztes, der im Auftrag der russischen Kaiserin und der europäischen Wissenschaft in der Kälte Sibiriens und des Fernen Ostens sein Bestes gab. So schrieb er am 1. April 1790 nach einem riesigen Sturm, in dem er beinahe umgekommen war, folgende geradezu poetischen Worte der Dankbarkeit:

»Welch Gefahren sind Sterbliche nicht al unterworfen. Gottheit unter welchem Nahmen dich die Welten all auch anruffen, laß mich meine Knie zu dir beugen, laß mich mit der dankbarsten Rürung für deinen Schutz zu dir hin seufzen - du bist $\ll^{39}$ !

An einer anderen Stelle, die sich mit dem Oktober 1790 datieren lässt, findet sich ein noch flammenderer Ausruf:

»Daß nur der Mensch, wo Gefahren ihm drohen, - inniger zu Dir, o Gottheit fleht, vergieb dem schwachen Sterblichen, - laß meinen Geist voll Reue zu Dir hinseufzen, - nimm den Dank, aller Schöpfung Urheber und Erhalter, für deinen Schutz, womit Du uns bishero geführt. Könnte ich doch die Tage, die Du mir noch zu durchleben bestimmst, so ganz dem Dienst, dem Wohl der Menschheit weihn! Würdige mich mit deinem Beistand, und nie lass dieses Beeifern erlöschen, das jetzt mit voller Rührung meinen Busen stärkt $\ll^{40}$.

Diese Zeilen stützen die Vermutung, dass Merck ein Reiseforscher aus Überzeugung war, der seine Teilnahme an der Expedition und ihm gegenüber erwiesenes Vertrauen als eine große Ehre betrachtete und die Bedeutung seiner Arbeit hoch schätzte.

Nach Abschluss der Expedition ließ Merck sich in St. Petersburg nieder. Außer umfassenden neuen Wissenschaftserkenntnissen brachte er aus Sibirien auch seine russische Ehefrau Nadežda Gavrilovna, geborene $\mathrm{Kačka}^{41}$, mit. Der Mädchen- sowie der Vatersname seiner Frau lassen vermuten, dass Merck in die Familie von Gavriil Simonovič Kačka $(1739-1818)^{42}$, dem erfolgreichen Leiter der metallurgischen Werke von Kolyvan' und Voskresensk, eingeheiratet hat. Unter welchen Umständen

\footnotetext{
39 Carl Heinrich MERcK, Sibirisch-Amerikanisches Reisetagebuch 1788 biß 1791, S. 32.

40 Ebd., S. 95.

41 Merck, Karl Heinrich (Christianov), in: Amburger-Archiv, Akte Nr. 62511.

42 M. V. KRIČEVCEV, Kačka Gavriil Simonovič, in: M. O. AKIŠIN / A. V. REMNEV (Hg.), Vlast' v Sibiri: XVI - načalo XX v., S. 587-590; ders., P. A. Sojmonov i reforma upravlenija kabinetskim chozjajstvom v Sibiri v 1785-1786 gg., in: Problemy istorii mestnogo upravlenija Sibiri XVII-XX vekov. Vypusk II, Regional'naja naučnaja konferencija 18-19 dekabrja 1997 g. Tezisy dokladov, Novosibirsk 1997, S. 21-30.
} 
der deutsche Arzt der Familie Kačka vorgestellt werden konnte, ist unbekannt. Naheliegend ist die Vermutung, dass die Bekanntschaft über den Irkutsker Gouverneur I. V. Jakobi zustandekam. Als ein aus St. Petersburg nach Irkutsk geschickter Arzt war Merck 1786 verpflichtet, sich nach seiner Ankunft dem Gouverneur vorzustellen. Höchstwahrscheinlich wurde er kurz danach in die höheren Schichten der lokalen Gesellschaft eingeführt. Dass er in Irkutsk auf Gavriil Kačka traf, der mit Gouverneur Jakobi eng zusammenarbeitete, erscheint realistisch. Es bleibt aber ungeklärt, ob die Ehe mit Nadežda Kačka (1767-1846) bereits während oder erst nach Beendigung der Nordostpazifischen Expedition geschlossen wurde ${ }^{43}$. Es steht aber fest, dass Merck erst in St. Petersburg zum ersten Mal Vater wurde. Der jungen Familie wurden zwei Kinder geboren - die Tochter Sophie (1797-1872) ${ }^{44}$ und der Sohn Friedrich Karl Wolfgang (1799-1857) ${ }^{45}$.

Mercks Kontakt zu den deutschen Familienangehörigen soll während der Expeditionsjahre sehr unregelmäßig verlaufen sein, was unter Berücksichtigung der Entfernung von mehreren tausend Kilometern und des Geheimstatus des Unternehmens nicht verwunderlich ist. Das einzige Dokument, das in diesem Zusammenhang bekannt blieb, ist der Brief von Johann Heinrich Merck vom 21. November $1789^{46}$, in dem er sich »tausendmal « ${ }^{47}$ bei der »hochzuehrenden Freundin $\aleph^{48}$ Christine Luise von Werner ${ }^{49}$ dafür bedankt, dass sie ihm und seinem Bruder so wichtige Nachricht von dem Leben des Neffen verschafft habe. Welcher Art diese Nachrichten waren und aus welcher Quelle Fräulein von Werner sie erhielt, läßt sich nicht mehr rekonstruieren. Kennzeichnend ist jedoch der abschließende Satz von Mercks Onkel: »Ohne Ihre gütige Verwendung würden wir noch lange hierüber in Ungewissheit gewesen seyn $\aleph^{50}$, in dem er seine Dankbarkeit zum Ausdruck brachte. Dies bestätigt, wie schwer sich die Verbindung zwischen den Verwandten aufrechterhalten ließ und wie sehr sie auf Informationen aus dritter Hand angewiesen waren.

43 Herrmann, Karl Heinrich Merck, Kaiserlicher Hofrat, S. 20; JACOBI, Der Forschungsreisende Karl Heinrich Merck und sein Tagebuch, S. 47.

44 Merck, Karl Heinrich (Christianov), in: Amburger-Archiv, Akte Nr. 62511.

45 HerrmanN, Karl Heinrich Merck, Kaiserlicher Hofrat, S. 20.

46 Brief 977. An Christine Luise von Werner, in: U. LEUSCHNER (Hg.), J. H. Merck. Briefwechsel, Bd. 3, S. 580-584.

47 Ebd., S. 580.

48 Ebd., S. 580.

49 Vgl. zu Christine Luise von Werner ebd., S. 582f. Christine Luise von Werner war die jüngste unverheiratete Tochter des Generals Leopold Christoph Daniel von Werner. Dieser war als Wirklicher Geheimer Rat und als Präsident des Kriegsrates zeitweise J. H. Mercks Vorgesetzter gewesen. Fräulein von Werner arbeitete als Erzieherin in Darmstadt und Straßburg. Darüber hinaus war sie eine Mitarbeiterin am Neuen Magazin für Frauenzimmer in Straßburg.

50 Ebd., S. 580. 
Um seine Angehörigen endlich wiederzutreffen, unternahm Carl Heinrich Merck in den Jahren 1796-1797 eine Erholungsreise nach Deutschland. In der Heimat erfuhr er auch eine würdigende Anerkennung seiner Leistungen auf wissenschaftlichem Gebiet. Auf Vorschlag des damaligen Direktors der Akademie der Wissenschaften zu Göttingen Johann Christoph Gatterer wurde er am 3. November 1797 zum korrespondierenden Mitglied der Physikalischen Klasse der Sozietät gewählt ${ }^{51}$. Die erste Bekanntmachung der wissenschaftlichen Expeditionsergebnisse im Ausland ist ebenfalls auf diesen Deutschlandbesuch Mercks zurückzuführen. Mercks Informationen ist nämlich zu verdanken, dass J. F. Blumenbach - das andere Mitglied der Sozietät der Wissenschaften zu Göttingen - im Jahre 1798 einen Artikel über die »letzte grosse Russische Entdeckungsreise im nordöstlichen Weltmeer $\aleph^{52}$ veröffentlichen konnte.

Die weitere Entwicklung von Mercks wissenschaftlicher Karriere wurde im Januar 1799 durch einen Schlaganfall unterbrochen, an dem der deutsche Arzt und Reiseforscher im Alter von 38 Jahren in St. Petersburg verstarb. Sein Grab auf dem Volkovo-Friedhof ist heute nicht mehr erhalten.

Obwohl Carl Heinrich Merck zweifellos zu den tüchtigsten Mitgliedern der Billings-Saryčev-Expedition gehörte, fand seine Arbeit lange Zeit kaum Würdigung in der wissenschaftlichen Literatur. Das hängt vor allem mit dem unglücklichen Schicksal seines wissenschaftlichen Erbes zusammen. Da Merck in seinen Forschungen stark an die Anweisungen von Pallas gebunden war, schickte er diesem unmittelbar nach Beendigung der Expedition nicht nur alle seine Notizen, sondern auch eine reiche Kollektion von Naturalien zu. Pallas verwendete allerdings nur einen kleinen Teil dieser Schriften - vor allem die zoologischen und ornithologischen Erstbeschreibungen - für sein eigenes großes Werk Zoographia Rosso Asiatica ${ }^{53}$ und verzichtete auf die weitere Bearbeitung der Aufzeichnungen von Merck. Der ethnologische Teil von Mercks Forschungen blieb der Öffentlichkeit daher vorenthalten. Lediglich zwei Auszüge über die jakutischen und čukčischen Stämme wurden in gekürzter Form in den Jahren 1806 und 1814 in St. Petersburg und Berlin publiziert ${ }^{54}$.

\footnotetext{
51 Archiv Akademie der Wissenschaften zu Göttingen, Pers. 12, Nr. 34.

52 Johann Friedrich BLUMENBACH, Nachricht von der letzten grossen Russischen Entdeckungsreise im nordöstlichen Weltmeer, in: Allgemeine Geographische Ephemeriden 1 (1798), 5, S. 525531.

53 Peter Simon Pallas, Zoographia Rosso-Asiatica: Sistens Omnium Animalium In Extenso Imperio Rossico Et Adjacentibus Maribus Observatorum Recensionem, Domicilia, Mores Et Descriptiones, Anatomen Atque Icones Plurimorum, St. Petersburg 1811.

54 Carl Heinrich MercK, O proischoždenii, vere i obrjadach jakutov, in: Ljubitel' slovesnosti (1806), Nr. 2, S. 117-147; ders, Nachrichten von den Sitten und Gebräuchen der Tschuktschen, gesammelt von Dr. K. H. Merck auf seinen Reisen im nördlichen Asien, in: Journal für die neuesten Land- und Seereisen 16 (1814), S. 1-27, 184-192; 17 (1814), S. 45-71, 137-152.
} 
1810 brachte Pallas den schriftlichen Nachlass von C. H. Merck im Rahmen seines persönlichen Archivs nach Berlin. Zusammen mit einigen anderen Materialien aus dieser Sammlung gingen die Merck'schen Schriften bereits kurz nach Pallas' Tod 1811 verloren. Vorher wurden sie jedoch im beschränkten Maße doch noch von der gelehrten Welt wahrgenommen. So verwies zum Beispiel Adelbert von Chamisso, der als Naturforscher 1815-1818 an der russischen Weltumseglung unter dem Kapitän Otto von Kotzebue teilnahm, in seinen Beschreibungen der Aleutischen Inseln lobend auf Merck:

»Steller zuerst, den Pallas den Unsterblichen nennt, hat die Naturgeschichte dieses Landes und Meerstriches enthüllt, und Merk ist unter Billing seiner Spur rühmlich ergänzend gefolgt « ${ }^{55}$.

Chamisso wusste, dass Mercks Schriften nur wenig bekannt wurden, und plädierte für eine gezielte Auseinandersetzung mit diesen wertvollen Aufzeichnungen. Leider ließ sich der Aufenthaltsort der Merck'schen Tagebücher zum Zeitpunkt der Veröffentlichung von Chamissos Reisebeschreibungen nicht mehr genau bestimmen.

Erst 1887 tauchte die Čukotka-Handschrift in den Akten erneut auf, als sie von der St. Petersburger Öffentlichen Bibliothek (Publičnaja biblioteka) aus einer unbekannten Quelle erworben wurde ${ }^{56}$. In der Handschriftenabteilung der heutigen Russischen Nationalbibliothek wird dieses Dokument seitdem aufbewahrt.

1936 entdeckte Professor Dr. Arnold Jacobi (1870-1948) in einem Leipziger Antiquariatskatalog auch das sibirisch-amerikanische Tagebuch von Carl Heinrich Merck wieder ${ }^{57}$. Als damaliger Direktor des Staatlichen Museums für Tier- und Völkerkunde in Dresden erkannte Jacobi schnell den besonderen zoologischen und ethnologischen Wert dieses Dokuments. Als Jacobi jedoch erfuhr, dass Merck mit Hilfe von J. P. Brinckmann nach Russland gelangt war, ist sein Interesse an dem Fundstück nochmals gestiegen. Der russische Hofmedikus war nämlich durch die Heirat seiner einzigen Tochter mit Georg A. Jacobi der Urgroßvater des Museumsdirektors. Ende 1936 wandte sich Arnold Jacobi an die Chemische Familienfabrik Merck in Darmstadt mit dem Vorschlag, das Manuskript für das

\footnotetext{
55 Adelbert VON CHAMISSO, Bemerkungen und Ansichten auf einer Entdeckungsreise unternommen in den Jahren 1815-1818 auf dem Schiff Rurick, in: Otto von KoTZEBuE, Entdeckungsreise in die Süd-See und nach der Berings-Straße zur Erforschung einer nördlichen Durchfahrt unternommen in den Jahren 1815, 1816, 1817 und 1818 auf Kosten des Herrn Reichskanzler Rumanzoff auf dem Schiffe Rurick unter dem Befehl des Leutnanten der Russisch Kaiserlichen Marine Otto von Kotzebue, Bd. 3, Weimar 1821, S. 173.

56 Publičnaja biblioteka. Otčet v upravlenii Imperatorskoju publičnoju bibliotekoju za 1887 g.,

St. Petersburg 1887, S. 211 f.

57 Vgl. JACOBI, Der Forschungsreisende Carl Heinrich Merck und sein Tagebuch, S. 49.
} 
Merck'sche Familienarchiv zu kaufen und auf diese Weise nicht nur für die Sicherung einer seltenen Forschungsquelle, sondern auch eines Stückes deutscher Familiengeschichte zu sorgen ${ }^{58}$. Der Bitte wurde schnell entsprochen und das Tagebuch gelangte nach Darmstadt, wo es bis heute aufbewahrt wird.

Eine hinreichende wissenschaftliche Aufarbeitung blieb bislang jedoch aus. Abgesehen von Arnold Jacobi und Erwin Stresemann, die sich in der ersten Hälfte des 20. Jahrhunderts mit dem Tagebuch befassten ${ }^{59}$, publizierte 1980 Richard A. Pierce ${ }^{60}$ die einzige Edition des Tagebuches. Die Ausgabe ist jedoch in modernes Englisch übersetzt, bleibt fast unkommentiert und kann somit kaum die sprachlichen, aber auch die inhaltlichen Besonderheiten des Originaljournals wiedergeben. Auch in der russischen Forschung wurde das Dokument nicht gebührend gewürdigt. Allein Z. Titova setzte sich 1978 mit dem Nachlass der Billings-Saryčev-Expedition auseinander. Dabei war sie die einzige, die gleichzeitig den beiden Teilen von Mercks Aufzeichnungen Beachtung schenkte und in einer Ausgabe die ethnographischen Beobachtungen aus dem sibirisch-amerikanischen Tagebuch und aus der Čukotka-Handschrift zusammenführte ${ }^{61}$. Zur Zeit beschäftigt sich in Deutschland außer der Forschungsgruppe des Bonner Geschichtsinstituts unter der Leitung von Prof. Dittmar Dahlmann ${ }^{62}$ einzig der Maler und Fotograph Ulrich Wannhoff ${ }^{63}$ mit dem Lebenswerk von Carl Heinrich Merck.

Allein die lange Periode, in der das Tagebuch für die wissenschaftlich interessierte Öffentlichkeit unzugänglich war, kann als Erklärung dafür die-

58 Vgl. den Brief von Arnold Jacobi vom 12.12.1936, in: Firmenarchiv der Familie Merck, Darmstadt.

59 Arnold JACOBI, Carl Heinrich Mercks ethnographische Beobachtungen über die Völker des Beringmeers 1789-91 (nach seinem Tagebuch bearbeitet), in: Baessler-Archiv 20 (1937), S. 113137; ders., Der Forschungsreisende Carl Heinrich Merck und sein Tagebuch, S. 46-51; Erwin StRESEMANN, Dr. C. H. Mercks ornithologische Aufzeichnungen während der Billingsschen Expedition von Ochotsk nach Alaska (1787-1791), in: Zoologische Jahrbücher, Abt. für Systematik, Ökologie und Geographie der Tiere 78 (1950), S. 97-132.

60 Richard A. PIERCE, Siberia and Northwestern America 1788-1792. The Journal of Carl Heinrich Merck, Naturalist with the Russian Scientific Expedition led by Captains Joseph Billings and Gavriil Sarychev, Kingston / Ontario 1980.

61 Z. D. Titova (Hg.), Ėtnografičeskie materialy severo-vostočnoj geografičeskoj èkspedicii 1785-1795 gg., Magadan 1978; dies., Nemeckie učenye XVIII v. v Rossii - K. G. Merk, in: Galina I. SMAGiNA (Hg.), Nemcy v Rossii, S. 76-79.

62 Dittmar Dahlmann / Anna Friesen / Diana Ordubadi (Hg.), Carl Heinrich Merck. Das sibirisch-amerikanische Tagebuch von 1788 bis 1791, Göttingen 2009 (in Druckvorbereitung).

63 Ulrich Wannhoff, Der hessische Arzt und Naturforscher Carl Heinrich Merck (1761-1799) und seine Seereise von Ochotsk nach Russisch-Amerika (1789-1790), in: Philippia 13 (2008), 4, S. 275-282; ders., Auf den historischen Spuren Carl Heinrich Mercks von Darmstadt nach Unalaska über St. Petersburg. Vortrag der Regionalgruppe Sibirien und Polargebiete in der Deutschen Gesellschaft für Völkerkunde. Anläßlich der Ausstellung Arktis - Antarktis, Bonn 1997. 
nen, dass der wissenschaftliche Nachlass des deutschen Arztes immer noch keine feste Beachtung in der Geschichte Sibiriens und der ethnologischen Beschreibung seiner Völker findet. Insofern verdient dieses wissenschaftliche Werk eine erschöpfende Wiederentdeckung. 


\title{
Heinz Duchhardt
}

\section{Ein deutscher Mediziner im Fernen Osten}

\author{
Joseph Rehmann und die Golovkin-Gesandtschaft 1806
}

Am Prozess der Erschließung des Fernen Ostens, also der Integration Sibiriens in das Russische Reich und der politisch-ökonomischen Annäherung Moskaus an die ostasiatischen Nachbarreiche, waren nicht nur »deutsche" Diplomaten, Militärs und Gelehrte beteiligt, also Männer, die man der politisch-sozialen Elite zuordnen würde, sondern auch viele hundert Menschen aus dem zweiten Glied, die, von Neugier, wirtschaftlichen Perspektiven und Abenteuerlust getrieben, oder auch um ein problematisches Kapitel ihres Lebens hinter sich zu lassen, sich in den Dienst dieser epochalen Aufgabe stellten. Die Große Nordische Expedition hatte das schlaglichtartig erkennen lassen, dass viele Männer das als die stimulierende Herausforderung ihrer Zeit ansahen - Johann Georg Gmelin etwa, der Tübinger Chemiker und »Kräuterwissenschaftler«, berichtet in seiner in Göttingen 1751 gedruckten Reise durch Sibirien, dass neben etlichen Russen auch ein deutscher Maler und ein deutscher Zeichenmeister seinem Tross angehörten'. Auch die beiden Kaufleute Eberhard Isbrand Ides und Adam Brand, die sich an der russischen Gesandtschaft nach Peking 1692/95 beteiligt hatten ${ }^{2}$, könnten hier als exempla genannt werden, aber etwa auch der oben vorgestellte hessische Arzt Carl Heinrich Merck ${ }^{3}$. Das waren durchweg Menschen, denen es nicht an der Wiege gesungen worden war, dass sie in unbekannte Regionen und in fremde Kontinente ausgreifen würden. Mit einer dieser Gestalten will sich dieser Beitrag paradigmatisch beschäftigen.

Er ordnet sich ein in die vielfältigen Bemühungen, den von Peter I., spätestens aber von Katharina II. eingeleiteten Prozess der »Europäisierung" Russlands personell zu füllen und zu konkretisieren. $\mathrm{Zu}$ diesem bunten Strauß von Ausländern, die in Russland reüssierten, ohne freilich immer ein Übermaß an Sympathie zu erwerben, zählten die vielen Akademiker wie

\footnotetext{
1 Vgl. Die Große Nordische Expedition von 1733 bis 1743. Aus Berichten der Forschungsreisenden Johann Georg Gmelin und Georg Wilhelm Steller, hg. von Doris Posselt, München 1990, S. 7.

2 Vgl. Beschreibung der dreijährigen Chinesischen Reise. Die russische Gesandtschaft von Moskau nach Peking 1692 bis 1695 in den Darstellungen von Eberhard Isbrand Ides und Adam Brand, hg., eingeleitet und kommentiert von Michael HunDT, Stuttgart 1999.

3 Beitrag Ordubadi, S. 79-96.
} 
etwa der Historiker und Geograph Gerhard Friedrich Müller ${ }^{4}$ oder August Ludwig von Schlözer ${ }^{5}$, aber auch die zahlreichen Diplomaten, Militärs und Verwaltungsbeamten, mochten sie nun aus den baltischen Provinzen oder aus dem deutschen Reich selbst stammen, von den Schweden, den Franzosen oder Briten einmal ganz abgesehen. Diese Europäisierung Russlands sollte dann mit einer entsprechenden Aufmerksamkeit und Hinwendung vieler Wissenschaftsdisziplinen zu diesem bisherigen »schwarzen Fleck» auf der europäischen Landkarte korrelieren ${ }^{6}$.

Joseph Rehmann, der 1831 sein Leben als kaiserlicher Leibarzt in St. Petersburg beschließen sollte, wurde 1779 als Sohn eines Arztes, der später zum fürstenbergischen Leibarzt aufstieg, im schwäbischen, seit längerem bereits wieder unter österreichischer Herrschaft stehenden Saulgau geboren, im »Hexenstädtle«, wie der Beiname wegen der extrem vielen Hexenverfolgungen im 17. Jahrhundert aufgekommen war. Der Familientradition gemäß studierte auch er Medizin, allerdings nicht etwa im vorderösterreichischen Freiburg, sondern in Wien, wo sein Vater eine Zeitlang beruflich tätig gewesen war. Nachdem er 1802 seine Approbation erhalten hatte, empfahl ihn einer seiner akademischen Lehrer dem russischen Gesandten Razumovskij, der als Freund und Förderer Haydns, Mozarts und Beethovens im kulturellen Leben der Kaiserstadt in jenen Jahren eine bedeutsame Rolle spielte. Es war offenbar Sympathie auf den ersten Blick, Razumovskij ernannte den jungen Mann zu seinem Hausarzt und nahm ihn nach Ende seiner Mission mit nach St. Petersburg, wo Rehmann dann auch die - in allen Fällen dieser Art vorgeschriebene - russische Approbation erhielt. Nur wenige Tage später wurde er der Gesandtschaft des Grafen Jurij Alexandrovic Golovkin nach China als Gesandtschaftsarzt zugeordnet mit dem zusätzlichen Auftrag, alle am Weg gelegenen Hospitäler und Lazarette zu visitieren. Die Gesandtschaft, die - ganz ähnlich wie die von 1692/95 dazu dienen sollte, bessere Handelsbeziehungen zwischen Russland und China herbeizuführen und den Regierungsantritt Alexanders I. offiziell dem chinesischen Kaiser zu notifizieren, blieb bereits in der Mongolei aus Gründen stecken, die - typisch für die interkulturellen Kontakte in der damaligen Zeit und ein Dauerthema in den russisch-chinesischen Beziehungen der Vormoderne - in unterschiedlichen Zeremoniellerwartungen wurzelten. Der unbefriedigende Verlauf dieser Gesandtschaft sollte sich nicht nur für die

\footnotetext{
4 Peter Hoffmann, Gerhard Friedrich Müller (1705-1783). Historiker, Geograph, Archivar im Dienste Russlands, Frankfurt/M. [usw.] 2005.

5 Martin Peters, Altes Reich und Europa. Der Historiker, Statistiker und Publizist August Ludwig (v.) Schlözer (1735-1809), Münster / Hamburg / London 2003.

6 Viele schöne Beispiele neuestens dazu in Dittmar Dahlmann (Hg.), Die Kenntnis Russlands im deutschsprachigen Raum im 18. Jahrhundert. Wissenschaft und Publizistik über das Russische Reich, Göttingen / Bonn 2006.
} 
Karriere Golovkins als abträglich erweisen, sondern auch für die Mitglieder seiner Delegation eher negative Konsequenzen haben. Für Rehmann hielten sie sich allerdings in Grenzen, weil sich die unveränderte Patronage Razumovskijs, der 1810 zum Unterrichtsminister aufsteigen sollte, als hinreichend erwies, ihn vor gesellschaftlicher Ächtung oder gar der Ausweisung aus dem Russischen Reich zu bewahren.

Dazu hatte auch beigetragen, dass er sich vor und auf dieser Reise einen Namen als Organisator und als Medizin-Politiker gemacht hatte. Schon vor Reiseantritt hatte er dem Petersburger Reichsmedizinalrat ein Memorandum vorgelegt, in dem er sich für die in die Gesandtschaft zu integrierende Durchführung der Pockenimpfung in Sibirien engagiert und sich für einen zukünftigen engen wissenschaftlich-literarischen Austausch mit chinesischen Ärzten ausgesprochen hatte. Die Praxis war das andere gewesen: In Irkutsk war es ihm gelungen, eine Scharlachepidemie einzudämmen; er hatte großflächig - bis hin nach Kamčatka - mit Unterstützung des deutschstämmigen Gouverneurs von Sibirien, Pestel, dafür gesorgt, dass die Gouvernements mit Impfstoff versorgt wurden, er hatte bei manchen Ethnien so besonders bei den Burjaten und den Tungusen - Überzeugungsarbeit geleistet, sich dem Impfen nicht zu verweigern - ein Vorgang, der extrem schwierig gewesen zu sein scheint, hatte sich diesem Anliegen doch schon seit den späten 1770er Jahren ein anderer deutscher Mediziner, Johann Schilling, mit weit weniger großem Erfolg angenommen. Rehmann hatte vor allem aber - ein großes Thema für die damalige Zeit - neue Erkundungen über die begehrte Rhabarber-Wurzel als eine der Heilpflanzen, von denen man sich wahre Wunderdinge versprach (und deren Vertrieb nicht zufällig dann zu einem Staatsmonopol erhoben wurden), eingeholt und Wege aufgezeigt, wie man an sie herankommen könne. Schließlich hatte er, zum Teil auf eigene Kosten, die heißen Mineralquellen am Turkafluss aufgesucht und untersucht und darüber einen Bericht vorgelegt, der nach allgemeiner Ansicht - nicht nur der des Reichsmedizinalrats - das Beste war, was überhaupt bis dahin über ein russländisches Heilbad veröffentlicht worden war. Überhaupt hat er diese mongolische Expedition in etliche Publikationen einmünden lassen, etwa eine zur Geburtshilfe nach Mandju-Quellen, die ihm bald nach seiner Rückkehr den Ruf eines der angesehensten Mediziner im Zarenreich einbrachten. 1810 wurde er zum Professor an der Moskauer Universität ernannt, 1812 wurde er aufgrund seiner Bäder-Abhandlung Mitglied des Medizinalrats, 1817 schließlich ordentlicher Professor der Pharmakologie an der Chirurgischen Akademie in Moskau. Auch staatliche Anerkennung blieb nicht aus; so zeichnete Alexander I. ihn bereits 1812 mit der Hofratswürde aus, 1814 mit dem Amt des kaiserlichen Leibarztes, später sollten dann noch die Verleihung des St. Annaordens 2. Klasse und des Wladimirordens folgen. Den Höhepunkt seiner akademisch-staatlichen Kar- 
riere bildete aber zweifellos die Ernennung zum Chef des russischen Zivilmedizinalwesens 1821 .

Der Freiherr vom Stein, um nur einen deutschen Gewährsmann hier anzusprechen, hat ihn während seiner Petersburger Monate im Sommer und Herbst 1812 in der Entourage des Zaren kennengelernt, sich von ihm sicher über seine chinesischen Erfahrungen berichten lassen und ihn in der Folgezeit dann wiederholt brieflich grüßen lassen? ${ }^{7}$. Die beiden Männer scheinen später in Deutschland sogar noch einmal zusammengetroffen zu $\operatorname{sein}^{8}$, was das Bild bestätigen würde, dass Stein seit seinen lebhaften Petersburger Tagen, in denen er sich längst nicht nur im Umkreis der vielen damals dort weilenden Deutschen - Fürsten wie der Herzog August von Oldenburg und deutsche Prinzessinnen, die in die Zarenfamilie verheiratet worden waren, Militärs, die aus der preußischen Armee ausgetreten waren, manche Napoleon-Flüchtlinge - bewegte, ein nachhaltiges Interesse am Fernen Osten und an China in specie geschöpft hat 9

Die glänzende Wissenschaftler- und Beamtenkarriere soll hier aber vor allem im Hinblick auf ihre mongolisch-chinesische Fundamentierung interessieren, wobei bisher unbekannt ist, ob Rehmann während seines Medizinstudiums in Wien in irgendeiner Form bereits auf die dort wohl hinlänglich bekannten ${ }^{10}$ besonderen Ausprägungen der chinesischen Medizin hingewiesen worden war, etwa die chinesische Pulslehre. In seinem handschriftlichen, in der Fürstlich Fürstenbergischen Bibliothek Donaueschingen liegenden Nachlass, der in den 1970er Jahren vor allem von dem Mongolisten Walther Heissig aufbereitet wurde ${ }^{11}$, findet sich nicht nur das Manuskript seines (dann ungedruckt gebliebenen) Reiseberichts mit 65 Aquarellen, sondern finden sich auch eine ganze Fülle von einschlägigen Vorarbeiten bzw. Vorträgen, die von seinem seit 1805 lebenslangen Interesse an der fernöstlichen Medizin künden: eine Studie über den Zustand der Arzneikunde bei den Chinesen, Übersetzungen aus einer chinesischen medizinischen Schrift über die Einwirkungen der Elemente auf den Menschen, das Konzept eines Vortrags über chinesische Medizin, Exzerpte aus einem Reisewerk über chinesische Makrobiotik, um nur einige herauszugreifen. Diese Manuskripte stehen neben einer ganzen Reihe von gelehrten Abhandlungen,

\footnotetext{
7 Stein an Uvarov, 1813 Jun 7: Freiherr vom Stein, Briefe und amtliche Schriften, 10 Bde., hg. von Erich Botzenhart und Walter Hubatsch, Stuttgart 1957-1974, hier 4, Nr. 264, S. 178

Stein an Uvarov, 1817 Jan. 20: ebd. 5, Nr. 501, S. 588f.

9 Vgl. Heinz DuchHardT, Der Freiherr vom Stein und China. Das Interesse an Ostasien im Deutschland des frühen 19. Jahrhunderts, in: H. D., Stein-Facetten. Studien zu Karl vom und zum Stein, Münster 2007, S. 31-42.

10 Vgl. Hartmut WaLRavens, China illustrata. Das europäische Chinaverständnis im Spiegel des 16. bis 18. Jahrhunderts, Weinheim 1987, Katalog Abschnitt N.

11 Mongolenreise zur spaeten Goethezeit. Berichte und Bilder des J. Rehmann und A. Thesleff von der russischen Gesandtschaftsreise 1805/06, hg. von Walther HeISSIG, Wiesbaden 1971.
} 
die im Druck erschienen sind, etwa einer von 1811 Beschreibung einer Thibetanischen Handapotheke. Ein Beitrag zur Kenntnis der Arzneykunde des Orients. Rehmann hat dadurch in einem Segment, das auch heute noch die breite Öffentlichkeit fasziniert, dem der fernöstlichen Medizin, zu einem Kulturtransfer zumindest im Sinn des Wissens um die asiatischen Spezifika beigetragen, den man hoch veranschlagen muss und mit dem zumindest die literaten gebildeten Schichten des Zarenreiches erreicht wurden.

Freilich darf man auf der anderen Seite die Dimension dieses partiellen einseitigen und auch nur eine bestimmte soziale Schicht berührenden - Kulturtransfers auch nicht überschätzen. Große Massen der Bevölkerung wurden damit selbstredend nicht erreicht, und es setzte im Russland des frühen 19. Jahrhundert ganz sicher auch keine breite Bewegung ein, die Spezifika der chinesischen Medizin in das russische Medizinalwesen zu integrieren.

Aber wie auch immer: In einem Teilbereich hat ein Mann wie Rehmann dabei mitgeholfen, dass sich das Zarenreich der Kultur seiner östlichen Nachbarn öffnete und wenigstens Interesse, wenn nicht sogar Sympathie dafür zu entwickeln begann. Das wird man um so eher so sehen müssen, als Rehmann mit seinen ostasiatischen Aktivitäten längst nicht allein auf weiter Flur stand. Die Reiseberichte - leider kam es wegen Rehmanns vorzeitigem Ableben nicht zur Publikation seines eigenen Reiseberichts - häuften sich in den 1820er Jahren; Timkowskis Bericht über eine Mongolei- und Chinareise beispielsweise war auch in Russland verbreitet, ebenso die in Paris publizierten Mémoires relatifs à l'Asie des Orientalisten Julius Heinrich von Klaproth $^{12}$, eines anderen Teilnehmers der Golovkin-Gesandtschaft, oder das Tafelwerk Andrej Martynovs Voyage pittoresque de Moscou aux frontières de la Chine ${ }^{13}$. Man wird zumindest so weit gehen können zu sagen, dass in den literaten Schichten des russländischen Reiches in den 1820er Jahren erstmals so etwas wie eine kulturelle Aneignung des Fernen Ostens Platz zu greifen begann, womit der Westen Europas mit seiner Chinabegeisterung Jahrzehnte früher ja bereits vorangegangen war. Diese Offenheit gegenüber den fernöstlichen Kulturen ging zwar noch nicht so weit, die Fächer Sinologie oder Mongolistik an russischen Universitäten zu implementieren, aber das darf nicht überraschen; die ersten Lehrstühle für Sinologie, das als Begriff sich erst vor dem Hintergrund neuer Überlegungen zur Wissensorganisation dem 19. Jahrhundert verdankte, wurden nach einem frühen Vorläufer am Collège de France (1814/15) erst an der Wende zum 20. Jahrhundert errichtet ${ }^{14}$ - was nicht ausschließt, dass faktisch Sinologie in Deutsch-

\footnotetext{
12 Paris $1824-1828$.

131819 .

14 Vgl. Helwig Schmidt-Guintzer, Sinologie und das Interesse an China, Mainz / Stuttgart 2007, S. 6.
} 
land beispielsweise bereits seit den 1830er Jahren gelehrt wurde, in Göttingen etwa von Johann Heinrich Plath ${ }^{15}$.

Auch wenn es zu Rehmanns Lebzeiten im Zarenreich also noch nicht zur förmlichen Errichtung sinologischer Lehrstühle kam: der Boden war durch Reisende wie ihn und ihre Vermittlung von Segmenten fernöstlicher Kultur bereitet worden. Unter den Wegbereitern der russischen Sinologie kommt dem deutschen Mediziner sicher ein Ehrenplatz zu, der freilich nach seinem durch die 1830/31 grassierende, von Russland sich auch nach Mittel- und Westeuropa ausbreitende Cholera verursachten Tod seine letzte Ruhestätte nicht etwas in Sibirien im russisch-mongolischen Grenzbereich fand, sondern in St. Petersburg.

Die Rezeption von Elementen einer fremden Kultur hat immer etwas mit dem Nehmerland zu tun, seiner geistigen Disposition, seiner Bereitschaft, sich der Neugier hinzugeben, seiner Fähigkeit, vermeintliches oder tatsächliches kulturelles Überlegenheitsgefühl zurückzustellen und das Fremde nicht als Bedrohung, sondern als Chance zu begreifen. Der Nicht-Spezialist kann nicht ausleuchten, wie es im russländischen Reich in den 1820er Jahren um diese generelle Disposition bestellt war, sich nicht abzuschotten, sondern sich dem Nachbarn zu öffnen - die »europäische« Politik Alexanders I. hatte jedenfalls wohl ihren Teil dazu beigetragen, dass Russland nicht mehr in strikter Isolierung verharrte. Hier sind freilich die Spezialisten gefordert. Rehmann hat, so scheint es aus dem biographischen Ansatz dieser Studie, jedenfalls das Seine dazu beigetragen, dass zumindest begrenzt eine veränderte Sicht des großen chinesischen Nachbarn Platz greifen konnte, die in der Vergangenheit nicht selten belastet gewesen war.

15 Ebd., S. 8. 


\section{Jan Kusber}

\section{Imperiale Wissenschaften und Expansion: Das Beispiel Fedor Petrovič Litke (1797-1882)}

Deutsche in russischen Diensten und ihr Anteil an der Erschließung des Fernen Ostens lautet das Thema des vorliegenden Sammelbandes. Es scheint allgemein und speziell zugleich zu sein. Man könnte sich mit einer schnellen Antwort begnügen: Natürlich gab es Deutsche in russischen Diensten, und bei der Erschließung des Fernen Ostens und nicht nur des Fernen Ostens waren sie auch dabei. Dann aber beginnen die Fragen aus diesen beiden schnell getroffenen Befunden. Was heißt im Kontext des Russländischen Imperiums vor $1917 » d e u t s c h «^{\prime}$ ? Deutsche, die zu verschiedenen Zeiten ins Russländische Reich kamen, wussten sicher nicht, dass sie später von Volkszählungen oder der Geschichtswissenschaft als solche kategorisiert würden. Sie hatten schon im geographischen Herkunftsraum ihrer Familien Identitäten, die die Vorbemerkung zwingend machen, dass in der Reduktion oder auch Erweiterung auf »deutsch « immer eine Verkürzung liegt.

Der deutschbaltische Adel, das Stadtbürgertum in Riga und Reval, deutschstämmige oder deutschsprachige Wissenschaftler im Dienste der Akademie und an den russischen Universitäten konstruierten ihre Identitätsbildungen über Abgrenzungsprozesse und über Alteritäten, die mit dem Gegensatzpaar deutsch-russisch für die Personengruppen, um die es in dem Band geht, sicher nur unzureichend erfasst werden ${ }^{2}$. Alexander von Benckendorff, einer der vielen deutschbaltischen Adligen, die in Militär und Verwaltung des Zarenreiches dienten, und der durch die Leitung der III. Abteilung seiner Kaiserlichen Majestät in der Zeit Nikolaus' I. notorische Berühmtheit erlangte, sprach kaum Russisch und war zugleich ein loyaler Diener der Dynastie und des Imperiums. Er sah sich

\footnotetext{
Siehe die unterschiedlichen Zugriffe in: Gerd STRICKER u. a., Deutsche Geschichte im Osten Europas. 2. Aufl., Berlin 2002; Hans HeCKER, Die Deutschen im Russischen Reich, in der Sowjetunion und ihren Nachfolgestaaten, Köln 1994.

2 Siehe die Bandbreite ihrer Betätigungsfelder dokumentiert in: V. A. Auman (Hg. u. a.), Nemcy v istorii Rossii. Dokumenty vysšich organov vlasti i voennogo komandovanija 1652 1917, Moskva 2006. Für die Überschneidung deutschbaltischer und russischer Heiratskreise innerhalb des Adels siehe: Genealogisches Handbuch der baltischen Ritterschaften. Hg. von den Verbänden des livländischen, estländischen und kurländischen Stammadels, 3 Bde., Görlitz 19291930.
} 
gleichsam als ihr Schwert und mag als Beispiel für hybride Identitätsbildung stehen ${ }^{3}$.

Und was heißt eigentlich »Anteil«? Der Begriff setzt ja voraus, dass es etwas zu quantifizieren gäbe. Da es nicht um die Zählung religiöser Zugehörigkeit oder sprachlicher Fertigkeiten geht und Anteile in Bezug auf Prozesse schon gar schwierig bestimmen zu sind, steht man vor einem nicht leicht lösbaren methodischen Problem ${ }^{4}$.

Ich möchte hier einen Weg gehen, der das Begriffspaar »deutsch-russisch « mitdenkt, mich aber im folgenden kursorisch mit dem Wirken und vor allem den Gedankenwelten von Wissenschaftlern befassen, die sich Sibirien und dem Fernen Osten, überhaupt ganz Asien aus ganz unterschiedlichen Selbstverständnissen zuwandten. Biographisches Arbeiten, in diesem Fall kollektivbiographisches Arbeiten, vermag auch für die Geschichte des Russländischen Imperiums vor 1917 neue Forschungsfelder erschließen und jene Zugriffe ergänzen, die sich mit dem Fernen Osten aus anderen Blickwinkeln beschäftigt haben ${ }^{6}$. Ethnos, Konfession und Sozialisation der hier diskutierten Gruppe waren zumal über das lange 19. Jahrhundert unterschiedlich, gemeinsamer Fluchtpunkt ihrer Zugehörigkeit zur Funktionselite war jedoch der Dienst am Imperium und dessen Größe.

In den Mittelpunkt der hier betrachteten Personengruppe stelle ich mehr oder weniger konsequent die Person Friedrich Benjamin Lütke/Fedor Petrovič Litke als Hauptfigur. Aufgrund seines langen Lebens und seiner breiten wissenschaftlichen Aktivität bietet er sich an, gehörte er doch über mehrere Jahrzehnte zur Funktionselite des Zarenreiches. Gleichsam um ihn herum gruppiert sei aber ein Sample von Personen, die im »gleichen Geschäft« unterwegs waren.

Ich beginne als Beispiel mit einem deutschbaltischen Adligen aus dem Gouvernement Estland, Adam Johann von Krusenstern (Ivan Fedorovič Kruzenstern, 1770-1846). Er war wie andere Weltumsegler auch im Seekadettenkorps erzogen worden, nahm an den Seeschlachten im kathari-

\footnotetext{
3 Zu seiner Tätigkeit und seinem Einfluss auf Nikolaus: B. N. TARASOV (Hg.), Nikolaj pervyj i ego vremja, T. 1-2, Moskva 2000.

4 Diese methodischen Probleme prägen mitunter manche Beiträge der insgesamt verdienstvollen, von G. I Smagina initiierten Konferenz- und Publikationsserie: G. I. SMAgINA (Hg. u. a.), Nemcy v Rossii, Moskva 1998-2005.

5 Hans-Christian Petersen, Russische und sowjetische Biographik, in: Christian Klein (Hg.), Biographie und Biographik. Ein interdisziplinäres Handbuch, Stuttgart / Weimar 2009 (im Druck).

6 S. C. M. PAINE, Imperial Rivals. China, Russia and their disputed Frontier, Armonk / London 1998; David SCHIMMELPENNINCK VAN DER OYE, Toward the Rising Sun: Russian Ideologies of Empire and the Path to War with Japan, DeKalb, Ill. 2001; Mark BASSIN, Nationalist Imagination and Geographical Expansion in the Russian Far East, 1840-1865, Cambridge 1999; DERS., Imperialer Raum - Nationaler Raum. Sibirien auf der kognitiven Landkarte Russlands im 19. Jahrhundert, in: Geschichte und Gesellschaft 28 (2002), S. 378-403.
} 
näischen Krieg gegen Schweden 1789-90 teil, diente dann jedoch einige Jahre in der britischen Marine, darunter während der Schlachten der Briten gegen die Flotten Napoleons. Zugleich erhielt er einen Eindruck von der Bedeutung des britischen Handels, auch im Fernen Osten, wo er auf britischen Schiffen eingesetzt war.

Vor dem Hintergrund dieser Erfahrungen sah er die Notwendigkeit für das Zarenreich, eine Handelsmarine aufzubauen, die den Fernen Osten von See her erschließen sollte. Er wurde unterstützt von zwei einflussreichen Vertretern der Funktionselite der ersten Regierungsjahre Alexanders I., Graf Nikolaj Mordvinov und Handelsminister Graf Rumjancev, die zu den Advokaten der großen Seeexpeditionen gehörten. Krusenstern erhielt für seine Expedition um die Welt zwei Schiffe, die in Britannien erworben wurden, und Alexander I. selbst stattete den Schiffen einen Besuch während der Vorbereitungen ab. Er war, wie andere »Entdecker« der Alexanderzeit auch, im Grunde ein Produkt der katharinäischen Reformen. Anders als frühere russische »Entdecker« wie zum Beispiel Grigorij Šelechov, der Sibirien erkundet und mit der Erschließung Kolonisierung Alaskas begonnen hatte, war Krusenstern ein typischer Vertreter der Funktionselite des Adels, der in sich die Sozialisationsergebnisse des Europäisierungsprozesses vereinigte, welcher über das 18. Jahrhundert, gegen dessen Ende aber noch einmal forciert vor sich gegangen war. Übergreifend waren sie weder reine Wissenschaftler noch Seeleute des Kriegs- oder Handelsmarine, sondern definierten sich über ihre Ausbildung und Erziehung im Seekadettenkorps vor allem in ihrem Dienst für das Imperium?

Ilja Vinkoveckij sprach jüngst davon, dass sich diese Personen in einem permanenten Dialog mit der europäischen Kultur befunden und in dem Konzept der Weltumsegelung auch ein Mittel Russlands gesehen hätten, in die Moderne vorzustoßen ${ }^{8}$. Marc Raeff hatte diesen Ansatz in einer älteren Arbeit im Übrigen noch zugespitzter angesprochen'. Diese »men on the spot« sahen sich nicht selten durch ihre Isolierung von den heimischen Gütern und ihren Familien in besonderer Weise dem Dienst an der Autokratie verpflichtet, und Namen wie Krusenstern, Ferdinand Vrangel oder der uns im folgenden noch näher interessierende Friedrich Benjamin Lütke (Fedor Petrovič Litke) waren deutschbaltischer Herkunft. Nicht wenige waren nota bene auch Waisen oder Halbwaisen, wie der Weltumsegler Vasilij

\footnotetext{
7 Adam Johann VON KRUSENSTERN, Reise um die Welt. Erlebnisse und Bordbuchnotizen des Kommandanten der Expeditionsschiffe »Nadeshda« und »Newa« bei der ersten Weltumseglung unter russischer Flagge in den Jahren 1803 - 1806, ausgw., bearb. und hg. von Christel und Helmuth PELZER. Mit einem Nachwort von Helmuth Pelzer, 2. Aufl. Leipzig 1985.

8 Ilya Vinkovetsky, Circumnavigation, Empire, Modernity, Race: The Impact of Round-theWorld Voyages on Russia's Imperial Consciousness, in: Ab Imperio 1-2 (2001), S. 198-201.

9 Marc RAEFF, Origins of the Russian Intelligentsia, San Diego 1966, S. 122-29.
} 
Golovnin, Ferdinand Vrangel oder Litke. Folgt man einer jüngeren Untersuchung von Richard Wortman, dann fungierte Vasilij Golovnin in gewisser Weise als Vorbild für diese Gruppe, die sich in manchem mit der ersten Generation von Carskoe Selo vergleichen lässt ${ }^{10}$. Was diese Institution an der russischen Literatur und Kultur vollbrachte, vollbrachte das Seekadettenkorps an den »Entdeckern « des Zarenreiches ${ }^{11}$. Unter diesen war der asketische Golovnin der älteste, aus einem ehrwürdigen Fürstengeschlecht stammend und seit dem Alter von neun Jahren Waise. Wie der »Vorläufer« Krusenstern diente er nach einer Ausbildung im Kronstädter Seekadettenkorps drei Jahre in der British Navy und zeigte sich wie andere Zeitgenossen sehr beeindruckt von Admiral Nelson, dem er persönlich begegnete. 1807 machte er sich auf dem Schiff »Diana« auf die Reise. Trotz zahlreicher Unglücke, die in die Gefangenschaft nach Südamerika und Japan führten, gelang ihm die Erforschung der Küste Alaskas weitgehend. Nach seiner Rückkehr verfasste er eine Beschreibung Japans, die alsbald ein klassischer Text wurde ${ }^{2}$. Das gleiche galt für den Bericht über seine zweite große Reise: Um die Welt auf der Kamčatka ${ }^{13}$. Golovnin führte auf seinen Expeditionen ein strenges Regiment, ein spartanisches Leben und inszenierte sich damit als Gegensatz zu den Lebensweisen, die gerade in der Zeit des Übergangs von Alexander I. zu Nikolaus I. en vogue wurden. Hierdurch wurde er zum Idol einer Reihe von Offizieren, die auf der »Kamčatka« dienten, wie etwa Fedor Litke, Ferdinand Vrangel und Fedor Matjuškin. Litke sprach später gar von der Golovnin-Schule, die sie alle durchlaufen hätten ${ }^{14}$.

Die Memoiren von Fedor Litke geben einen lebensweltlichen Eindruck davon, welche einsame Existenz diese Personen führten, bevor sie in den Dienst traten. Litkes Familie war unter jenen, die im 18. Jahrhundert ins Land gerufen worden waren, um ihre Expertise und ihr Wissen für das Russländische Imperium zu nutzen. Sein Großvater diente als stellvertretender Rektor des Gymnasiums der Akademie der Wissenschaften, also jener Institution, die eigentlich neben der Akademischen Universität den indigenen

10 Zur Bedeutung der ersten Generation von Schülern für die Entwicklung einer Funktionselite des Imperiums: S. D. RudEnSKAJA, Carskosel'skij-Aleksandrovskij licej 1811-1917, Sankt Petersburg 1999, S. 9-138.

11 Richard WorTMAN, Exploration and Conquest as Signs of National Consciousness, Paper für den VII. ICEES World Kongress, Berlin 25.-30.7.2005.

12 [Vasilij M. Golovnin] Gegebenheiten des Capitains von der russisch-kaiserlichen Marine Golownin, in der Gefangenschaft bei den Japanern in den Jahren 1811, 1812 und 1813: nebst seinen Bemerkungen über das japanische Reich und Volk und einem Anhange des Capitains Rikord, Leipzig o. J. Siehe hierzu die knappen Bemerkungen bei Jürgen OsterHAMMEL, Die Entzauberung Asiens. Europa und die asiatischen Reiche im 18. Jahrhundert, München 1998, S. 98 f.

13 Siehe die englische Ausgabe seiner Beschreibung: V. M. GolovnIN, Around the world on the Kamchatka, 1817-1819. Transl. with an introd. and notes by Ella Lury WISWEL, Honolulu 1979.

14 Graf F. P. Litke, Avtobiografiia, in: V. P. Bezobrazov, Graf Fedor Petrovich Litke, St. Petersburg 1888, 1, S. 88-95. 
Nachwuchs für die petrinische Akademie der Wissenschaften schaffen sollte, jedoch nie so recht florierte ${ }^{15}$. Großvater Litke schrieb über Physik, Chemie und Theologie, der Vater hingegen, ebenfalls (Amateur-)Chemiker, schrieb Aufsätze mystischen Inhalts im Kontext seiner Mitgliedschaft der in Russland in der späten Katharinazeit stark expandierenden Freimaurerszene ${ }^{16}$. Er arbeitete als Verwalter auf den Gütern der Fürsten Repnin, um schließlich im Petersburger Fiskalamt und Kommerzkollegium tätig zu werden.

Litkes Memoiren beginnen mit dem traurigen Satz: »Am 17. 9. 1797 wurde ich der Mörder meiner Mutter«. Seine Mutter starb zwei Stunden nach seiner Geburt, wenig später beging sein Vater aus Gram Selbst$\operatorname{mord}^{17}$. Aus der Kindheit erinnere er keinen erfreulichen Moment, fasste er in seinen Memoiren bündig zusammen. Vielmehr flüchtete er sich in die Welt der Bücher, will man seiner Autobiographie folgen, bevor er bei einem Besuch 1811 mit seiner Schwester in Kronstadt gleichsam ein intellektuelles und soziales Erwachen hatte: Er schloss sich einer Gruppe von jungen Seeoffizieren an. Einer von ihnen, Dmitrij Golovnin, Bruder des erwähnten Vasilij, begann ihn in Arithmetik und Geographie zu unterrichten. Das Jahr 1812 erlebte er, so die Memoiren, nur aus der Ferne, allerdings mit dem Wunsch, selbst in den Militärdienst einzutreten. Die Liebe zur See obsiegte freilich: Er trat in die Marineakademie ein und fiel hier durch Fleiß und harte Arbeit auf, so dass er eingeladen wurde, mit Vasilij Golovnin auf der »Kamčatka« auf Entdeckungsreise zu gehen. Golovnin empfahl seinen Seeoffizieren eine große Zahl Beschreibungen von Seereisen und Entdeckungen zur Lektüre an, um seinem Team das rechte wissenschaftliche Ethos zu vermitteln. Litke lebte, so seine Erinnerung, in der Zukunft. Vasilij Golovnin, der Leiter der Expedition, wurde von Litke aufgrund seines Pflichtbewusstseins und seiner hohen Auffassungen von Ehre und Adel geschätzt, keinesfalls jedoch wegen einer besonderen Wärme, die der Kapitän ausgestrahlt hätte. Litke kam von dieser großen Reise zurück als ein »Segler« der Schule Golovnins. Das bedeutete für ihn ein wissenschaftliches Ethos, welches in manchem an den bürokratischen Beamten Weberschen Typs erinnert ${ }^{18}$, der von Pflichterfüllung und einem Arbeitethos der Sache wegen erfüllt sein sollte.

\footnotetext{
15 Jan KusBer, Eliten- und Volksbildung im Zarenreich während des 18. und in der ersten Hälfte des 19. Jahrhunderts. Studien zu Diskurs, Gesetzgebung und Umsetzung, Stuttgart 2004, S. $96-100$.

16 Hierzu Douglas SMiTH, Working the rough Stone: freemasonry and society in eighteenthcentury Russia, DeKalb, Ill.1999.

17 Zitate und zum Folgenden: LiTKE, Avtobiografiia, 33-45.

18 Siehe die Diskussion hierzu bei Susanne Schattenberg, Die korrupte Provinz? Russische Beamte in 19. Jahrhundert, Frankfurt a. M. 2008, S.13-21.
} 
Golovnin wiederum betrieb für seine fähigen Seeoffiziere und Wissenschaftler Patronage. Ferdinand Vrangel (1797-1870) bekam auf seine Initiative hin den Auftrag, die arktische Küste Sibiriens zu kartieren ${ }^{19}$ und Litke sollte sich der Inselgruppe Novaja Zemlja annehmen: Es ging also um den Aufschluss und die Verwissenschaftlichung der bekannten Nordostpassage und um eine exakte Beschreibung des asiatischen Kontinents, soweit er zum Zarenreich gehörte ${ }^{20}$. In der Tat waren diese Expeditionen und ihre Beschreibungen nur die Vorläufer für Expeditionen die dann weit über das hinaus gingen, was Golovnin vorgeschlagen hatte. Beide, Vrangel ${ }^{21}$ und Litke, begannen als 24-jährige veritable Weltumsegler.

Litke analysierte seine Reise in der berühmten Beschreibung Eine Reise um die Welt, 1826-1829. Er verstand sich in dieser Beschreibung mehr als Wissenschaftler denn als Repräsentant russischer Macht. In der Einleitung zu seiner Beschreibung vermerkte er, dass es sich bei seiner Expedition um eine streng wissenschaftliche gehandelt habe, im Gegensatz zu denen 15 Jahre zuvor, die darauf abgezielt hätten, Handelsrouten nach Ochotsk und Kamčatka zu erschließen und den Weg zu den Kolonien der Russisch-Amerikanischen Kompanien aufrecht zu erhalten. Diese hätten bei solchen Zieldefinitionen nicht die wünschenswerten wissenschaftlichen Resultate gezeitigt. In Ergänzung also zu der Erforschung der Küsten entlang der Beringstraße und der Pazifischen Inseln bis hin zur nordamerikanischen Küste bis zu Fort Ross ${ }^{22}$ unternahm Litke zahlreiche Experimente, die Auskunft über Erdkrümmung und Erdanziehung geben sollten. Klimatische Phänomene erfasste er mit Versuchsreihen während der Fahrt. Zwölf neue Inseln entdeckte er auf seiner Reise. Seine Beschreibungen gerade auch des Zusammenlebens von Russen und indigener Bevölkerung in Alaska und Nordamerika verrieten so etwas wie den nüchternen Blick des Ethnographen und Ethnologen, der sich bemühte, Zivilisationen genau so zu beschreiben wie die Natur, die vor ihm lag. Litke wurde in der Wissenschafts- und Entdecker»szene« aufgrund dieser Beschreibung weltberühmt. Vor allem boten seine Experimente die Grundlage für weitere wissenschaftliche Beschäftigung $^{23}$. Litke selbst sah seine Beschreibung als Beiträge zu einem europäi-

19 F. B. S̆MIDT, O zaslugach barona F. P.Vrangelja po otkrytiyu Vrangelevoj Zemli, in: Izvestija Russkogo Geograficheskogo Obščestva 19/I (1883), S. 27-35.

20 Hierzu: F. P. LITKE, Četyrechkratnoe putešestvie v Severnyj Ledovityj okean na voennom brige. Novaja Zemlja v 1821-1824 godach, Moskva 1948.

21 Vrangel sollte sich später als Generalgouverneur von Alaska (1828-1834) Meriten verdienen: Ferdinand von Wrangel, in: Allgemeine Deutsche Biographie (ADB) 44, 1898, S. 222-226.

22 Zusammenfassend: Erwin OBERLÄNDER, Auch eine Entdeckung Amerikas. Die Russen in Alaska 1799-1867, in: Winfried Herget (Hg.), Amerika. Entdeckung, Eroberung, Erfindung, Trier 1995, S. 105-120.

23 Siehe die Bemerkungen im Vorwort zur englischsprachigen Ausgabe: Frederic LiTKE, A Voyage Around the World, 1826-1829, Kingston, Ontario, 1987, S. i-xi. 
schen und kulturellen Projekt ${ }^{24}$. Als die ersten Folgen seiner Beschreibung 1835 erschienen, schrieb ein anonymer Rezensent in dem Journal Bibliote$k a$ dlja čtenija, es handele sich um ein wahrhaft europäisches Buch: »Das Erscheinen eines europäischen Buches ist ein Ereignis wie das Erscheinen eines Kometen $\ll^{25}$.

Expeditionen zur Erschließung und Aneignung von »fremden Kulturräumen« führten im 19. Jahrhundert zur Gründung geographischer Gesellschaften in den europäischen Staaten, zunächst 1821 in Frankreich, in Preußen 1828 und 1830 in England. Sie waren gewissermaßen Teil des europäischen Projekts der Erschließung der Welt. Das russische Zarenreich folgte mit der Gründung einer solchen Gesellschaft 1845, und es war konsequent, dass man dabei auf einen Vorschlag zurückkam, den Fedor Litke damals ganz im Zuge der Zeit bereits vorgelegt hatte ${ }^{26}$. Nach seiner Weltumsegelung in den Jahren 1825-1827 unterbreitete er dem russischen Innenministerium den Vorschlag, eine staatliche Organisation zur geographischen Erforschung des Russischen Reiches zu gründen. Hatte im 18. Jahrhundert die Organisation der Großen Expeditionen in der Akademie der Wissenschaften gelegen, waren die Expeditionsunternehmungen in den ersten Jahrzehnten des 19. Jahrhunderts weniger großzügig alimentiert. Sie schienen gleichsam halbprivaten Charakter zu tragen ${ }^{27}$. Mit der Frage, in wessen Regie solche Expeditionen verliefen, war wesentlich auch über ihren Charakter und ihre Zielsetzung zu entscheiden. Litkes Vorschlag schien zunächst ungehört zu verhallen. Es bedurfte vielmehr einer großen Landexpedition, deren Nutzen der politischen Elite unmittelbar einleuchtete, um seinen Vorschlag zu aktualisieren:

Am Beginn der Russischen Geographischen Gesellschaft im engeren Sinn stand Alexander von Middendorff (1815-1894). Von seiner Expedition durch Sibirien zurückgekehrt, die er im Auftrag der Petersburger Akademie der Wissenschaften 1843 bis 1844 unternommen hatte, berichtete er in

24 Boris BARTh / Jürgen Osterhammel (Hg.), Zivilisierungsmissionen. Imperiale Weltverbesserung seit dem 18. Jahrhundert, Konstanz 2005.

25 Putešestvie vokrug sveta, in: Biblioteka dlia čteniia 9 (1835), č. 5, S. 1-32.

26 Hierzu ausführlich: Claudia WeIss, Wie Sibirien »unser« wurde. Die russische Geographische Gesellschaft und ihre Einfluss auf die Bilder und Vorstellungen von Sibirien im 19. Jahrhundert. Göttingen 2007.

27 Dies gilt auch für die zahlreichen Reisen in den Nahen Osten, die überkommene Grand Tour, Wissenschaft und Pilgerfahrt miteinander verbanden. Ihre Protagonisten waren über Ausbildung und Herkommen eng mit den »Entdeckern « verbunden und wirkten in der Akademie der Wissenschaften und in den Salons der beiden Hauptstädte weiter zusammen. Siehe am Beispiel des späteren Bildungsministers Avraam S. Norov: Izabela KALINOWSKA, Between East and West: Polish and Russian Nineteenth-century Travel to the Orient, Rochester 2004, S. 121-123; für das Zusammenwirken von Litke und Norov siehe Peter R. WeIsENSEL, Avram Sergeevich Norov: Nineteenth Century Russian Traveller, Bureaucrat and Educator, Ph.D. Diss. Univ. of Minnesota 1973. 
Petersburger Hörsälen und Salons anschließend von seiner Reise. Die Beschreibung wurde von Middendorff bewusst mit Blick auf ein breiteres Publikum abgefasst ${ }^{28}$. Eines der zentralen Motive der Darstellung war der kritisch-verantwortungsvolle Blick des von der Aufklärung geprägten, sich zivilisatorisch überlegen fühlenden Kulturträgers auf die indigene Bevölkerung. Obwohl Middendorffs Interesse auch der Landschaft, ihrem Klima, der Flora, Fauna und den Bodenschätzen galt, näherte er sich diesen Themen in seinen Beschreibungen meist über die Menschen vor Ort. Beeindruckt zeigte er sich immer wieder von den Fähig- und Fertigkeiten der Ureinwohner, sich so geschmeidig in die harten Vorgaben der Natur zu fügen, an denen Kulturmenschen aus »zivilisierteren« Gegenden schnell an ihre Grenzen stießen. Doch ein tieferer Zweifel an der Überlegenheit der europäischen Zivilisation gegenüber den sibirischen »Barbaren « kam Middendorff dabei nicht ${ }^{29}$. Eher war es Stolz auf die Vielfalt des Landes und den daraus resultierenden Reichtum des Russländischen Imperiums. In diesem Tenor schilderte er seine Erfahrungen mit den Einheimischen und sparte nicht mit Kritik am bisherigen Umgang der staatlichen Administration mit ihnen. Ihm fielen die gut funktionierenden sozialen Ordnungen auf, die auf der patriarchalischen Gewalt der Häuptlinge beruhten. Er erkannte ihren Wert für den Staat und leitete daraus dessen Verantwortung als Herrscher und Zivilisator ab:

»Sind wir nicht verpflichtet eben daraus eine umso größere Verantwortlichkeit der befehlenden Gewalten abzuleiten? In deren Hand es gegeben ist, ganze Stämme des Menschengeschlechtes entweder sicherem Verderben zu überlassen, oder aus beneidenswertem Kindheitszustande möglichst unvermittelt zu Kulturständen emporzuziehen $\ll^{30}$.

Middendorffs Expedition in der Tradition des imperialen Auftrags im Rahmen eines gesamteuropäischen Zivilisationsprojekts, und damit an Litke anknüpfend, sah den politischen Wert solcher Unternehmungen sehr viel klarer. Nicht allein die Erkundung des Landes zum Wohl der Wissenschaft war wichtig, sondern auch der Beherrschung und Nutzbarmachung seiner Ressourcen durch den Menschen galt das Interesse des Forschers. Genau dieses Interesse war es, das sich in der Idee der Kaiserlichen Geographischen Gesellschaft wiederfand und sie auf vielfältige Weise mit den politischen Interessen des Russländischen Imperiums verband. Middendorffs Expedition fand statt in einem politisch-gesellschaftlichen Kontext, der ein ganz anderer war als jener nach der Weltumsegelung Litkes. Es gab nun einen engen

28 Als Beispiel für die internationale Popularisierung: Narrative of M. Middendorff's Journey of Northern Siberia, in: Journal of the Royal Geographic Society 14 (1844), S. 247-259.

29 WeISS, Wie Sibirien »unser« wurde, S. $57 \mathrm{f}$.

30 Zitiert nach WeIss, S. 63. 
Schulterschluss von Wissenschaftlern, wie Litke und den Offizieren, die zum Teil durch ihren Militärdienst eine starke regionale Basierung in Sibirien besaßen. Sie betrieben gemeinsames Lobbying, um schließlich mit Unterstützung von Großfürsten und hochrangigen Trägern der Funktionselite im Mai 1845 vom russischen Innenminister L. A. Perovskij die Genehmigung zur Gründung der Russischen Geographischen Gesellschaft zu erhalten. Damit begann im 19. Jahrhundert Russlands glanzvolles Zeitalter der Geographie ${ }^{31}$.

Die Russische Geographische Gesellschaft wurde direkt dem Innenministerium unterstellt. Nach der Gründungssatzung von 1845 unterhielt die RGO vier Abteilungen: 1) Allgemeine Geographie, 2) Geographie Russlands, 3) Statistik Russlands und 4) Ethnographie Russlands. 1851 erfolgte die Gründung zweier regionaler Abteilungen der Geographischen Gesellschaft - der kaukasischen in Tiflis und der sibirischen in Irkutsk. In den nächsten vier Jahrzehnten kamen noch weitere regionale Abteilungen hinzu: in den 1860er Jahren die Orenburgische und die südwestliche (Vil'no, ab 1872 in Kiev), 1877 die westsibirische Abteilung in Omsk, 1894 die für den russischen Fernen Osten zuständige Priamur-Abteilung (Chabarovsk) und 1897 die Turkestanische (Taškent). Die Region, die entlang der nach etwa 1850 geltenden administrativen Grenzen als der Ferne Osten galt, wurde zunächst von Irkutsk aus betreut.

In den Erschließungsprozess schalteten sich in hohem Maße auch die regionalen Eliten ein. Bereits am 17. November 1851 eröffnete Niko laj N. Murav'ev, der Generalgouverneur Ostsibiriens ${ }^{32}$, die sibirische Abteilung der RGO in Irkutsk. Deren zentrales Vorhaben wurde alsbald, begleitet durch das Militär, eine Expedition der Kaiserlich-Geographischen Gesellschaft, in der geographische Erschließung und imperialer Expansionsdrang Hand in Hand arbeiteten ${ }^{33}$. Es war die Annexion des Amur 1858 und die in ihrem Hintergrund 1856 bis 1863 durchgeführte »Große Sibirien-Expedition«. Diese Expedition zog zusammen mit Truppen des General-Gouverneurs Murav'ev den Amur entlang und sammelte Daten für die erste vollständige Karte des Flus-

\footnotetext{
31 Dies war nota bene keine Besonderheit im Zarenreich: Morag Bell, Robin A. ButLIN, Michael HEFFERNAN, Geography and imperialism, 1820-1940, Manchester 1995.

32 P. N. ZYrJanov, Nikolaj Nikolaevič Murav'ev-Amurskij, in: Voprosy Istorii 1 (2008), S. 22-46.

33 Zum militärisch-strategischen Aspekt: Nikolaus KATZER, Russische Regierung und Militär zwischen Krimkriegstrauma und imperialer Expansion, in: Das Militär und der Aufbruch in die Moderne 1860 bis 1890. Armeen, Marinen und der Wandel von Politik, Gesellschaft und Wirtschaft in Europa, den USA sowie Japan, hg. v. Michael EPKENHANS und Gerhard P. GROSs. München 2003, S. 51-73, hier S. 63-66.
} 
$\operatorname{ses}^{34}$. Weiterhin erforschte sie fast die gesamte Region östlich des Baikalsees bis hin zum Pazifik und erfasste auch die Tatarenstraße kartographisch. Zwischenzeitlich hatte Russland dank der politischen Ambitionen Murav'evs - dieser erhielt dafür den Titel Graf Amurskij - das Amurgebiet gemäß des Vertrags von Aigun vom 16. Mai 1858 annektiert. Der Nutzen für das Russländische Imperium lag auf der Hand: Der Ferne Osten wurde für Russland gesichert und so der russische Zugriff auf den Pazifik aufrechterhalten ${ }^{35}$. Einerseits hatten sich damit die Grenzen des Russländischen Imperiums weiter auf Kosten Chinas ausgedehnt, andererseits wurde bereits über die Konsequenzen dieser Erwerbungen diskutiert.

Die frühen Berichte schilderten die Amurregion in einem positiven Grundton und insgesamt eher verhaltenen kritischen Kommentaren. Sie gingen detailliert auf die agrarwirtschaftliche Nutzung der Region ein und zeigten ein starkes Interesse an der dort ansässigen Bevölkerung. Mit wissenschaftlichem Anspruch charakterisierten sie die verschiedenen indigenen Völker meist positiv und strichen immer wieder deren gutes und friedliches Verhältnis zu den Russen heraus. Damit suggerierten sie ein Zugehörigkeitsgefühl dieser Menschen zum Russländischen Imperium. Mit dem so dokumentierten gegenseitigen Verständnis untermauerten sie kulturell den russischen Annexionsanspruch. Die genaue wissenschaftliche Erkundung zeigte den Einsatz der Geographie als Werkzeug der imperialen Aneignung: Landvermessungen wurden vorgenommen, infrastrukturelle Probleme erörtert, Karten angefertigt ${ }^{36}$.

Nach der Annexion und mit den in ihrer Folge sich vertiefenden Kenntnissen der Region legte sich die erste Begeisterung. Exemplarisch erwähnt seien Gustav Raddes Ausführungen, der Teilnehmer der Großen SibirienExpedition war. 1860 hielt er an der Petersburger Universität eine Vorlesungsreihe über »Sibirien und das Amur-Land « ${ }^{37}$. Radde (1831-1903) distanzierte sich von einem zu euphorischen Sibirien-Bild. Unbeirrt und wenig geschönt sprach er die Widrigkeiten der Region an. Doch zeigte er eine po-

34 A. Petermann, Peschtschuroff's Aufnahme des Amur-Stromes in Jahre 1855. Und die russisch-chinesische Grenze im Amurlande von 1689 bis 1856, in: Petermanns Mitteilungen 2 (1856), S. 472-479.

35 Jan KusBer, Koloniale Expansion und die Wahrnehmung »Asiens« um die Mitte des 19. Jahrhunderts: Das Beispiel Ivan A. Gončarov, in: Studia Eurasiatica. Kieler Festschrift für Hermann Kulke zum 65. Geburtstag, hg. v. Stephan CONERMANN und Jan KusBer, Hamburg 2003, S. 189-211.

36 Nathanial KNIGHT, Science, Empire and Nationality: Ethnography in the Russian Geographical Society, in: Jane Burbank, David L. Ransel (Hg.), Imperial Russia. New Histories for the Empire, Bloomington 1998, S. 108-141.

37 Gustav RADDE's Vorlesungen über Sibirien und das Amur-Land. Gehalten im Saal der Kaiserl. Universität zu St. Petersburg, März 1860, Teil 1, in: Petermanns Mitteilungen 7 (1860), S.. 257-263. 
sitiv anmutende Entwicklung der russischen Bevölkerung Sibiriens auf und betonte die Verbindung jener Menschen mit dem europäischen Russland. Die Sibirjaken, die von den europäischen Russen als naši (»Unsrige«) begriffen wurden, wie Claudia Weiss meinte ${ }^{38}$; waren in seinem Verständnis die »menschliche Verknüpfung« zwischen dem europäischen Teil des Russländischen Imperiums und Sibirien und führten zu dessen Europäisierung. Allmählich würden sich die Grenzen Europas auf diese Weise bis an den Pazifik schieben. Das Argument, Sibirien und der Ferne Osten trügen zur imperialen Größe Russlands bei, war mithin schon in der ersten Hälfte des 19. Jahrhunderts verankert und verstärkte sich.

Von Fedor Litke, dessen Name prominent im Titel dieses Beitrages steht, haben wir uns damit nur scheinbar entfernt. Er spielte in der Geographischen Gesellschaft insofern noch eine bedeutende Rolle, als er lange Jahre als deren Präsident fungierte, wobei ihm sicher die Präsidentschaft derjenigen Institution, die seinem Verständnis von Wissenschaft entgegenkam der Akademie der Wissenschaften -, mehr am Herzen lag. Ihr stand er 1864-1882 vor. Auch wenn er im fortgeschritteneren Alter noch Expeditionen im Atlantik und im Azowschen Meer durchführte, der Wissenschaft durch grundlegende meteorologische und hydrologische Studien und als Wissenschaftsorganisator verbunden blieb, war bei der Erschließung »Asiens « die Initiative auf neue Typen und Charaktere übergegangen, die einem anderen Impetus folgten.

Hier sei ein bekanntes Beispiel genannt: Unter dem Einfluss der deutschen Philosophie und Wissenschaft versuchte Petr Semenov imperiales Entdeckertum mit nationaler Absicht zu verbinden ${ }^{39}$. In einer Einleitung zu Karl Ritters Erdkunde von Asien sprach er von Wissenschaft als »Selbsterkenntnis«. Was er damit meinte, wurde im Fortgang deutlich, als er von dem Erkennen der Gegenstände und Kräfte der Natur und der Fähigkeit sprach, diese der eigenen Macht zu unterwerfen und für die Bedürfnisse und Erfordernisse des Lebens der eigenen Nation nutzen zu können. Die wissenschaftlichen Schätze des menschlichen Wissens könnten, so Semenov, am besten in der Geographie sichtbar gemacht werden, die er, hier durchaus in Übereinstimmung mit Litke, als Leitwissenschaft ansah.

In einem weiteren Artikel, in dem es um eine Beschreibung der Amurregion ging, stellte Semenov fest, dass die Entdeckungen der letzten dreißig Jahre gezeigt hätten: Russland bewegt sich vorwärts, wie die Vorsehung es aufgegeben hat, und zwar im allgemeinen Interesse der Menschheit. Die

38 Hierzu: Claudia WeIss, 'Nash', Appropriating Siberia for the Russian Empire, in: Sibirica. Interdisciplinary Journal of Siberian Studies 5 (2006), S. 141-155.

39 Und zum Folgenden: W. Bruce LinColn, Petr Petrovich Semenov-Tian-Shanskii: The Life of a Russian Geographer, Newtonville, Mass., 1980. 
Methoden im Umgang mit den indigenen Völkern seien im Übrigen andere als die der Spanier in Südamerika. Es gehe darum, die halbwilden Völker Asiens und des Fernen Ostens schrittweise an die eigene Zivilisation heranzuführen, an ihr soziales Leben und an ihre Nationalität.

Semenov stellte damit einen neuen Typus des adligen Entdeckers dar ${ }^{40}$. Wie Litke und Vrangel kam er aus dem Militär, und wie diese war er aufgrund fehlender Ressourcen auf den Dienst, der die soziale Stellung und das Prestige unter den Bedingungen der Rangtabelle absicherte, angewiesen. Aber Semenov entstammte, wie andere auch, nicht der Marine, sondern den Landstreitkräften. Die Sozialisation, die damit verbunden war, war eine andere. Er entstammte der Landadel der Provinz Rjazan', kam also, wenn man so will, aus dem Gebiet Russlands, in dem Nikolaus I. vor dem Hintergrund der Revolution von 1848 die ideologische Basis seiner Herrschaft $\operatorname{sah}^{41}$.

Litke hingegen repräsentierte im Vergleich zu Semenov eine eher urban und europäisch orientierte Richtung. Seine Memoiren geben lebhafte Auskunft über seine Eigensicht als jemand, der dem Kaiser und dem russländischen Staat diente. Semenov und andere dienten in dem neuen Sinn dem Russländischen Land und dem russischen Volk. Wenn Geoffrey Hosking einen schwach ausgeprägten russischen Nationalismus für das Zarenreich vor dessen Ende ausmachte ${ }^{42}$, so hatte er eher Elitenvertreter wie Litke im Blick, weniger Semenov: Dessen Familie war stark geprägt durch die Erfahrung des Jahres 1812, das in gewisser Weise als Umbruch einer Lebenswelt der Eliten des Russischen Reiches verstanden wurde.

Litke hingegen, und damit komme ich wieder zu den biographischen Verläufen, bot die Ankunft in Sankt Petersburg den Eintritt in eine neue Welt. Wenn man so will, finden wir hier den Antagonismus zwischen Reichspatriotismus und russischem Nationalismus. Die Klammer zwischen beiden war die Loyalität zum Herrscher. Gerade die »Entdecker« sind also die Speerspitze eines aufkommenden Nationalismus gewesen, und dies, wie Andreas Renner gezeigt hat, ab der Mitte des 19. Jahrhunderts durchaus im Zusammenspiel mit der öffentlichen Meinung.

\footnotetext{
40 Und zum Folgenden: Petr Semenov, Memuary P. P. Semenova-Tjan-Šanskago, Petrograd 1917.

41 Martin SchUlze Wessel, Städtische und ländliche Öffentlichkeit in Russland 1848, in: Zeitschrift für Geschichtswissenschaft 48 (2000), S. 293-308.

42 Geoffrey Hosking, Russland, 1552-1917. Nation oder Imperium? 1552-1917, Berlin 2000, S. 20-24, 39 f. Abweichend: Andreas RENNER, Nationalismus und Diskurs. Zur Konstruktion nationaler Identität im Russischen Zarenreich nach 1855, in: Ulrike v. HIRSCHHAUSEN, Jörn LEONHARD (Hg.), Nationalismen in Europa. West- und Osteuropa im Vergleich, Göttingen 2002, S. 433-449; Alexei Miller, The Empire and the Nation in the Imagination of Russian Nationalism, in: Alexei Miller, Alfred J. RIEBER, (Hg.), Imperial Rule, Budapest 2004, S. 9-26.
} 
Semenov, der in Sankt Petersburg Lehrveranstaltungen von Nikolaj Danilevskij besucht hatte ${ }^{43}$, komplettierte seine Studien in Berlin, gerade zu dem Zeitpunkt, als die Kaiserliche Geographische Gesellschaft ihre große Expedition den Amur hinab durchführte. Semonovs eigener Ruhm begründete sich in der Besteigung des Tjan-Šan-Gebirges, das eine natürliche Grenze zwischen dem Zarenreich und China darstellte ${ }^{44}$. In der Durchführung dieses Vorhabens, das offiziell der Überprüfung der Annahme Alexander von Humboldts dienen sollte, dass dieser Gebirgszug vulkanischen Ursprungs sei, überschritt er unerlaubter und unabgesprochener Weise die Grenze zu China, weil sich die Gipfel nur von der chinesischen Seite bestiegen ließen. Mithin zählte er zu jenen »Men on the spot«, derer es im $\mathrm{Zu}-$ ge der Expansion nach Zentral- und Ostasien noch mehrere geben sollte, wenn auch freilich zunehmend in militärischer Funktionalisierung. Ein Beispiel hierfür ist der auch noch im postsowjetischen Russland zur Schullektüre gehörende Asienreisende Nikolaj M. Prževalskij war, der einem russischen Konquistadorentum im Stile eines Cecil Rhodes oder eines Carl Peters um 1880 das Wort redete und damit nicht unmittelbar, aber doch eine Generation später, auf die Eliten des Zarenreiches prägend wirkte. Nikolaus II. und andere verdankten seiner Publizistik, in der er zur Annexion der muslimisch besiedelten Gebiete Chinas aufrief, ein Gefühl der Überlegenheit, das sich zu einer Mission des »Weißen Zaren« auswachsen konnte ${ }^{45}$. Die Kaiserliche Geographische Gesellschaft stellte freilich gerade für die Expansion im Fernen Osten um die Mitte des 19. Jahrhunderts einen Ort der Soziabilität dar, wie Claudia Weiss herausgearbeit hat, der auch für Semenov das motivierende Umfeld und nicht zuletzt auch die materielle Basis darstellte, aus der heraus sich sein Ruhm in der Konsequenz seiner Biographie entwickelte ${ }^{46}$.

Betrachtet man die Biographien von Litke und Semenov, der den Beinamen Tjan-Šanskij erhalten sollte, so lässt sich festhalten, dass ihre Entdeckungen in ganz unterschiedlicher Weise instrumentalisiert wurden und von ihnen auch selbst so verstanden wurden, weil die Zeitumstände andere geworden waren. Litke kam aus der Spätaufklärung und repräsentierte einen Wissenschaftlertypus und Seeoffizier, der auch Daniel Kehlmanns

\footnotetext{
43 Zu seinem Einfluss auf einen nationalen Diskurs im Imperium noch immer instruktiv: Konrad Pfalzgraf, Die Politisierung und Radikalisierung des Problems Russland und Europa bei N. J. Danilevskij, in: Forschungen zur Osteuropäischen Geschichte 1 (1954), S. 55-204; siehe darüber hinaus seine programmatische Schrift: N. J. DANILEVSKIJ, Russland und Europa. Eine Untersuchung über die kulturellen und politischen. Beziehungen der slawischen zur germanisch-romanischen Welt. Übersetzt und eingeleitet von Karl Nötzel, Osnabrück 1965 (Reprint der Ausgabe von 1920).

44 P. P. Semenov-Tuan-ŠanskiJ, Putešestvie v Tjan'-Šan' v 1856-1857 godach, Moskva 2007.

45 SChimmelPenNing VAN DER OYe, Towards the Rising Sun, S. 23-41.

46 WeISS, Wie Sibirien unser wurde, S. 37-66.
} 
kongenialem Roman Die Vermessung der Welt hätte entsprungen sein können und der im Humboldtschen Sinn Expeditionsreisen zur Erforschung der Welt vorantreiben wollte ${ }^{47}$. Diese Erkundungen erfolgten nicht ohne politischen Zweck. Die nationalen Gedankenwelten, die beispielsweise im Kontext des Panslavismus und der Eroberung Zentralasiens in den sechziger, siebziger und achtziger Jahren des 19. Jahrhunderts stark gemacht wurden ${ }^{48}$, waren ihm jedoch fremd, weil er im Rahmen des Vielvölkerimperiums Russland nachgerade zwangsweise nur eine Identität zum Imperium und zum Zaren aufbauen konnte. Seine Biographie verbot die ausschließliche Selbstdefinition als »deutsch«. Das Gleiche wäre in Abstufungen sicher auch für Ferdinand Vrangel und Alexander von Middendorff zu sagen, bliebe bei Gustav Radde zu überprüfen. Konzepte wie die Trinität »Autokratie, Orthodoxie, Narodnost' « Sergej Uvarovs waren in dieser Hinsicht wegen ihres partiell exkludierenden Charakters der Narodnost" (Volkstümlichkeit), der eine ethnische Komponente innewohnte, gefährlich ${ }^{49}$.

Die nationale, auf die Russen und die Orthodoxie bezogene Welle führte bei einem gleichzeitig imperialen Selbstverständnis des Herrschers und Teilen der Eliten durchaus zu einer Motivationslage, die nicht nur ein neues Ausgreifen nach Asien beförderte, sondern auch noch eine andere Art der Inbesitznahme. Dass dies für den Fernen Osten umso stärker unter ethnisch-rassischen Gesichtspunkten gesehen wurde, je mehr das Jahrhundert sich seinem Ende näherte, wäre Gegenstand eigener Erörterungen ${ }^{50}$. Gerade anhand der Personengruppen lässt sich jedoch auch Übergreifendes festhalten. Mit der Kombination von Wissenschaft, Entdeckung und Expansion ließ sich Politik und Karriere machen. Litke war nach 1864 bis zu seinem Tode ja nicht nur Präsident der Akademie der Wissenschaften, sondern auch Admiral, Graf und Mitglied des Reichsrates. Semenov wurde zum Politiker, der sich für die Aufhebung der Leibeigenschaft einsetz-

47 Daniel Kehlmann, Die Vermessung der Welt, Reinbek bei Hamburg 2005. Siehe auch: Alexander von Humboldts Reise durchs Baltikum nach Russland und Sibirien 1829. Bearbeitet von Hanno BECK. Stuttgart 2005.

48 Dietrich GEYER, Der russische Imperialismus. Studien über den Zusammenhang von innerer und auswärtiger Politik 1860-1914, Göttingen 1977, S. 55-82.

49 Cynthia WhitTAKer, The Ideology of Sergei Uvarov: An Interpretive Essay, in: Russian Review 37 (1978), S. 158-176; M. M. ŠEvČENKO, Sergej Semenovič Uvarov, in: Russkie konservatory, Moskva 1997, S. 97-135.

50 Raphael UTZ, Die Orientreise Nikolaus II. und die Rolle des Fernen Ostens im russischen Nationalismus, in: Maik Hendrik SprotTe / Wolfgang SeIFERT / Heinz-Dietrich Löwe (Hg.), Der russisch-japanische Krieg (1904/05): Anbruch einer neuen Zeit?, Wiesbaden 2007, S. 113-145. Siehe hierzu die aufschlussreichen Gedanken, die schon Otto Hoetzsch über Ethnizität und Identität anhand eines Eroberers und Generalgouverneurs von Turkestan, Konstantin von Kaufmann (1817-1882), anstellte: Otto HoEtzsCH, Russland in Asien. Geschichte einer Expansion, Stuttgart 1966, S. 90-94. 
te $^{51}$ und die große Volkszählung von 1897 konzipierte. Auch er zog schließlich bis zu seinem Tode 1914 in den Reichsrat ein. Dass sich ihr Wissenschaftsverständnis fundamental unterschied, war, wie bei anderen, auch Zeitläuften und Kontexten geschuldet, nicht aber ihrer ethnischen Herkunft, die deutsch, russisch oder wie auch immer war. Sie einte eine immer deutlicher artikulierte Mission aus dem Gestus der Überlegenheit heraus, und sie alle bezogen sich auf das Imperium, dessen Größe und Staatsform sie als Wert an sich sahen.

51 Siehe hierzu die Separatauszüge mit biographischen Kommentaren: Petr SEMENov, Épocha osvoboždenija krest'jan v Rossii 1857-1861 gg. v vospominanijach P. P. Semenova-TjanŠanskago, byvšago člena-èksperta i zavědyvajuščago dělami Redakcionnych Komissij, S-Peterburg 1911-1913. 


\section{Personenregister}

Aleksej Michajlovič, russischer Zar 35

Alexander I., russischer Zar 69, 98-100, $102,105,106$

Amurskij, Nikolaj N. Graf Siehe Murav'ev, Nikolaj N.

Asch, Georg Thomas von 83

Augustine-Wilhelmine von Hessen-Darmstadt 81

Bagrow, Leo 11-15, 17, 20, 22, 24, 26

Bajkov, Fedor I. 36, 37

Beethoven, Ludwig van 98

Bellinghausen, Fabian Gottlieb 2, 28

Benckendorff, Alexander von 103, 104

Benge, Alexander von 2

Bering, Vitus 26, 28, 56, 64, 80

Billings, Joseph 79, 80, 82-84, 89, 93-95

Blaeu, Joan 10

Blaeu, Willem 10

Blumenbach, Johann Friedrich 93

Boris Godunov, russischer Zar 33

Brand, Adam 2, 42-47, 97

Brinckmann, Johann Peter 81, 82, 94

Brjus, Jakov 27

Bunge, Alexander von 52, 71-74

Centurione, Paolo 31

Chabarov, Erofej 34-36

Chamisso, Adelbert von 94

Čichačev, Petr Aleksandrovič 68, 75, 76

Clemens VII., Papst 14

Cook, James 80

Dal', Vladimir 70

Danilevskij, Nikolaj 115

Delisle, Guillaume 10, 24

Demidov, Akinfij Nikitič 71

Dorn, Ivan 15

Dschingis-Chan, Chan der Mongolen 53

Elisabeth, russische Zarin 71

Engelhardt, Moritz von 71

Ermak Siehe Timofeevič, Ermak

Falck, Johann Peter 66, 72

Fedor I., russischer Zar 33
Gantimur, Fürst der Tungusen 40

Gatterer, Johann Christoph 93

Georgi, Johann Gottlieb 2, 51, 65-68, 71, 72,74

Gerasimov, Dmitrij 14

Gerritz, Hessel 13, 27

Giovo, Paolo 14

Gmelin, Johann Georg 2, 24, 26, 28, 51, $62-64,66,73-75,79,80,97$

Godunov, Semen 17

Goethe, Johann Wolfgang von 81

Golovin, Fedor A. 38, 40

Golovkin, Jurij Alexandrovic 97-99, 101

Golovnin, Dmitrij 107

Golovnin, Vasilij 105-108

Gorochov, Aleksandr Michajlovič 53

Haydn, Joseph 98

Helmersen, Gregor von 2, 73, 74

Herberstein, Sigmund von 13-15, 17, 27, 28,42

Hondius, Heinrich 10

Humboldt, Alexander von 52, 53, 71, 75, 115,116

Ides, Eberhard Isbrand 2, 20, 42-47, 97

Ivan III., russischer Zar 8, 12, 13

Ivan IV., russischer Zar 13, 14, 32, 33

Ivan V., russischer Zar 38

Jacobi, Arnold 94, 95

Jacobi, Georg A. 94

Jakobi, Ivan Varfolomeevič 82, 92

James Bruce Siehe Brjus, Jakov

Jenkinson, Anthony 10, 27, 33

Jiaqing, Kaiser von China 98

K'ang-hsi, Kaiser von China 37, 38, 45

Kačka, Gavriil Simonovič 91, 92

Kačka, Nadežda Gavrilovna Siehe Merck, Nadežda Gavrilovna

Karoline von Hessen-Darmstadt 81

Katharina II., russische Zarin 9, 70, 71, 80, $81,91,97,105,107$

Kaufmann, Konstantin von 116

Kiprianov, Vasilij 24 
Kirillov, Ivan 24

Klaproth, Julius Heinrich von 101

Konstantin XI., byzantinischer Kaiser 12

Kotzebue, Otto von 94

Krusenstern, Adam Johann von 2, 28, 104 106

Kruzenstern, Ivan Fedorovič Siehe Krusenstern, Adam Johann von

Kurakin, Ivan S. 33

Laxmann, Erich 83

Ledebour, Carl Friedrich 2, 52, 71, 72, 74, 75

Leibniz, Gottfried Wilhelm 43, 45-47, 79

Litke, Fedor Petrovič 3, 103-111, 113-116

Litke, Johann F. 107

Lütke, Friedrich Benjamin Siehe Litke, Fedor Petrovič

Martini, Martino 40

Martynov, Andrej 101

Massa, Isaac 13, 27

Matjuškin, Fedor 106

Maximilian I., Kaiser des Heiligen Römischen Reiches 12

Mendoza, Juan González de 31

Mengden, Jurij A. 27

Mercator, Gerhard 14

Merck, Carl Heinrich 2, 3, 79-97

Merck, Franz Christian 81, 92

Merck, Friedrich Karl Wolfgang 92

Merck, Johann Heinrich 81, 82, 92, 95

Merck, Nadežda Gavrilovna 91, 92

Merck, Sophie 92

Messerschmidt, Daniel 79

Messerschmidt, Daniel Gottlieb 24, 51

Meyer, Karl Anton 71

Michael I., russischer Zar 33

Middendorff, Alexander Theodor von 52, $109,110,116$

Mordvinov, Nikolaj 105

Mozart, Wolfgang Amadeus 98

Müller, Gerhard Friedrich 2, 26, 28, 51, 58, 79, 98

Münsters, Sebastian 13

Murav'ev, Nikolaj N. 111, 112

Napoleon Bonaparte, Kaiser von Frankreich 100,105

Naryschkina, Natalia Kirillowna 23

Natal'ja Alekseevna Siehe AugustineWilhelmine von Hessen-Darmstadt

Nelson, Horatio 106
Nikitin, Afanasij 31

Nikolaus I., russischer Zar 75, 103-106, 114,116

Nikolaus II., russischer Zar 115, 116

Norov, Avram Sergeevich 109

Oldenburg, August von 100

Ortelius, Abraham 10, 13, 14

Pallas, Peter Simon 2, 51, 52, 65, 66, 70, $72,75,79,80,83,84,86,93,94$

Patrin, Eugène-Melchior Louis 52, 82

Paul I., russischer Zar 81

Perovskij, Lev A. 111

Pestel, Iwan 99

Peter I., russischer Zar 6, 23, 24, 28, 32, 38, 40-42, 45, 70, 77, 79, 97

Peters, Carl 115

Petlin, Ivan 33, 34

Plath, Johann Heinrich 102

Pojarkov, Vasilij 34

Polo, Marco 31

Prževalskij, Nikolaj M. 115

Ptolemaios 10, 12, 14

Purcha, Samuel 34

Pypin, Aleksandr N. 51, 56

Radde, Gustav 112, 113, 116

Razumovskij, Andrej Kirillovič 98, 99

Rehmann, Joseph 3,97-102

Remezov 17

Remezov, Semen 17, 20, 22, 28

Remezov, Uljan 17

Repnin, Nikolaj Vasiljevič 107

Rhodes, Cecil 115

Ricci, Matteo 31

Ritter, Karl 113

Rohbeck, Michael 83

Rumjancev, Nikolaj Petrovič 105

Rybakov, B. A. 13

Saryčev, Gavriil Andreevič 79-81, 83, 84, $89,93,95$

Ščerbatov, Konstantin 37

Schilling, Johann 99

Schlözer, August Ludwig von 98

Schrenk, Alexander Gustav 52

Schrenk, Ernst Hofmann 52

Šelechov, Grigorij 105

Semenov, Petr 113-117

Shunzhi, Kaiser von China 35

Sofija, Regentin von Russland 40

Sophia Paleolog 12, 14 
Spafarij, Nikolaj G. Siehe Spatharij, Uvarov, Sergej 100, 116

Nikolaj G.

Spasskij, Grigorij Ivanovič 2, 66- 68, 72

Spatharij, Nikolaj G. 38-40, 44, 46, 47, 51, Spathary, Milescu 20, 22

Speranskij, Michail Michajlovič 2, 68, 69

Stein, Heinrich Friedrich Karl vom 100

Steller, Georg Wilhelm 79, 97

Strahlenberg, Philip Johan 10

Stresemann, Erwin 95

Struve, Wilhelm 71

Tatiščev, Vasilij 29, 70

Timkowski, Georg 101

Timofeevič, Ermak 36, 50

Tolbuzin, Aleksej 38
Verbiest, Ferdinand 39

Vlasov, Ivan 37

Vrangel, Ferdinand 105, 106, 108, 114, 116

Wanli, Kaiser von China 33

Wassili III., russischer Herrscher 14

Weber, Max 107

Werner, Christine Luise von 92

Wettermann, Johannes 14

Wied, Anton 14

Witsen, Nicolaas 46,47

Wolff, Christian 79 


\section{Autorenverzeichnis}

Professor Dr. Dittmar Dahlmann, Rheinische Friedrich-Wilhelms-Universität, Seminar für Osteuropäische Geschichte, Lennéstraße 1, 53113 Bonn

Professor Dr. Heinz Duchhardt, Institut für Europäische Geschichte, Abteilung Universalgeschichte, Alte Universitätsstrasse 19, 55116 Mainz

Professor Dr. Jan Kusber, Johannes Gutenberg-Universität, Historisches Seminar, Saarstr. 21, $55122 \mathrm{Mainz}$

Eugenia Massold, M.A., Rheinische Friedrich-Wilhelms-Universität, Seminar für Osteuropäische Geschichte, Lennéstraße 1, 53113 Bonn

Diana Ordubadi, M.A., Rheinische Friedrich-Wilhelms-Universität, Seminar für Osteuropäische Geschichte, Lennéstraße 1, 53113 Bonn

Professor Dr. Christine Roll, RWTH Aachen, Historisches Institut, Theaterplatz 14, 52062 Aachen 